\title{
2012 ANNUAL REPORT
}

\section{SECA Coal-Based Systems - LGFCS}

August 14, 2013

\section{WORK PERFORMED UNDER AGREEMENT \\ DE-FE0000303}

(period of performance Oct. 1, 2011 through Sept. 30, 2012)

\section{SUBMITTED BY}

LG Fuel Cell Systems Inc. 6065 Strip Ave. NW

North Canton, OH 44720

\section{PRINCIPAL INVESTIGATOR}

\author{
Richard Goettler \\ 330-491-4821 (phone) \\ 330-491-4808 (fax) \\ richard.goettler@lgfcs.com
}

\section{SUBMITTED TO}

U. S. Department of Energy

National Energy Technology Laboratory

Patcharin Burke

Patcharin.Burke@netl.doe.gov 


\section{Disclaimer:}

This report was prepared as an account of work sponsored by an agency of the United States Government. Neither LG Fuel Cell Systems Inc. nor the United States Government nor any agency thereof, nor any of their employees, makes any warranty, express or implied, or assumes any legal liability or responsibility for the accuracy, completeness, or usefulness of any information, apparatus, product, or process disclosed, or represents that its use would not infringe privately owned rights. Reference herein to any specific commercial product, process, or service by trade name, trademark, manufacturer, or otherwise does not necessarily constitute or imply its endorsement, recommendation, or favoring by the United States Government or any agency thereof. The views and opinions of authors expressed herein do not necessarily state or reflect those of the United States Government or any agency thereof. 


\section{TABLE OF CONTENTS}

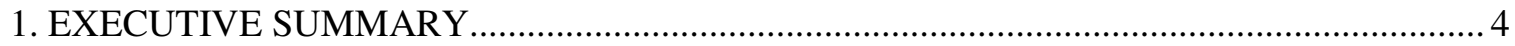

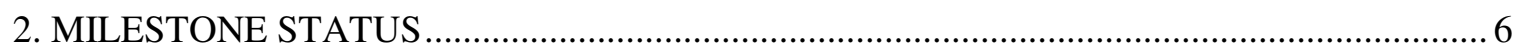

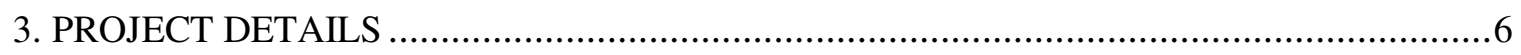

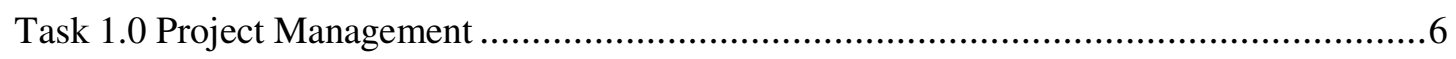

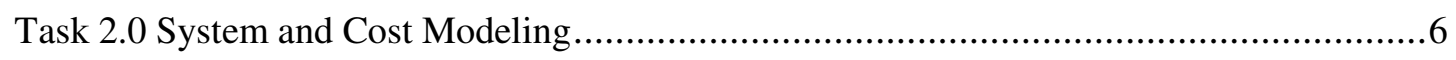

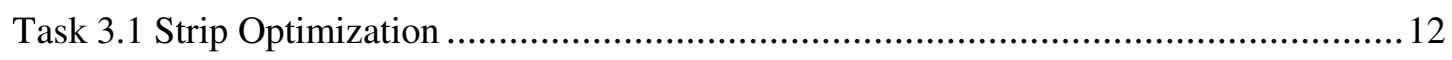

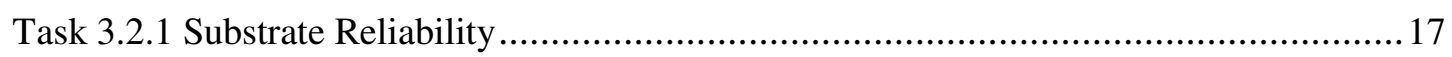

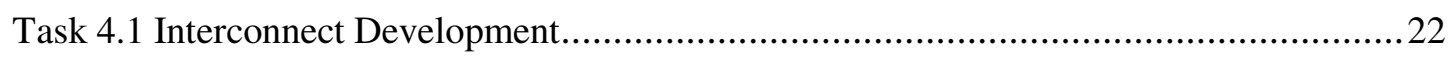

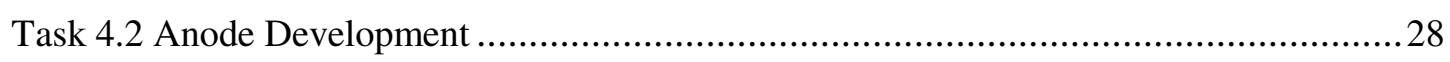

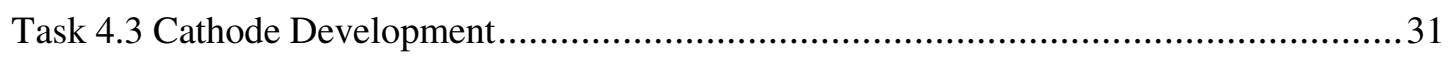

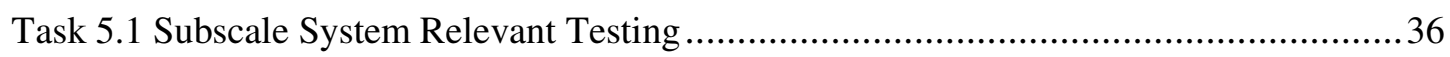

Task 5.2 Stack Test Stand Preparation ................................................................... 43

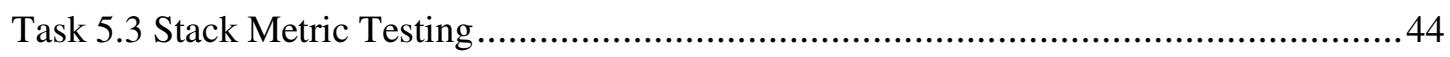

Task 6.0 Manufacturing................................................... 48 


\subsection{EXECUTIVE SUMMARY}

LGFCS is developing an integrated planar (IP) SOFC technology for mega-watt scale power generation including the potential for use in highly efficient, economically competitive central generation power plant facilities fuel by coal synthesis gas. This Department of Energy Solid-State Energy Conversion Alliance (SECA) program is aimed at achieving further cell and stack technical advancements and assessing the readiness of the LGFCS SOFC stack technology to be scaled to larger-scale demonstrations in subsequent phases. LGFCS is currently in Phase 2 of the program with the Phase 1 test carrying over for completion during Phase 2.

Major technical results covering the initial Phase 2 budget period include:

Metric Stack Testing:

1. The Phase I metric test is a $\sim 7.6 \mathrm{~kW}$ block test (2 strips) in Canton that started in March 2012 and logged 2135 hours of testing prior to an event that required the test to be shutdown. The degradation rate through 2135 hours was $0.4 \% / 1000$ hours, well below the Phase I target of $2 \% / 1000$ hours and the Phase 2 target of 1.5\%/1000 hours.

2. The initial Phase II metric test consisting of 5 strips $(\sim 19 \mathrm{~kW})$ was started in May 2012. At the start of the test OCV was low and stack temperatures were out of range. Shutdown and inspection revealed localized structural damage to the strips. The strips were repaired and the test restarted October 11, 2012.

3. Root cause analysis of the Phase 1 and initial Phase 2 start-up failures concluded a localized short circuit across adjacent tubes/bundles caused localized heating and thermal stress fracture of substrates. Pre-reduction of strips rather than in-situ reduction within block test rigs now provides a critical quality check prior to block testing. The strip interconnect design has been modified to avoid short circuits.

Stack Design:

1. Dense ceramic strip components were redesigned to achieve common components and a uniform design for all 12 bundles of a strip while meeting a flow uniformity of greater than $95 \%$ of the mean flow for all bundles. The prior design required unique bundle components and pressure drops specifications to achieve overall strip fuel flow uniformity.

2. Slow crack growth measurements in simulated fuel environments of the $\mathrm{MgO}-\mathrm{MgAl} 2 \mathrm{O} 4$ substrate by ORNL reveal favorable tolerance against slow crack growth. Evidence as well of a high stress intensity threshold below which crack growth would be avoided. These findings can have very positive implications on long-term structural reliability. More testing is required, including under actual reformate fuels, to gain a deeper understanding of such time dependent reliability mechanisms.

3. A next generation (Gen2) substrate from the LGFCS supplier has been qualified. The substrate incorporates cost reductions and quality improvements.

\section{Cell Developments:}

1. Subscale testing of the epsilon technology under system relevant conditions surpassed 16,000 hours with a power degradation rate of $<1 \% / 1000$ hours. Key degradation mechanisms have been identified: (1) MnOx accumulation near the cathode-electrolyte interface and cathode densification (2) metals migration across the anode-ACC bilayer and general microstructure coarsening at high temperatures and peak fuel utilizations and (3) metal migration into primary interconnect (lesser mechanism) 
2. Alternate LSM cathodes show slightly lower ASR and lesser free MnOx and chromium contamination. Long-term durability screening of three alternate cathodes is being performed.

3. Single layer anodes show very significant improvement in microstructure stability after 5000 hours testing at aggressive conditions of $925 \mathrm{C}$ and bundle outlet, high utilization fuel.

4. New primary interconnect designs are being tested that achieve lower ASR. Modeling performed to further balance ASR and cost through optimized designs. 


\subsection{MILESTONE STATUS}

The Milestone Log shown in Table 1 represents that included in the Program Management Plan (PMP) for Phase 2.

\section{Table 1 - Milestone Log}

\begin{tabular}{|c|c|c|c|c|c|}
\hline \multicolumn{6}{|c|}{ Phase 2} \\
\hline \multirow{2}{*}{$\begin{array}{c}\text { Task/ } \\
\text { Subtask }\end{array}$} & \multirow{2}{*}{ Milestone Description } & \multicolumn{4}{|c|}{$B P 1-F Y 2012$} \\
\hline & & Q1 & Q2 & Q3 & Q4 \\
\hline 1 & Kick-off meeting & $\mathrm{x}$ & & & \\
\hline 1 & Updated Project Management Plan & $x$ & & & \\
\hline 6 & Start printing for Ph II block test & $\mathrm{x}$ & & & \\
\hline 5.3 & Initiate Ph I Metric Test & & $x$ & & \\
\hline 3.1 & $\begin{array}{l}\text { Manifold supplier demonstrates orifice } \\
\text { tolerance }\end{array}$ & $\mathrm{x}$ & & & \\
\hline 4.3 & $\begin{array}{l}\text { Select next-gen LSM cathode for EIS } \\
\text { qualification }\end{array}$ & & $x$ & & \\
\hline 2 & Phase I Factory Cost model update & & & & $x-$ \\
\hline 4.2 & $\begin{array}{l}\text { Select candidates anodes for } 3000 \mathrm{hr} \\
\text { durability test }\end{array}$ & & $\mathrm{x}$ & & \\
\hline 4 & Freeze cell materials for $\mathrm{Ph} \|$ block test & & $x$ & & \\
\hline 6 & Start printing for Ph II Metric Test & & $x$ & & \\
\hline 3.1 & Next-gen parts ready to manufacture & & & & $x$ \\
\hline 5.3 & Initiate Phase II Metric Test & & & $\mathrm{x}$ & \\
\hline 5.3 & Submit Ph II Test Plan & & $x$ & & \\
\hline 5.1 & $\begin{array}{l}\text { Complete pressurized bundle } 3000 \text { hr test of } \\
\mathrm{Ph} \text { II materials }\end{array}$ & & & & $x-$ \\
\hline 3.1 & Qualify GEN2 substrates & & & & $x-$ \\
\hline 2 & Phase II Factory Cost model & & & & \\
\hline & & & & & \\
\hline
\end{tabular}

\subsection{PROJECT DETAILS}

Activities and technical progress on the individual tasks with the LGFCS SECA program are described in this section.

\section{Task 1.0 - Project Management}

Approach - The purpose of this task is to manage and direct the project in accordance with the Project Management Plan to meet all technical, schedule and budget objectives and requirements and ensure that project plans, results, decisions, etc. are appropriately documented and project reporting and briefing requirements are satisfied

Results and Discussion-LGFCS has participated in semi-annual technical reviews, the Annual SECA Workshop and Core Technology Reviews.

\section{Task 2.0 - System and Cost Modeling}

\section{System Modeling:}

Approach - It is the objective of the process modeling task to develop an IGFC power plant that integrates the LGFCS design while achieving SECA program objectives. The primary program objectives assessed through the process modeling task are included in Table 2. As IGFC plant configurations were established during the Phase 1 budget period for meeting efficiency and $\mathrm{CO}_{2}$ capture targets, systems 
modeling activity during Phase 2 was limited to block rig simulations to guide execution of the peak power excursion as required for the Phase 1 metric test that extended into the initial Phase 2 budget period.

Table 2. Primary SECA Program Objectives Assessed with Process Modeling

\begin{tabular}{|c|c|}
\hline Efficiency & $\geq 60 \%$ \\
\hline Plant Anode Off-gas Effluent & $>95 \%$ pure CO2 \\
\hline Peak Power Density & 0.52 watt $/ \mathbf{c m} 2$ \\
\hline Cost FC Power Block (FC Stack) & $\$ 700 / \mathbf{k W}(\$ 175 / \mathbf{k W})$ \\
\hline
\end{tabular}

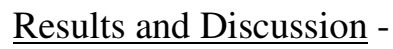

During Phase 1 a system configuration for an IGFC plant was devised that closely matches that of the distributed generation natural gas fired MW-scale plant (Figure 1). SimSci-Esscor Pro/II Simulation Modeling was applied to assess the efficiency of the IGFC plant while satisfying the numerous operational constraints that include coal as a fuel source and $\mathrm{CO}_{2}$ as a purified product stream. The analysis results for an advanced catalytic gasifier and using the Selexol gas cleaning process combined with the LGFCS power module could attain the $60 \%$ efficiency target by operating at a fuel utilization (species based) of $90 \%$ and a stack technology at roughly $0.2 \mathrm{ohm}-\mathrm{cm}^{2}$. LGFCS epsilon-stage of cell technology included in metric block testing and long-term durability evaluations is at $0.29-0.32 \mathrm{ohm}-\mathrm{cm}^{2}$, ranging from bundle to strip scale. Cell technology advances as described in Task 4.0 provide pathways for achieving the lower ASR required to meet a $60 \%$ IGFC plant efficiency.

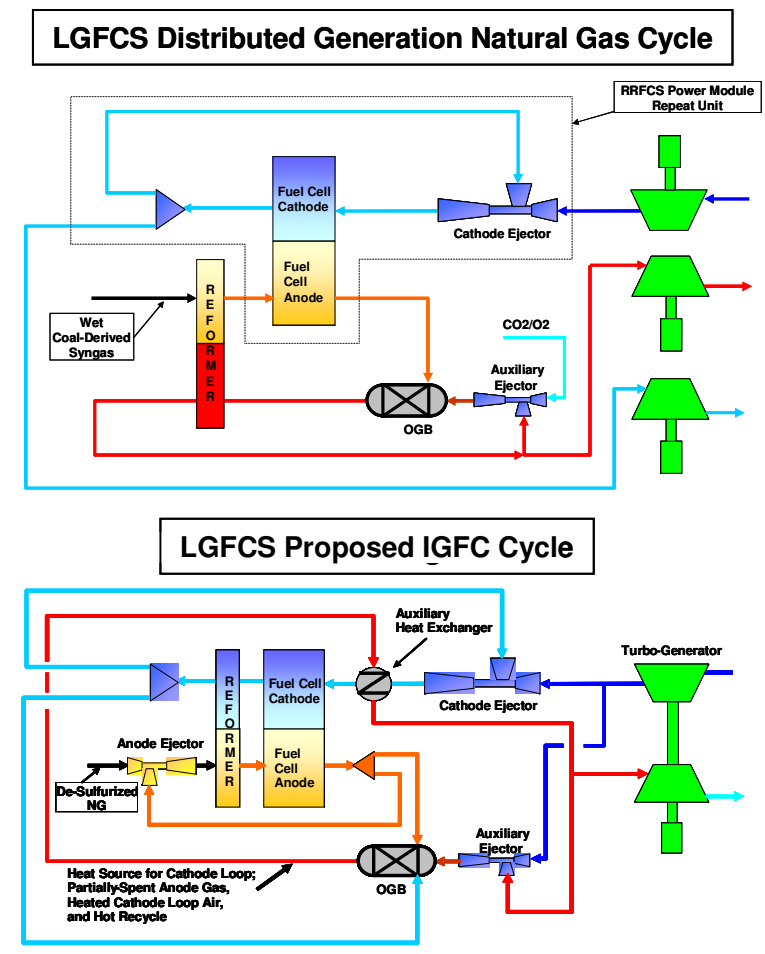

Figure 1. LGFCS system cycles for distributed and centralized generation (IGFC) power plants

The SECA Stack Block Test Stand (SBTS) used for the Phase 1 test contained a partial plant cycle representing the Fuel Cell Power Plant repeat unit. The existing components included the cathode loop and a single pass configuration for the fuel. The cathode loop injected primary air to an ejector that induced a recycle flow of hot cathode exhaust back into the fuel cell inlet. The fuel side contained no 
ejector, and therefore, no recycle flow was induced. The fuel flow was once-through and did not pass through an internal reformer. The design represented an early proposal for a coal-derived power plant that centralized a large reformer which was not incorporated on a small scale within the FC Power Plant repeat unit. As the power cycle progressed under the SECA program, both the current LGFCS natural gas cycle and proposed coal cycle became much more similar, and both included small scale internal reformers and heat exchangers. The overall progression of the IGFC cycle is described in the Phase I Final Report. A consequence of the progression was that the SECA stack block rig was less representative of the current cycle. Therefore, process simulations were used to help direct rig operation to conditions that were as representative to the real cycle as possible while demonstrating the SECA performance targets.

The SECA targets required the power plant to operate over a large load range, with peak power required for meeting the cost target necessitating high power density, and nominal power required for meeting the efficiency target necessitating lower power density. Process simulation modeling was used to examine tradeoffs in process conditions with the goal of demonstrating nominal and peak power conditions which were as representative as possible of the real cycle.

\section{Test Rig Simulations using 4 Strips}

A process simulation model was used to predict operating conditions for the available fuel cell surface. The process simulation integrates fuel cell models that represent fuel cell strips. However, the number of strips was less than the design value of five for a full block. The initial Phase 1 test configuration used four fuel cell strip: 3 of the epsilon technology (to provide nominal $11 \mathrm{~kW}$ ) and 1 of the old alpha technology included for heat balancing and not factored into the power calculation (there was a shortage of epsilon strips as a result of substrate quality, supply issues at the time). Since the SECA test cycle had no means to recover the excess (i.e. un-utilized) chemical energy as heated air, the test compensated for the lack of heat recovery by elevating the air preheat, which was accomplished using an external electric heater closely integrated with the cathode loop. The simulation model had predicted that sufficiently high cathode recycle rates were possible at relatively high, but still achievable preheat temperature, and therefore, the required stack inlet temperature could be sustained, which was confirmed experimentally. The targeted stack inlet temperature was $830^{\circ} \mathrm{C}$, and since this condition did not require additional fuel to heat the cathode air, the cathode chemistry was kept dry.

The 4-strip process simulation strategy for peak power would double the temperature differential across the second strip (referred to as peak power strip 2) from $840^{\circ} \mathrm{C}$ to $880^{\circ} \mathrm{C}$. The anode fuel supply was doubled in the simulation in order to accommodate the elevated power density in the peak power strip. A Summary of the simulated test results is shown below for the intermediate temperature strip (strip 2) operating at $860^{\circ} \mathrm{C}$.

\begin{tabular}{|l|c|c|}
\hline \multicolumn{3}{|c|}{ Process Simulation results for strip 2 of 4-strip configuration operating at 860C and 6 bar,a } \\
\hline Parameter / Power Level & Nominal Power & Peak Power \\
\hline Fuel Feed per strip, g/s & $1 \mathrm{~g} / \mathrm{s}$ & $2 \mathrm{~g} / \mathrm{s}$ \\
\hline Air Feed for Block, g/s & $23 \mathrm{~g} / \mathrm{s}(\mathrm{max})$ & $23 \mathrm{~g} / \mathrm{s}(\mathrm{max})$ \\
\hline Assumed Air Preheat, ${ }^{\circ} \mathrm{C}$ & 650 & 650 \\
\hline Current density, m-amps / cm2 & 380 & 720 \\
\hline $\begin{array}{l}\text { Power, } \mathrm{kW} \text { per strip } \\
(\text { watt/cm2) }\end{array}$ & $3.8(0.31)$ & $6.3(0.52)$ \\
\hline ASR, ohm-cm2 & 0.32 & 0.32 \\
\hline Strip DT, ${ }^{\circ} \mathrm{C}$ & 20 & 40 \\
\hline Flammables Out, mole\% & 30 & 30 \\
\hline
\end{tabular}


The simulations predicted current density, power density, and the temperature change across each strip that were comparable to the nominal conditions in the actual cycle. Experimental nominal values very close to those reported in the simulation table were achieved. The predicted cathode air flow, temperature, and pressure were also considered fairly close representations of the real cycle at nominal conditions. The compressed air system feeding the cathode ejector was able to operate at the correct air flow per unit fuel cell surface for nominal power at a pressure of about 6 bar,a. A pressure of 6 bar,a would likely represent an intermediate pressure in between nominal power and peak power in the real cycle.

The fuel blends that were simulated and tested were designed to represent NG operation at nominal conditions. The fuel flow was produced using an Oxy-CPOX reactor which blends feed streams of $\mathrm{CO}_{2}$, $\mathrm{O}_{2}$, Steam, and Natural Gas (NG) and can be designed to represent the fuel cell inlet composition for a range of fuels and process conditions including Coal-Derived Synthesis Gas under both single-pass and reduced anode recycle configurations. The process simulation modeled the Oxy-CPOX to predict flow rates that would generate fuel cell inlet conditions representing the NG cycle. These flow rates were used to conduct these tests. The coal cycle would have required Oxy-CPOX feed conditions that would have resulted in lower inlet to outlet anode-side compositions for the summation of $\mathrm{H}_{2}$ and $\mathrm{CO}$ (by $10 \%$ to $20 \%$ ) and would represent the required anode-side conditions for high efficiency in the real coal cycle for the nominal case. The lean coal-derived composition range was deemed to be too high a risk under which to test the fuel cell at the current stage of development.

\section{Additional Test Rig Simulations}

At the initiation of the 2200 hour block test, a strip failure reduced the total number of strips in the block from four to three ( 2 epsilon and heat-balancing alpha strips) for the first 700 hours. Therefore, just prior to re-starting the test, the simulations were repeated with three strips. Unlike the four-strip simulations, in order to sustain the nominal strip DT at the design value of $20^{\circ} \mathrm{C}$ over the correct operational temperature range, additional fuel as a $\mathrm{H}_{2} / \mathrm{N}_{2}$ blend was fed to the internal Off-Gas Burner (OGB). The OGB burner was a vestige of the previous cycle (wet) which vitiated cathode loop air with spent fuel from the fuel cell. In the current test configuration the spent fuel from the fuel cell was isolated from the OGB. However, the feed of external hydrogen to the OGB represented a deviation from the current real cycle (dry). The problem with this approach was the steam content would be elevated higher than that which would exist on the cathode in the dry cycle. However, since the test compressor supplied bone dry air, the process simulation predicted that the humidification due to the required level of OGB hydrogen combustion resulted in a cathode moisture level of roughly 3\%, which is only slightly higher than the wettest conditions that would result in the dry cycle using very humid ambient air on a warm rainy day. On this basis, the test was justified as representative at the nominal conditions. The process simulation showed that all other operating parameters could be maintained as they were in the 4-strip simulation.

Direct comparisons of the 3-strip process simulations to the block test could not be made because; 1 ) the Oxy-CPOX fuel was replaced with a $\mathrm{H}_{2} / \mathrm{CO}_{2}$ blend up to 700 hours, and 2) a strip leak developed over this period. At about 700 hours into the test, the heat-balancing alpha strip experienced unacceptable leakage and the remainder of the test was conducted with two epsilon strips until 2200 hours. At this point, Oxy-CPOX fuel had already been implemented into the testing. In these tests, the measured steam due to the additional OGB fuel was 3\%, about the same as the 3-strip process simulation predictions. However, a two-strip process simulation would have predicted a higher steam requirement unless the DT per strip was increased slightly above the target DT of $20^{\circ} \mathrm{C}$ to sustain the heat input from the fuel cell and maintain the same outlet temperature. In fact, a higher strip DT of $25^{\circ} \mathrm{C}$ to $30^{\circ} \mathrm{C}$ was implemented experimentally to yield an outlet temperature of $885^{\circ} \mathrm{C}$, very close to the outlet of strip 3 in the above process simulation at $890^{\circ} \mathrm{C}$. Therefore, the total experimental fuel cell stack heat release was comparable to that of the process simulation. 


\begin{tabular}{|c|c|c|}
\hline \multicolumn{3}{|c|}{$\begin{array}{l}\text { Process simulation results for strip } 2 \text { _of 3-strip configuration vs. 2-strip experimental } \\
\text { results }\end{array}$} \\
\hline Parameter & $\begin{array}{l}\text { Simulation at Nominal } \\
\text { Power (3-strip case) }\end{array}$ & $\begin{array}{l}\text { Simulation at Nominal } \\
\text { Power (2-strip case) }\end{array}$ \\
\hline Fuel Feed per strip, g/s & 1 & 1 \\
\hline Air Feed for Block, g/s & 23 & 23 \\
\hline Assumed Air Preheat, ${ }^{\circ} \mathrm{C}$ & 650 & $\sim 650$ \\
\hline Current density, m-amps / cm2 & 380 & 380 \\
\hline Power Density, watt/cm2 (kW/strip) & $0.32(3.87)$ & 0.31 \\
\hline ASR, ohm-cm2 & 0.32 & 0.34 to 0.38 \\
\hline Strip DT, ${ }^{\circ} \mathrm{C}$ & 20 & 20 to 30 \\
\hline Flammables Out, mole \% & 30 & 25 \\
\hline$\%$ Steam, Cathode Inlet, mole\% & 3 & 3 \\
\hline
\end{tabular}

In the real cycle, peak power requires additional air for cooling. Fifty percent higher power density requires roughly 50\% more air. Since the compressors and expanders are pushing more air, the system pressure would be elevated. Unfortunately, the SECA bock test could not push more air through the compressor / ejector system since the ejector inlet was operating just below the maximum allowable outer vessel pressure. Therefore, the only means to demonstrate peak power density while preserving the correct stack temperature characteristics was to operate a single strip at higher temperature differential while the others operated at a lower temperature differential to compensate. The approach was verified in the simulation results and confirmed experimentally in the two strip test. The four-strip model simulations showed a power density of 0.52 watts $/ \mathrm{cm}^{2}$ for the peak power strip when the strip temperature differential of $20^{\circ} \mathrm{C}$ was doubled to $40^{\circ} \mathrm{C}$. The current was increased while proportionally adding more fuel in the peak power case. Likewise, when the Strip DT of strip 2 of the 2-epsilon strip peak power test was doubled to about $57^{\circ} \mathrm{C}$, the experimentally measured power density was $0.53 \mathrm{watt} / \mathrm{cm}^{2}$. The higher strip DT is considered a severe operating condition, and the test demonstrated that the targeted peak power density could still be reached and sustained under a severe condition as opposed to the relatively benign condition that would represent a true peak power air flow which sustains strip DT at the levels representing nominal operating conditions.

\begin{tabular}{|c|c|c|}
\hline \multicolumn{3}{|c|}{$\begin{array}{l}\text { Peak Power Process simulation results for strip } 2 \text { of 4-strip configuration vs. 2-strip } \\
\text { experimental results }\end{array}$} \\
\hline Parameter & $\begin{array}{l}\text { Original Simulation for } 4- \\
\text { strip configuration }\end{array}$ & $\begin{array}{l}\text { Experimental result for } \\
\text { 2-strip configuration }\end{array}$ \\
\hline Fuel Feed per strip, g/s & 1 & 1 \\
\hline Air Feed for Block, g/s & 23 & 23 \\
\hline Assumed Air Preheat, ${ }^{\circ} \mathrm{C}$ & 650 & $\sim 650$ \\
\hline Current density, m-amps / cm2 & 720 & 720 \\
\hline Power Density, watt/cm2 (kW/strip) & $0.52(6.3)$ & $\mathbf{0 . 5 3}$ \\
\hline ASR, ohm-cm2 & 0.32 & 0.34 to 0.38 \\
\hline Strip DT, ${ }^{\circ} \mathrm{C}$ & 40 & 57 \\
\hline Flammables Out, mole\% & 30 & 27 \\
\hline
\end{tabular}

Conclusions - For stack tests with less than four strips, simulation predictions correctly predicted the requirement of a small amount of additional OGB fuel to sustain the fuel cell stack in the correct temperature range $\left(\mathrm{T}_{\mathrm{avg}}=860^{\circ} \mathrm{C}\right)$, while operating at a strip DT close to the operating target of $20^{\circ} \mathrm{C}$. Thus the experimental dry cycle test was actually operating slightly more humid than that which would occur on the upper end of the ambient atmospheric dew point range. In addition, 2-strip operation required a slightly higher experimental strip DT of about $27^{\circ} \mathrm{C}$. The process simulations also correctly predicted the 
higher preheat requirement of the cathode ejector motive air (in the $650^{\circ} \mathrm{C}$ range) to offset the absence of heat recovery from the unspent fuel cell fuel in the experimental dry cycle test. Finally, the simulations correctly predicted a doubling of the fuel cell strip DT to reach the targeted power density as long as the fuel supply was also proportionally increased. Since the compressor/expander equipment in a real power plant was not available for integration into the block test, both the peak and nominal power test were operated at an intermediate pressure 6 bar,a relative to the range that would likely be set-up in a real power plant operating from nominal to peak. Finally, the anode side fuel concentrations were simulated and tested at compositions that more closely represent natural gas operation than coal derived synthesis gas.

\section{Cost Modeling:}

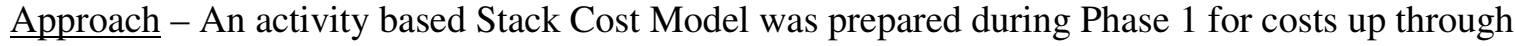
assembly of the fuel cell block that was initially designed as a seven strip block for a 1MW natural gas distributed power generation system in which the block would achieve an $\sim 27 \mathrm{~kW}$ power rating at normal operating conditions. The cost model does not utilize any learning curve assumptions. Raw material costs are based on recommended values provided by the DOE in the Minimum Requirements Document where possible. Otherwise, high volume cost estimates are requested for raw materials/components and cost analyses performed for high volume substrate and components. Ultimately the strip and block size may be increased for coal-based system and the cost model will then be modified, but such information would not be available until completion of the IGFC preliminary system design. A Factory Cost Model Reports are submitted that includes the balance of plant components of the SOFC module (anode protection gas system, turbogenerator, power electronics, control system, and packaging) along with the stack costs. Probablistic analysis was also added to the cost analysis through the use of Crystal Ball software to run Monte Carlo simulations. Variables chosen for the Monte Carlo runs were those that ranked high in their contribution to the overall cost and which had greater risk for cost increase or potential for cost reduction. Probabilities were assigned to a range of projected costs for those variables/components.

Results and Discussion - The Draft Phase 1 Factory Cost Model that used an assumed peak power of 0.51 $\mathrm{W} / \mathrm{cm}^{2}$ was independently audited during Phase 1 and recommendations thereafter incorporated into a revised cost calculations showing the LGFCS technology meeting the Phase 1 cost metric of $<\$ 700 / \mathrm{kW}$ (\$2007). The peak power excursion for the 2-strip ( 7.6kW) Phase 1 test was performed at the end of the test period that occurred during the quarter following the reporting period for this report. The achieved peak power density was $0.53 \mathrm{~W} / \mathrm{cm}^{2}$ essentially matching the assumed value in the original Cost Report, and thus meeting the $<\$ 700 / \mathrm{kW}$ requirement.

The Phase 2 program has an additional cost target for the fuel stack of $<\$ 175 / \mathrm{kW}(\$ 2007)$. The cost model was further revised and exercised during Phase 2 to investigate the LGFCS stack costs. As the model was initially structured, the block costs exceeded the $\$ 175 / \mathrm{kW}$ target, but the block included metal balance of plant components such as the anode and cathode ejectors, the off-gas burner, the reformer and heat exchanger and air ducting. For the Phase 2 cost analysis the block with encompass the ceramic strips and the metal hardware confining the strips into the block configuration shown in Figure 2. To meet the stack cost target, a lower cost anode versus that utilized in the epsilon technology is required and such an anode technology has been demonstrated (reported in section 4.2). Further cost reductions are realized through a more efficiently printing of multiple tubes at once; this is a strong recommendation from the LG Production Research Institute who design automation production equipment, including printers, for LG businesses. Cost savings can also be gained by reducing the number of print/fire steps for active substrate, and progress continues to be made in this area. 


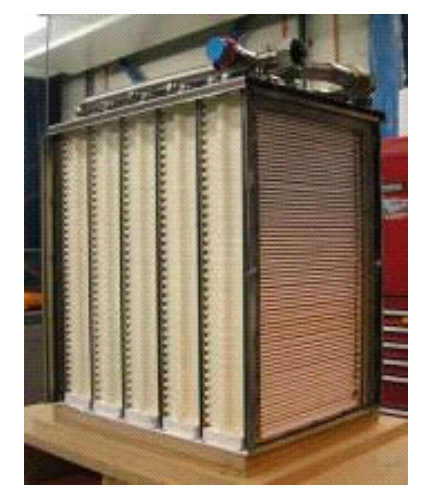

\section{Figure 2. Components included in the stack costs}

Conclusion- The Phase 1 Factory Cost Model shows the ability of a LGFCS IGFC SOFC power module to meet the $\$ 700 / \mathrm{kW}$ cost target for the IGFC power module based on the peak power level achieved for the Phase 1 test. The $<\$ 175 / \mathrm{kW}$ stack cost requirement in Phase 2 represents a greater challenge however the revised cost model and new assumptions on processes, stack components and validated lower cost materials allows meeting the stack cost target using the same $0.53 \mathrm{~W} / \mathrm{cm}^{2}$ peak power as the Phase 1 test. The Phase 2 Cost Report is to be submitted in the subsequent Phase $2 \mathrm{~B}$ extension budget period following the Phase 2 metric test.

\section{Task 3.1 Strip Optimization}

Approach - The LGFCS stack technology is being evaluated for changes to improve performance, electrochemical durability and cost. Analysis of the current stack design is being performed to extend the understanding of fuel distribution and pressure drop throughout the $\sim 4 \mathrm{~kW}$ strips (at normal operating condition) which make up the LGFCS fuel cell system. Fuel manifold components that distribute fuel into and out of the 12 parallel bundles of each strip are designed/optimized to achieve improved flow uniformity across all bundles and across the width of the substrates making up each bundle (a bundle consists of 6 substrates with series connection of electrical current and fuel flow). Design options are evaluated by 1-D network and computational fluid dynamic modeling with validation of the modeling results achieved through gas chromatography, tracer gas techniques. Fuel manifold designs used during Phase 1 were an interim design that incorporated pressure drop control features to improve flow uniformity, but resulted in too many unique parts, and several bundle types were required. A subsequent design modification has been pursued to achieve additional improvements in overall strip-to-strip, bundleto-bundle and intra-bundle flow distributions, in addition to seeking further cost reductions and to improve strip manufacturability through requiring fewer unique parts and each of the bundles having an identical design and pressure drop.

The LGFCS stack consists of a block containing 5 strips (Figure 3). Each strip contains 72 porous Magnesia Magnesium Aluminate (MMA) substrates onto which the fuel cell layers are printed. These substrates are converted into a sub-assembly by attaching dense MMA components to each end of the substrate using a glass-ceramic material. These substrates are then built up into a bundle which contains six of each of these sub-assemblies. The bundle is essentially the smallest sub unit in terms of the functioning of the stack, each bundle has a fuel inlet and outlet substrate, and 12 bundles combined to form the strip. The strip is connected to the fuel system using metallic elbows connected to the strip via a 
metal ceramic joint to feed the fuel into and out of the stack. Bundles within the strip are in parallel with respect to fuel flow. Inside an LGFCS strip, there are three types of fuel connectors:

- Pipes: main fuel lines that feed all twelve bundles and remove the excess fuel out of the strip.

- Manifolds: connectors between pipes and bundles. These components distribute fuel from the fuel pipes into the first substrate of the bundle and connects the sixth substrate of the bundles into the outlet pipe.

- End-caps: substrate connectors within a bundle. There are 5 pair of end-caps in a bundle, each pair connects two substrates.

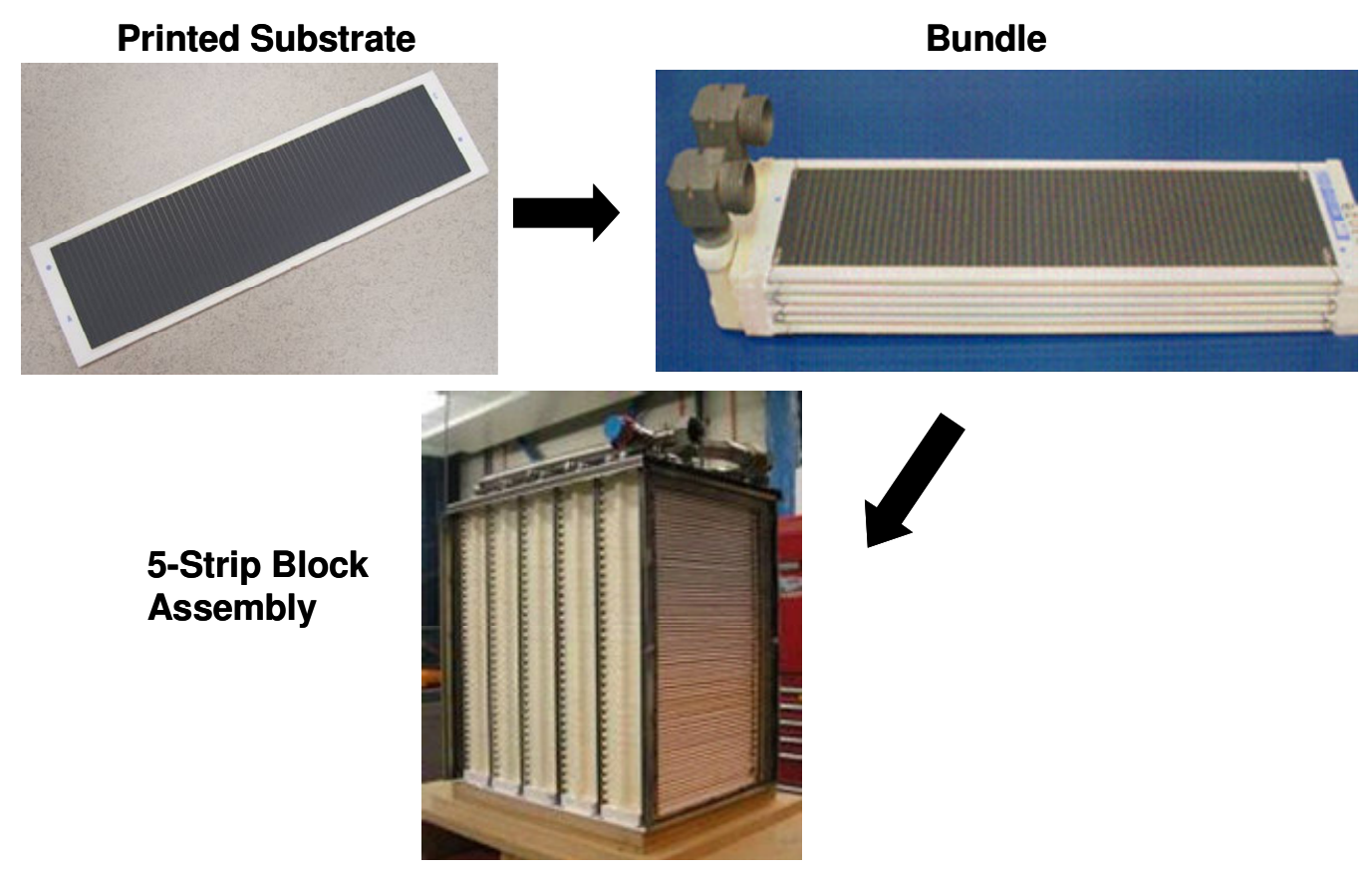

Figure 3. Building blocks of the RRFCS stack

Results and Discussion - The primary change to the strip design during the Phase II program was an increase in the cross-sectional area of the fuel pipes providing fuel into and out of the strip containing the 12 in-parallel bundles. The lower pressure drop through the fuel pipes was the key modification that allowed common bundle designs with uniform pressure drops. An early redesign of the manifold and end-cap, combined with the larger fuel pipes achieved a fuel distribution of $98 \%$ to $102.6 \%$ (percent of mean) across the 12 bundles based on the CFD analysis. When the basic redesign of these components was approved by LGFCS engineering team, the manufacturers suggested some further changes to the fuel connectors: mainly changes due to the tooling tolerances in curve parts and some fillet radiuses.

With these proposed changes a second set of analyses was generated to account for the changes due to manufacturing. The CFD simulations were prepared in house and ran at a computer cluster at Ohio State University. Several flow rates were considered to fulfill the requirements from the 1D models and to characterize the new components into resistances of those networks. The results from before and after the manufacturer's changes are illustrated in Figure 4. 


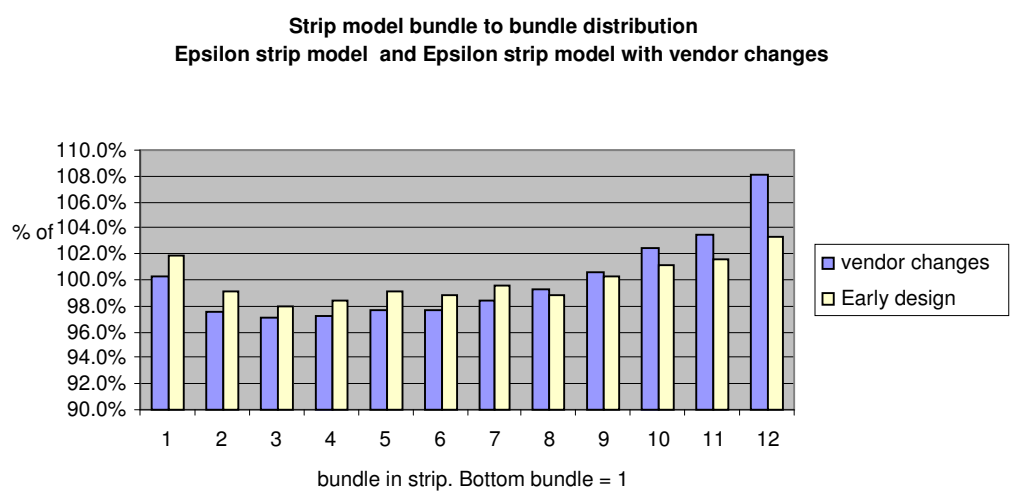

Figure 4. Bundle to bundle distribution with and without vendor requested changes

The results from the CFD analyses show similar trends for both cases. The re-distribution of the fuel flow changed by only $\sim 1 \%$ in bundle 3 to a minimum value of $\sim 97 \%$. The CFD analysis also examined the fuel distribution across the channels of the substrate. This distribution is most important for the sixth (last) tube of the bundle where flammable contents are low and where fuel mal-distribution could result in localized areas of fuel starvation or operation at high fuel utilization levels that can contribute to accelerated degradation. The minimum channel to channel fuel distribution was $97.7 \%$ as shown in Figure 5. The bundle-to-bundle and channel-to-channel distributions can be combined to give an overall worst case scenario for the strip: bundle 3 at $~ 95 \%$.

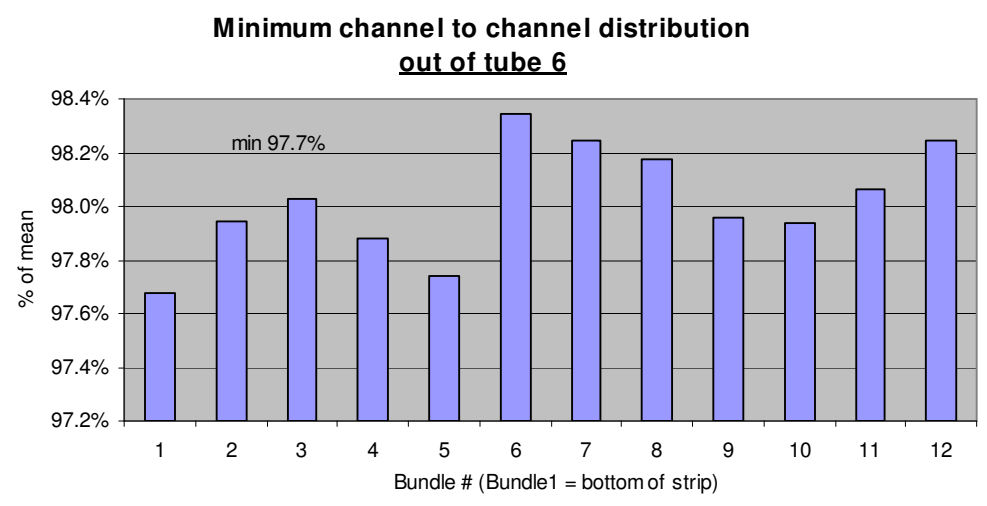

Figure 5. Worst channel to channel distribution located at bundle 1

$1 D$ and $3 D$ modelling of the strip _- The results generated by the CFD were later used in a network model. This 1D model comprises much of LGFCS $1 \mathrm{MW}$ system. The resistances in this model play key roles of the analyses because each resistance represents a pressure drop or a loss in the system. A fraction of this model is devoted to strips only and it breaks down further into individual bundles and fuel connectors, which include pipes and manifolds, bundles are simplified to single nodes in a much larger network model.

The 1D and 3D models are complementary. The physical geometry detail captured by CFD is used to derive resistances in the network model. By characterizing the losses on the individual parts, a resistance substitutes a component from three dimensional effects into one dimension simplification. The CFD simulations provides pressure drop and fuel flow rates at selected positions inside the strips and serve as the basis for the resistances of the 1D model. The pressure losses in each strip part are characterized and 
introduced in the network. These losses determine fuel distribution based on the losses of each of the components.
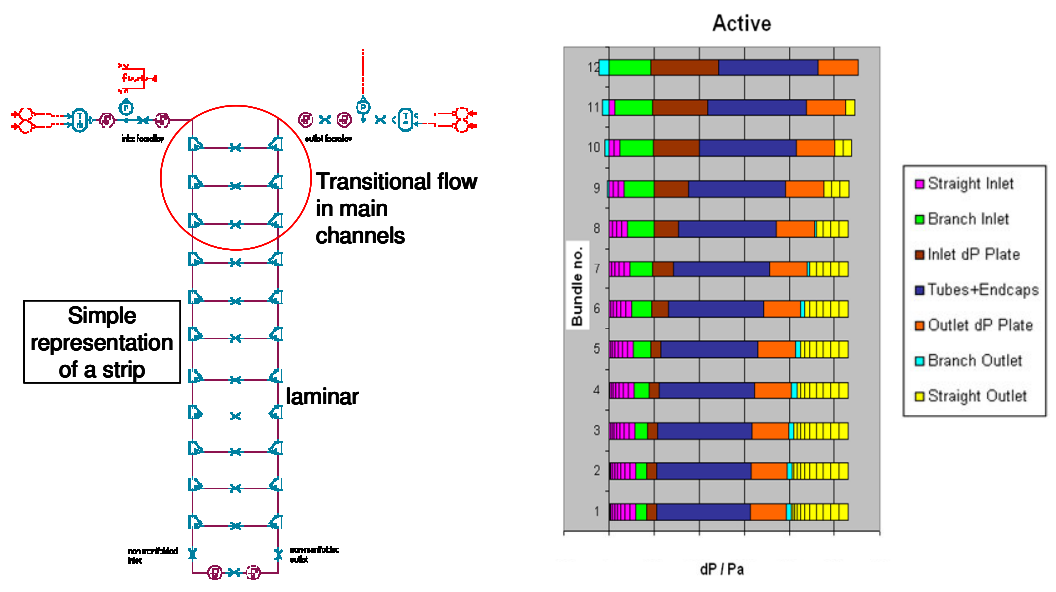

\section{Figure 6. Representation of a strip in a 1D network model and sum of pressure losses across the strip components}

These 1D simulations are normally used to model a more extensive array of conditions and to understand the trends. The trends are useful to identify the key areas of the design that needs improvement. As shown in Figure, losses can be broken down into connectors and it becomes evident the size of the losses and what the margin is. In essence 1D models are much more flexible and run a lot faster than 3D models, the main purpose of this exercise is to be able to run the model in real time.

Fuel distribution validation - In an effort to validate the computer modelling performed on the redesigned strip a 'mock up' strip was built using a combination of actual and stereolithographic strip components. Flow measurements, distributions were taken using a gas chromatography, tracer gas resonance time technique initially developed during Phase I but improved upon in Phase II. The location where the tracer pulse is injected and where it is measured was now performed in substrate 1 and 5 respectively.

- With this new technique the assumption of channel to channel flow uniformity of the tracer pulse is no longer important because the accuracy of the measured residence time does not need this as a requirement.

- The previous experiment introduced a fixed volume of trace gas, which was no longer a requirement for the new case. For this new experiment the size of the tracer gas is no longer a requirement.

- This new experiment used an accurate synchronised tracer injection and detection. Gas chromatographs (GC) have in-build synchronised injection/sampling and a thermal conductivity detector measures the pulse.

The results shown in Figure 7 indicate most of the bundles lie within $\pm 5 \%$ of the mean flow. This number was also produced by the CFD, however the trends are not in agreement. Within the relative accuracy of the measurement technique it was deemed that the new design achieves good flow uniformity. The error bars are large due to short residence time in bundle, sampling frequency $=16.7 \mathrm{~Hz}(0.06 \mathrm{~s})$. Other techniques for validating flow distribution are being considered. 


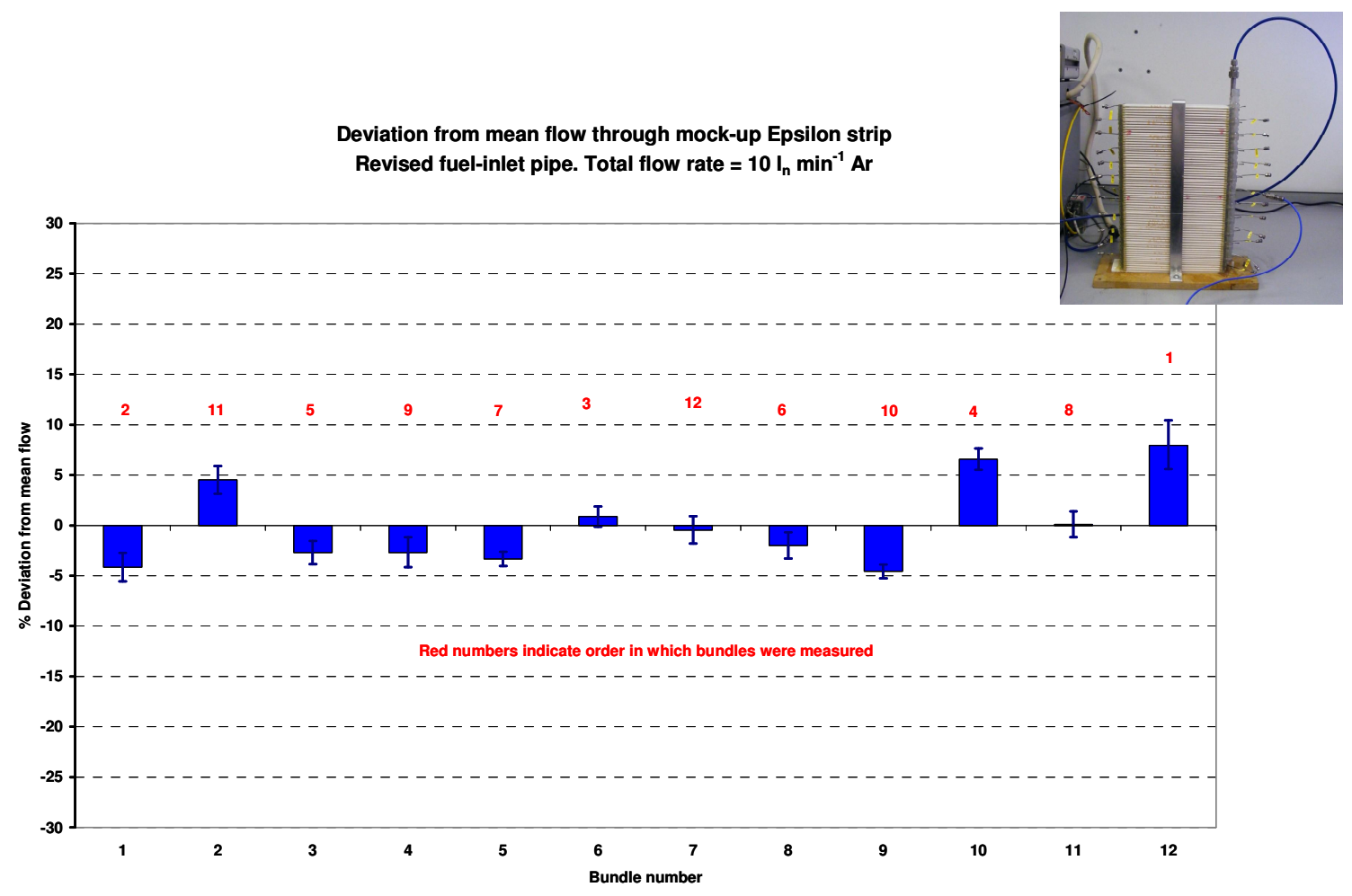

Figure 7. Experiment to measure gas residence time in bundle

New bundle model__ LGFCS engineers learned about a new technique for building CAD geometries within Star CCM+ modelling software that improves the mesh generation. A new bundle model was created (Figure 8). Unlike previous CFD versions of the bundle this model included all the dense components. Fuel manifolds, pipes and end-caps became part of the model to allow future analysis of the thermal gradients in these dense ceramic components. Some of these dense components have difficult internal shapes, and a great effort was spent in building the CAD geometry for all of these parts.

The purpose of including all the solid parts in a bundle model is to produce a complete thermal map of the substrates and dense components as generated by the multi-physics code. This map could then be imported as suitable input for stress analysis. So far we have developed a good interface between the CFD and the FE models and hope to start building up a database to gain more confidence in our overall stress results. This bundle model will be used to better understand the operational thermal stresses, particularly in bundle 12 (top bundle) where temperature differences between the inlet fuel and outlet fuel differs for the various strips depending on location within the block. The model is also an important tool for analyzing off-design cases and validating the ability of the FEA to predict mechanical failure of the ceramic components and extreme operating conditions: this is an important future activity for validating the reliability models. 


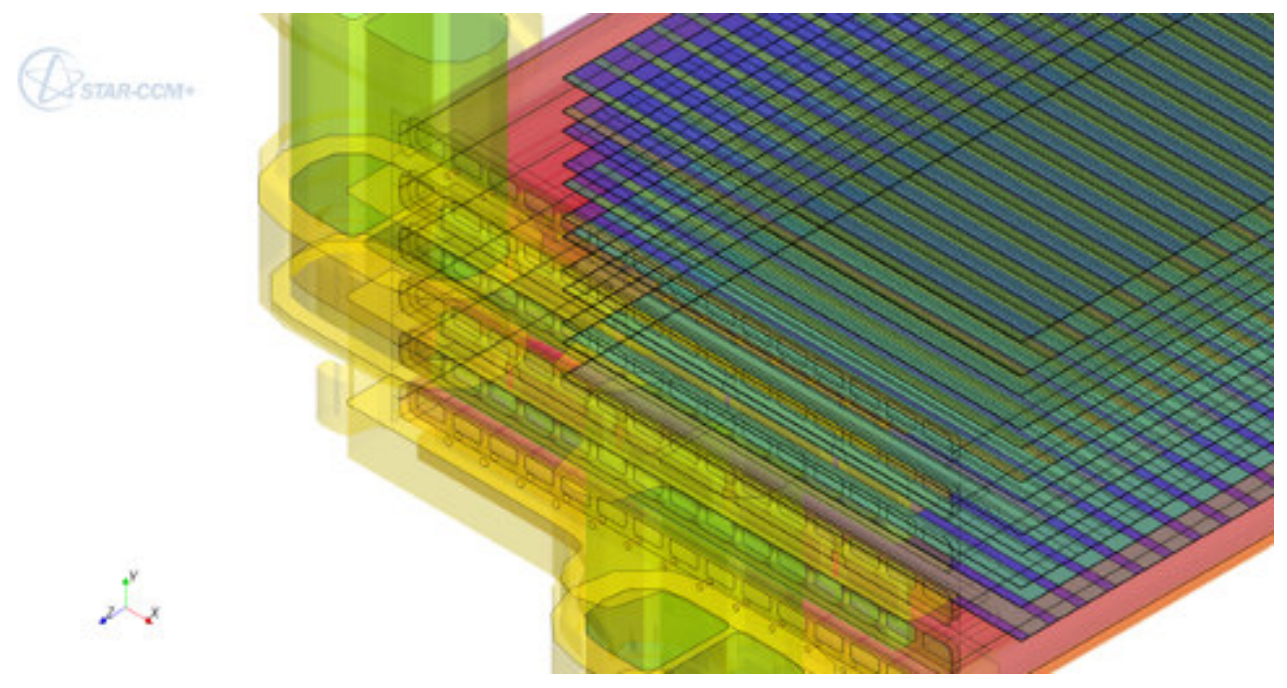

Figure 8. 'new' bundle model with dense components included

Conclusion: A strip redesign has been completed that achieves targeted fuel distribution using a lesser part count and common manifold features for improved manufacturing. Uniform flow distribution is important for running blocks at high design point utilization to meet efficiency targets and avoiding high cell degradation that can occur if there were localized regions of fuel starvation. LGFCS is beginning to receive substrates from alternate suppliers in our effort to develop a broader supply chain as will be necessary for commercialization. Supply chain development is also being pursued for the dense MMA fuel manifold components and this task will support the evaluation supplied components.

\section{Task 3.2 - Substrate Reliability}

Approach - Detailed mechanical property characterization of the substrate has been performed by ORNL and LGFCS through a CRADA. Characterizations include strength, modulus, fracture toughness, creep and slow crack growth of a next generation substrate from the primary LGFCS substrate supplier. The Gen2 substrate offer cost reductions at high volumes as a result of material and processing changes including: tunnel versus batch firing, lower purity raw material and fewer machining steps. Quality improvements are also realized based on improved uniformity of extrusion feedstock that reduces the occurrence of elongated pores observed in Gen1 tubes.

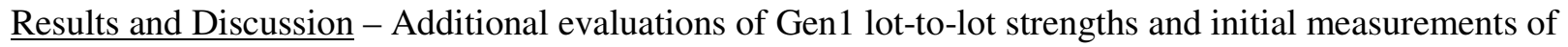
the strength of Gen2 lots was performed. The strength specification for the substrate is $>29 \mathrm{MPa}$ (based on modulus of rupture at $63.2 \%$ probability of failure) and a Weibull modulus over 15 . This has been achieved for Gen1 tubes compiling the strength data of several tube lots (Figure 9). Gen2 tubes have shown slightly higher strength and the Weibull modulus was under specification for early lots of tubes. More recent tube lots that were part of an initial 3600 substrate order under the LGFCS internal development program are meeting the specification. Electrochemical durability testing has shown no adverse impact of the slightly higher $\mathrm{CaO}$ content of the substrates on the power degradation rate. 

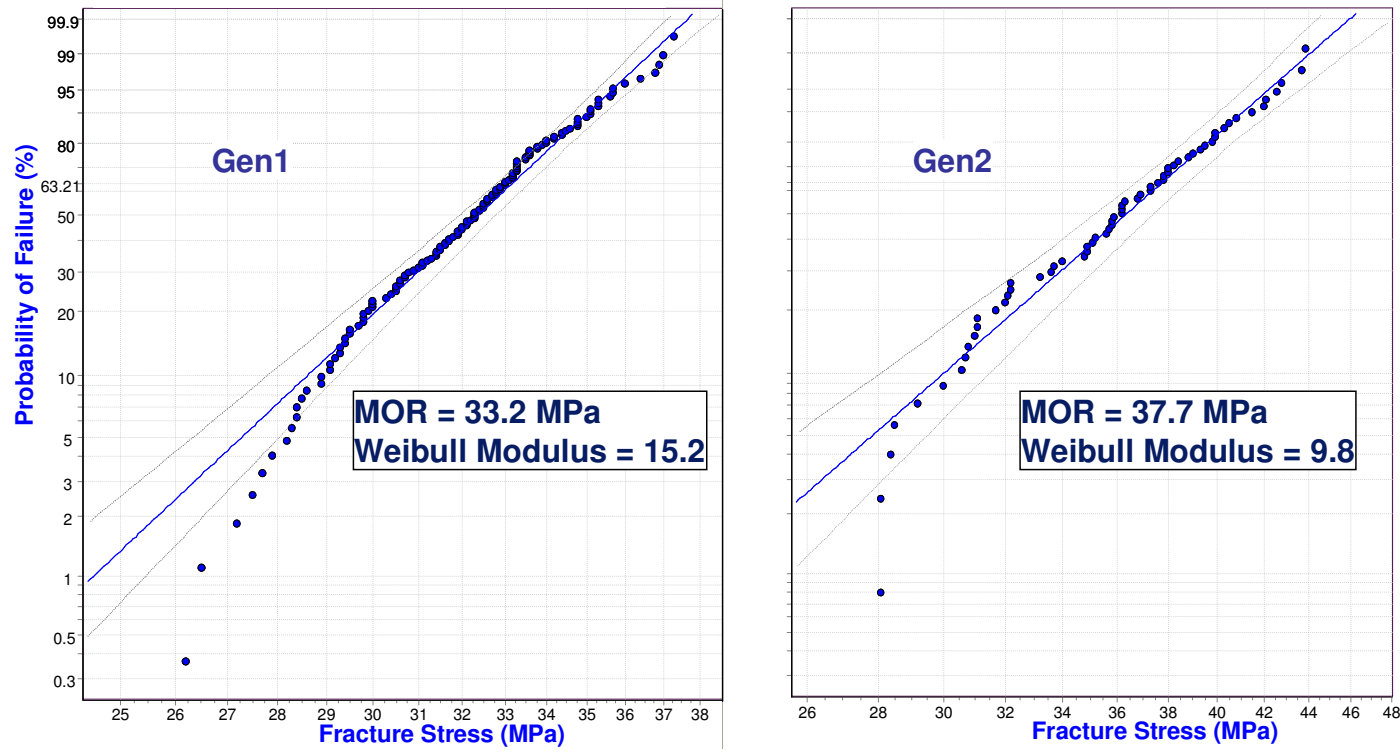

Figure 9. Strength comparison of Gen1 and Gen2

The mechanical property characterization of the substrate was the highest priority versus other components of the strip because of its high volume within the strip and being a porous material $(\sim 25 \%)$ and thus lower strength than the dense ceramic fuel supply/manifold ceramic components. Of particular interest and concern was the slow crack growth (SCG) behavior of the substrate under the moist fuel environment as it is well known that ionic oxide ceramics can be very susceptible to this time-dependent failure mechanism. ORNL has experience in SCG testing of porous ceramics is developing a database for the $\mathrm{MgO}-\mathrm{MgAl}_{2} \mathrm{O}_{4}$ substrate under several environments:

- Air (room temp., 900C)

- $\quad 3.5 \% \mathrm{H}_{2} \mathrm{O}, 3.5 \% \mathrm{H}_{2}, 93 \% \mathrm{~N}_{2}(800 \mathrm{C}, 900 \mathrm{C})$

- $48.5 \% \mathrm{H}_{2} \mathrm{O}, 1.5 \% \mathrm{H}_{2}, 50 \% \mathrm{~N}_{2}(800 \mathrm{C}, 900 \mathrm{C})$

- $48.5 \% \mathrm{H}_{2} \mathrm{O}+$ air $(800 \mathrm{C}, 900 \mathrm{C})$

SCG measurements are performed using a double cantilever specimen and measuring load relaxation during crack growth. Reduction of the data results in plots of crack velocity versus the applied stress intensity per the relationship $\mathrm{v}=\mathrm{AK}_{\mathrm{I}}^{\mathrm{n}}$. The higher the slow crack growth exponent $\mathrm{n}$, the less susceptible is the material to crack growth, and the preference is for a material with a high critical stress intensity factor (i.e., fracture toughness) such that the SCG exponential curves are shifted to high a stress intensity allowing component design to be at as low a fractional stress intensity as possible. The general SCG data for ceramics falls into 3 regions as shown in Figure 10. Region I is a threshold, region II is linear and region III enters instability and fast fracture. 


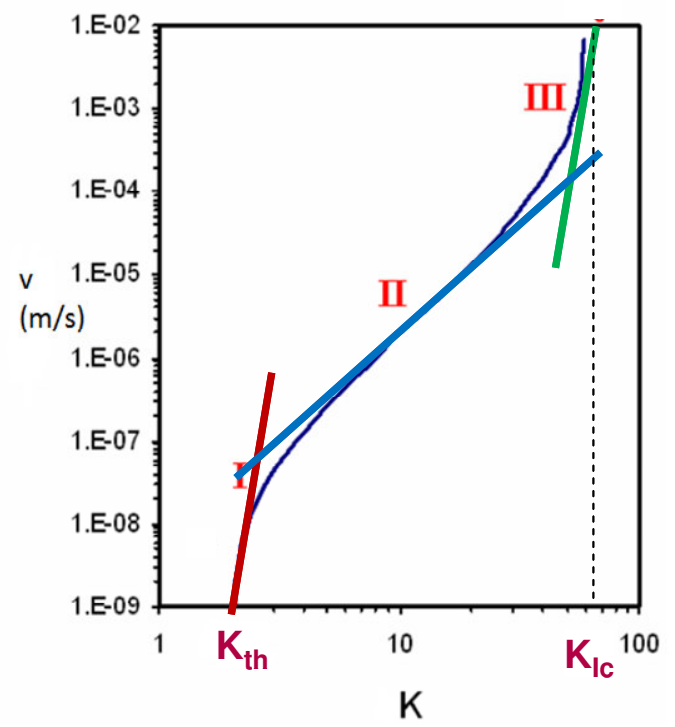

Figure 10. Theoretical regions of slow crack growth of ceramics

The result for tests in air and $3.5 \% \mathrm{H}_{2} \mathrm{O}, 3.5 \% \mathrm{H}_{2}, 93 \% \mathrm{~N}_{2}$ have shown very favorable SCG parameters for the substrate material (Figure 11).

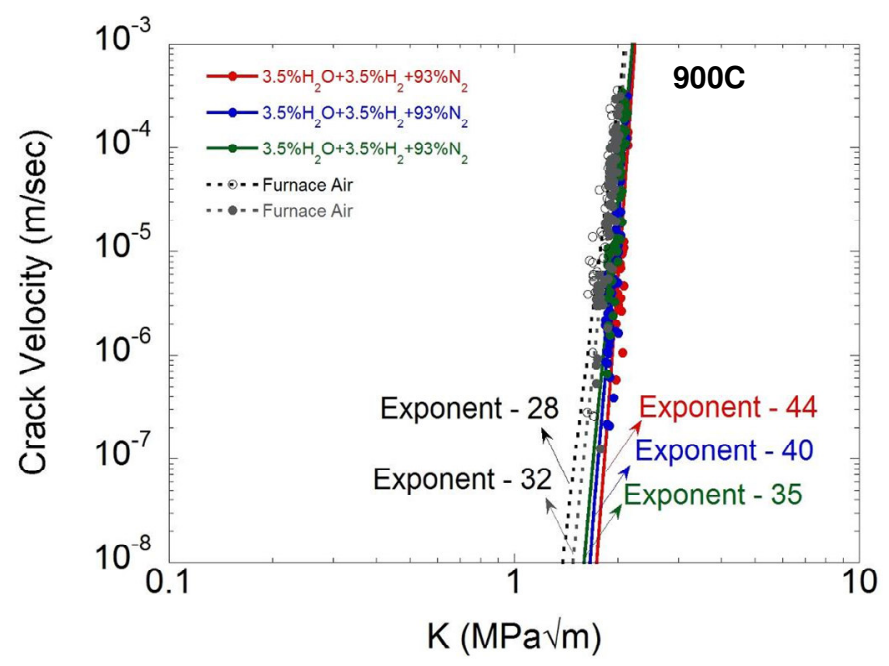

Figure 11. SCG behavior of substrate in $3.5 \% \mathrm{H}_{2} \mathrm{O}, 3.5 \% \mathrm{H}_{2}, 93 \% \mathrm{~N}_{2}(900 \mathrm{C})$

Under the SECA Core Technology program, ORNL has measured SCG properties for a Ni-YSZ cermet of similar porosity as the LGFCS substrate under very similar environments (although the LGFCS substrate included moisture) and the SCG exponent for the LGFCS substrate shows very favorable behavior, comparatively (Figure 12). Future SCG measurements will include higher moisture levels in a simulated low oxygen partial pressure fuel condition $\left(48.5 \% \mathrm{H}_{2} \mathrm{O}, 1.5 \% \mathrm{H}_{2}, 50 \% \mathrm{~N}_{2}\right)$ and ORNL is setting up a new test rig in which the SCG measurements can be made in the actual bundle inlet and outlet fuel environments. 


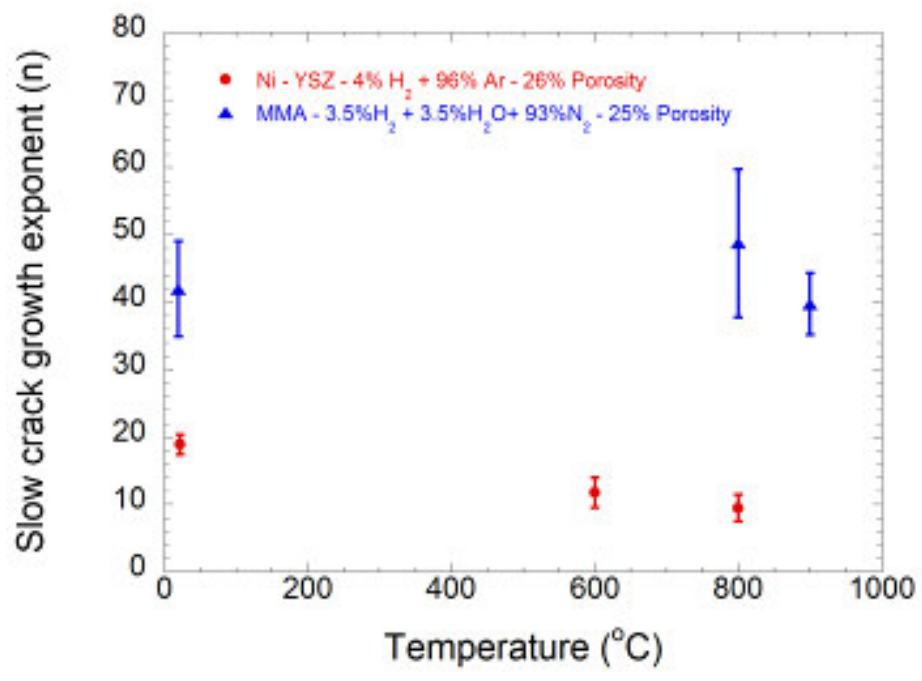

Figure 12. Comparative SCG data for LGFCS substrate versus Ni-YSZ anode support

RRFCS and ORNL are developing a methodology for lifetime prediction built upon the fundamentals of fracture mechanics combined SCG versus stress intensity relations with the Weibull statistics for the substrate at the SOFC operational temperatures. An equation is thus available that allows a time to failure predictions as a function of the substrate properties (SCG, Weibull strength and fracture toughness) and dependent on the volume of material under stress in the article, the design stress of the article and the desired probability of failure. Estimates of the time to failure can be made as shown in Figure 13 for illustrative purposes only. The reliability of the MMA substrate is most influenced by the SCG exponent (n), the Weibull modulus (the higher the better for both) and through designs that minimize the operational stresses on the tubes. Similar analyses will be performed once SCG data is obtained for the substrate in the actual reformate fuel environment. RRFCS is seeking sufficient stack reliability for 5 years service.

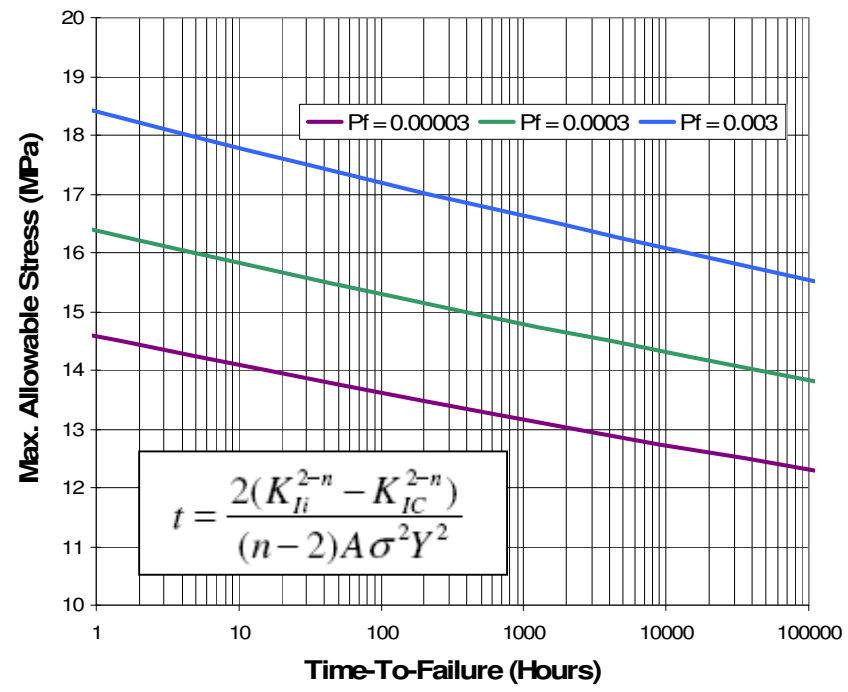

Figure 13. Illustration of substrate lifetime prediction being explored based on SCG mechanism

Validation of the reliability predictions methodology has been first pursued doing simple flexure testing of substrates in air. We find that the samples last 3-4 orders of magnitude longer than expected indicating some flaws in our methodology, but we also see that failures can be generated at $90 \%$ of failure loads in 
reasonable times, but at $85 \%$ of failure loads, failures just have not occurred. ORNL also did not experience failures in their 900C/air attempts at SCG validation. This indicates that the threshold stress intensity factor for the MMA may be at a high value, and SCG does not occur below the threshold which is very beneficial for reliability. A threshold value is common to ceramics, and can be various fractions of the critical stress intensity factor depending on the nature of the materials (covalent ceramics such as $\mathrm{SiC}$ have a very high threshold). In fact, on more detailed analysis of the SCG data we see evidence of threshold behavior at a high percentage of the critical stress intensity factor.

We are considering whether the 4-pt flexure test for SCG is suitable or whether a tensile test would be better for insuring stress intensity levels. An alternate ASTM technique (C1368-10) for obtaining slow crack growth data using a constant stress rate is planned to supplement the validation testing. The advantage of this technique is a more rapid generation of slow crack growth/failure compared to long holds at a constant stress level.

The other time-dependent failure mechanism being examined is creep/creep rupture. ORNL has completed the creep testing set-up for the substrate materials and data at several temperatures and stress levels is now required to accurately assess the tendency of creep in this material. Initial testing does not suggest that this is a mechanism to be overly concerned about though.

Active layer property determination - The integrity of the active cell layers printed on the substrate is also very important to the reliability of the stack and system. The fuel-air boundary is a $\sim 10$ micron electrolyte held onto the substrate by the anode-side layers. Accurate elastic properties and thermal expansion of the active cell layers is required for FEA analysis. ORNL initially measured elastic properties from bulk specimens but it was determined that in-situ properties are most preferred. ORNL developed a clever technique of obtaining elastic properties by extracting a 175 micron section of substrate from a series of samples provided by LGFCS in which the SOFC was printed/fired up to each layer (Figure 14). The remove thin multilayer samples were tested in a micro-tensile machine. The progression in the measured elastic properties for sequential layers can be deconvoluted to yield the elastic properties of an individual layer. These tests were just commencing at the end of the budget period, however very reasonable initial values were obtained for the initial active layers and there is high confidence in the technique.

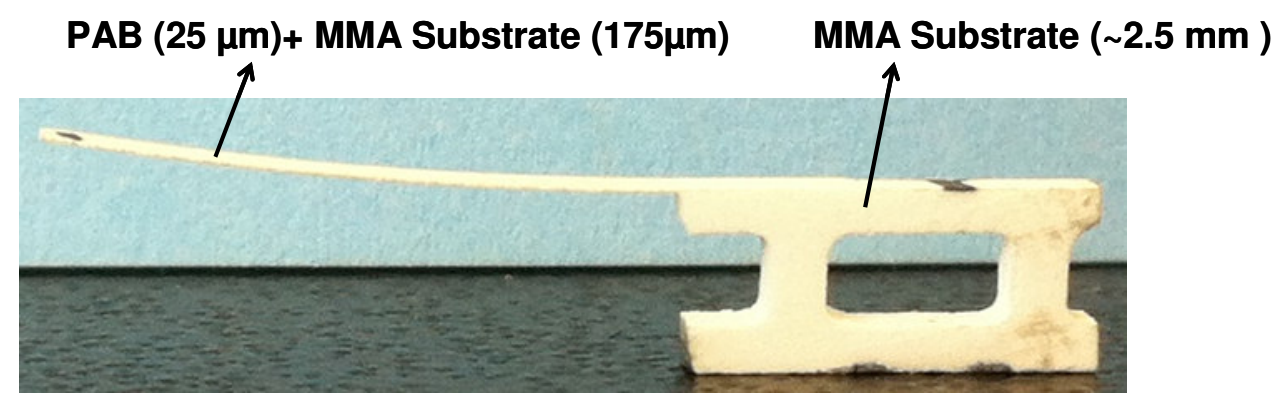

\section{Figure 14. Removal of sequentially printed layers from substrate for progressive elastic modulus measurements}

Conclusion - Given that roughly 18,500 active substrates will constitute a $1 \mathrm{MW}$ system, a detailed understanding of substrate mechanical properties is necessary to ensure long-term structural reliability of the SOFC modules. Data generated thus far on the ORNL FWP/CRADA supports the selection of MgO$\mathrm{MgAl}_{2} \mathrm{O}_{4}$ as a suitable substrate material, and in fact the MMA shows very encouraging SCG resistance in simulated fuel environments - future testing will be actual reformate environments. ORNL has been emphasizing the mechanical characterization of the porous substrate material since it is the lowest 
strength ceramic component within the strip. Mechanical characterization will be extended to the dense $\mathrm{MgO}-\mathrm{MgAl}_{2} \mathrm{O}_{4}$ components and the glass-ceramic based joints used in the strip assembly. Having a complete characterization of the properties of the materials is only part of the challenge, equally important is having confidence in the knowledge of the boundary conditions of the ceramics in service and the accuracy of the stress FEA predictions. The goal is to be able to induce severe boundary conditions on SOFC components at various scales and have the models predict the structural failures that occur. This is a long-term goal dependent on establishing a deeper understanding of the material properties, time dependent failure mechanisms, micromechanics of the materials and the stress states the parts are subjected to in service both at normal operating conditions as under transients.

\subsection{CELL DEVELOPMENT}

During the Phase 2 program, the cell development objectives were to focus on degradation issues for both cathode and anode in order to achieve 2-3 years service life. For primary interconnect (PIC), new degradation mechanism was identified due to precious metal loss through vapor phase, which was addressed through minor PIC design change. Other activities include demonstrating extreme low PIC ASR for LGFCS technology and design modification to achieve lower PIC ASR with more cost effective design. For anode, the team demonstrated $5000 \mathrm{hrs}$ of testing under simulated system conditions for zeta anode technology. The key advantage of zeta technology is to eliminate the major degradation mechanism of epsilon anode, poor anode/ACC interface due to metal phase migration. The post-test analysis shows zeta anode has more uniform microstructure after $5000 \mathrm{hrs}$ of testing than epsilon anode. For cathode, a new degradation mechanism, cathode densification near cathode/electrolyte interface, was identified after $16,000 \mathrm{hrs}$ of testing under simulated system conditions. Cr deposition in cathode was also observed by TEM after the cells being tested in Cr-containing environment. Testing plan is in place to better understand cathode densification issue. Mitigation scheme is being discussed and under investigation.

\section{Task 4.1 - Interconnect Development}

Approach - In the RRFCS technology, the primary interconnect (PIC) connects two adjacent cells to form the integrated planar (IP) SOFC design on a porous ceramic substrate. Interconnect materials must meet the following requirements: dense/impermeable, conductive, exhibit chemical compatibility with adjacent fuel cell materials, stable in both reducing and oxidizing environment, and exhibit long term stability under fuel cell operating conditions. In the IP-SOFC technology, unique designs within the PIC region facilitate meeting the above requirements. A via design is preferred for the PIC to minimize stack cost while continuing to use a precious metal cermet. By implementing electronic packaging design features within the IP-SOFC, the combination of vias and dense ceramic layers can improve the gas tightness of the PIC area, thus maintaining high fuel utilization. The current baseline interconnect is a precious metal cermet, in via form, selected based on its low ASR contribution. Refinement of this baseline approach addresses maintaining low resistance interfaces between the via and the Ni-based active anode materials and optimizing the PIC materials and designs to avoid fuel loss.

Ceramic-based primary interconnects are being developed as the next generation primary interconnect to achieve further cost reductions and improved long-term durability for 4-5 year service lifetimes. The greatest challenge to adopting a ceramic-based interconnect is achieving sufficient density in a constrained sintering condition. Dilatometry is used to study ceramic interconnect sintering and densification. Dry pressed bar and printed films coupons are used to evaluate ceramic interconnect conductivity in both air and forming gas in the furnace with controlled oxygen partial pressures. SEM and EDS are used for routine post-test analysis for microstructure change and materials migration during long term durability test. In addition to single layer interconnects of chromites and other perovskites, alternate designs, such as bi-layers of n-type and p-type conductors are being explored. 
Results and Discussion - Precious metal cermet vias in a 5-cell subscale test had been tested for 16,000 hrs (PCT63) at $860^{\circ} \mathrm{C}$ under SECA Phase I. In Phase II, another $16,000 \mathrm{hrs}$ test at $800^{\circ} \mathrm{C}$ (PCT89B) was also completed (Figure 15). The two tests generally have good repeatability. In both tests, the PIC have initial ASR of about 0.07-0.08 ohm- $\mathrm{cm}^{2}$. During testing, PIC ASRs improve with time and reached 0.05$0.06 \mathrm{ohm}-\mathrm{cm}^{2}$ after one year testing, then slightly increased to the original value and leveled off. Based on long term durability test results, the precious metal cermet vias (epsilon PIC) can meet minimum two-year service life for the fuel cell systems we are developing. Post test analysis of similar vintage of cells relates the PIC degradation during the second year to materials migration across PIC layers caused by some misalignment issues or pinholes formed during cell printing. Processing optimization will help to eliminate or reduce PIC degradation mechanism during operation of the fuel cell system.

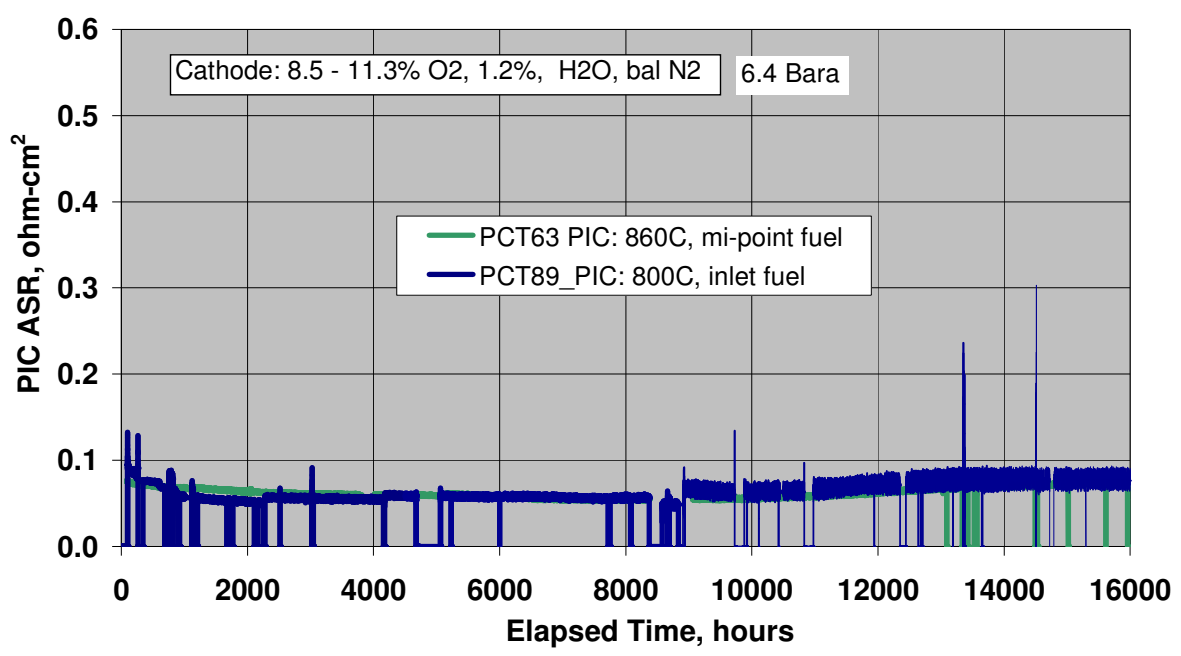

Figure 15. PIC ASR of 5-cell subscale long term durability (PCT63: 860C, mid-bundle fuel, PCT89: 800C, bundle inlet fuel))

Parasitic currents in the vicinity of the primary interconnect remain an area of study and optimization. Overall fuel loss within the stack from physical leakage and parasitic cell occurrences is targeted at $1 \%$ to maximize system efficiency. Modifications to the epsilon PIC are being explored to reduce fuel loss from both physical fuel transport across the interconnect and local parasitic cell operation. The major change is to avoid potential parasitic cell formation in PIC area during cell fabrication. Most long term durability tests, including Figure 15, were performed using 5-cell subscale articles before the PIC design change. When scaling up to full tubes, a design change was implemented to provide greater margin on print resolution. Test articles of the changed PIC design, at both the full tube and 5-cell subscale size, have been prepared and tested. The durability testing results show unexpected new degradation mechanism, which is associated with the PIC design change (Figure 16). The PIC ASRs are usually stable within about first $1000 \mathrm{hrs}$, and then started higher degradation rate, which is unacceptable. Post-test analysis indicates precious metal loss in PIC area, close to cathode current collector layer, possibly due to higher air flow and oxide vapor phase formation. To avoid this degradation mechanism, the PIC was changed back to original design. The parasitic loss was measured using full tube with both the original PIC design and the altered design to compare the difference in parasitics between the designs. The purpose of measurement is to understand the effect of PIC design change on parasitic loss. Parasitic loss of multiple TR (full tubes) tests is summarized in Figure 17. It can be seen that the tubes have similar parasitic loss before and after the PIC design change, which means the design change does not influence parasitic losses. 


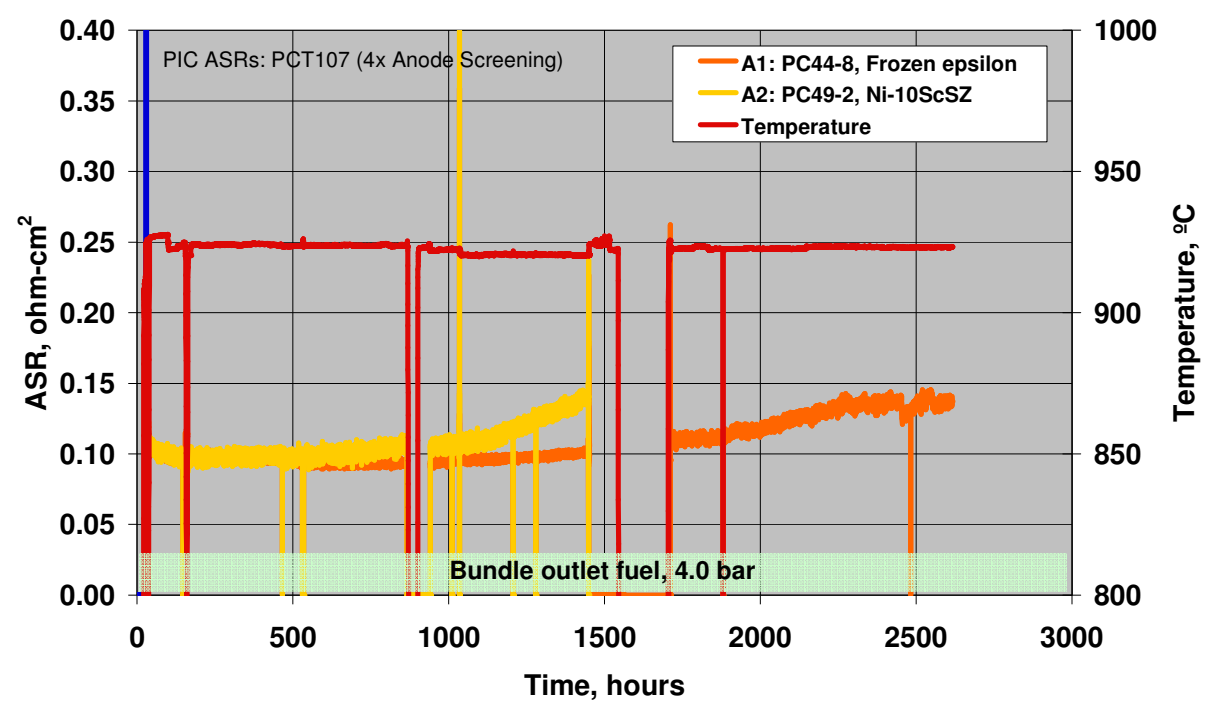

Figure 16. PIC long term durability for 5-cell subscale after PIC design change (PCT107: 925C, bundle outlet fuel)

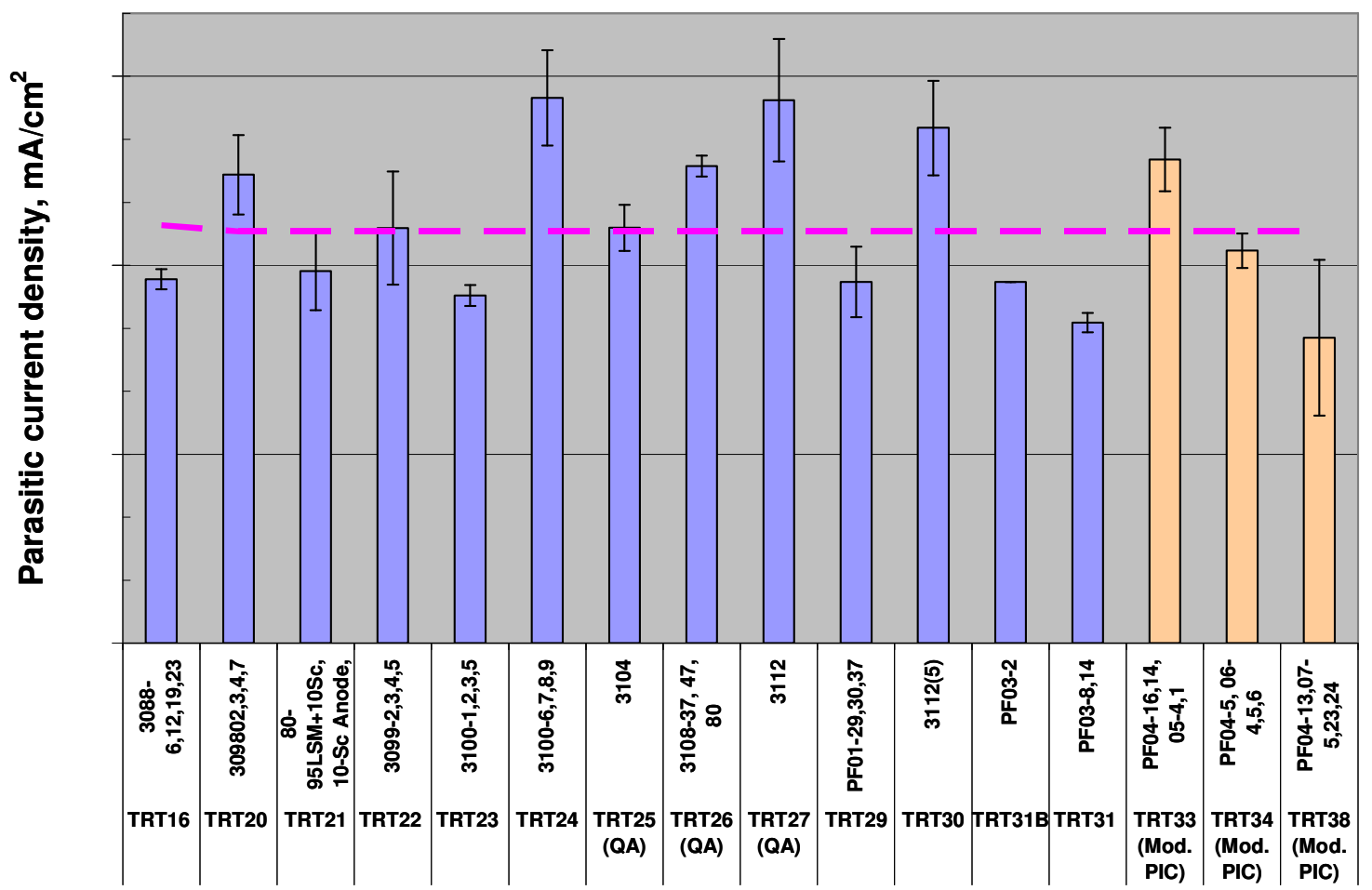

Fig. 17 Parasitic loss measured from TR test using full size tubes at 900C

In applying the epsilon PIC technology to zeta anodes, it has become apparent that the CTE of an important layer within the PIC region needs some adjustment downward to improve the yield/quality of 
the interconnect region and to provide a greater degree of freedom for combining this current interconnect technology with a range of anodes that are being explored for improved long-term durability. In addition, we've observed materials interactions between the zeta anode and the interconnect layers causing ASR issues. During phase II alternate primary interconnect materials were screened for compatibility with zeta anode. Screening tests included printed layer sintering and thermal ageing studies for compatibility studies and conductivity measurements.

Several candidates resulted from this screening and 5-cell subscale articles have been processed. These solutions are being applied to primary interconnects based on the precious metal cermet vias. Screening of ceramic interconnect materials has continued with the identification of several compositions having suitable electronic conductivity over the range of fuel $\mathrm{pO}_{2}$ experienced during fuel cell operation. Constrained sintering experiments are still required.

Solutions to minimize the interactions between the zeta anode and the interconnect layers were identified. Alternate primary interconnect materials for pairing with zeta anodes were tested at the 5-cell scale, screened for compatibility with zeta anode. As shown in Figure 18, the two primary interconnect candidates show improving ASR, although still higher than the target. The rapid initial improvement for PIC B is related to its chemistry and reduction kinetics. Additional modifications are being considered to lower the ASR level.

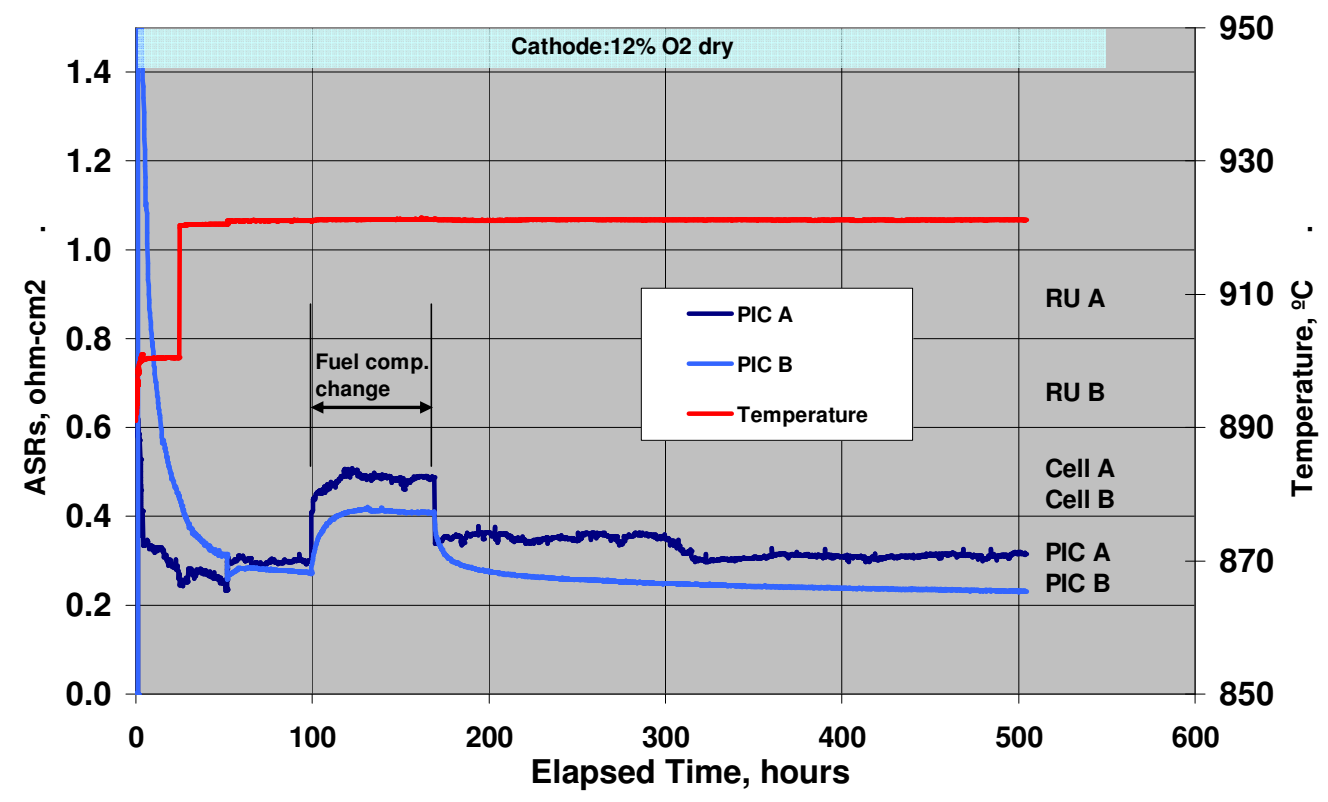

Figure 18. Initial ASR results for modified primary interconnect combined with zeta anode

Further testing of solutions to minimize the interactions between the single layer anode and the primary interconnect layers was then performed. In Phase I we reported primary interconnect ASR levels, when combined with certain single layer anodes, of greater than $0.2 \mathrm{ohm}-\mathrm{cm}^{2}$. Two modifications to the primary interconnect design/materials were evaluated and applied to cells also having an optimized single layer anode that has shown improved microstructure stability compared to the current baseline epsilon bilayer anode technology (active anode plus anode current collector layers). Figure 19 shows that PIC ASR levels as low as $0.06 \mathrm{ohm}-\mathrm{cm}^{2}$ have been obtained now when paired with a single layer anode technology. 5-cell subscale test articles, showing no degradation trend after $3500 \mathrm{hrs}$ of testing (modified PIC 2) under simulated system fuel composition, was shut down for post-test analysis to investigate whether any materials interactions exist, but that have just not shown up yet as an increase in ASR. More repeat tests are going under different period of testing stage, showing similar low PIC ASRs. 


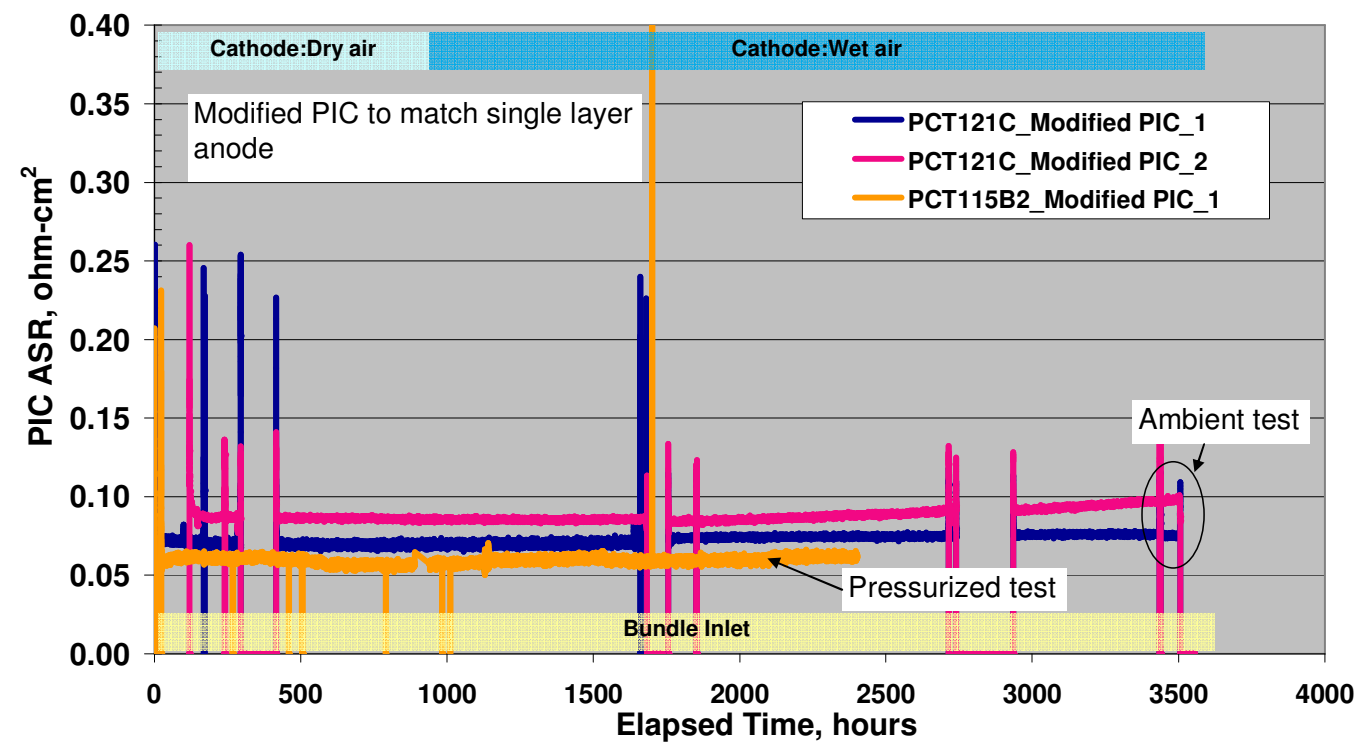

Figure 19. PIC ASR results (900C) for modified PIC combined with a single layer anode

A more substantial redesign of the primary interconnect is now being considered as a means to potentially reduce the PIC ASR for epsilon and zeta technology to $<0.02 \mathrm{ohm}-\mathrm{cm}^{2}$. The drive for this is to reduce overall cell ASR to allow a reduction in the peak operating temperature to improve long-term overall cell durability. The PIC redesign started at the modeling stage where PIC ASRs with different design were calculated and compared to that of the epsilon design. The principal of the redesign is to reduce PIC ASR while not significantly increasing printing area to keep materials consumption, thus cost low. Model calculations (Figure 20) indicates the epsilon PIC design has ASR of $\sim 0.044 \mathrm{ohm}-\mathrm{cm}^{2}$. For a non-via, full strip design, which has biggest printing area, a PIC ASR as low as $0.01 \mathrm{ohm}-\mathrm{cm}^{2}$ is predicted, however, it will significantly increase materials cost. When PIC design of Case IVE, is used, the PIC ASR can be reduced from $0.044 \mathrm{ohm}-\mathrm{cm}^{2}$ to $0.022 \mathrm{ohm}-\mathrm{cm}^{2}$ with the printing area is only increased slightly. The model calculated ASRs are lower that that actual measured. The reason is there is interface resistance effect in the real cells that the model did not take into account. By comparing the model calculation and the measured results, interface effect accounts for about $0.02 \mathrm{ohm}-\mathrm{cm}^{2}$ contribution.

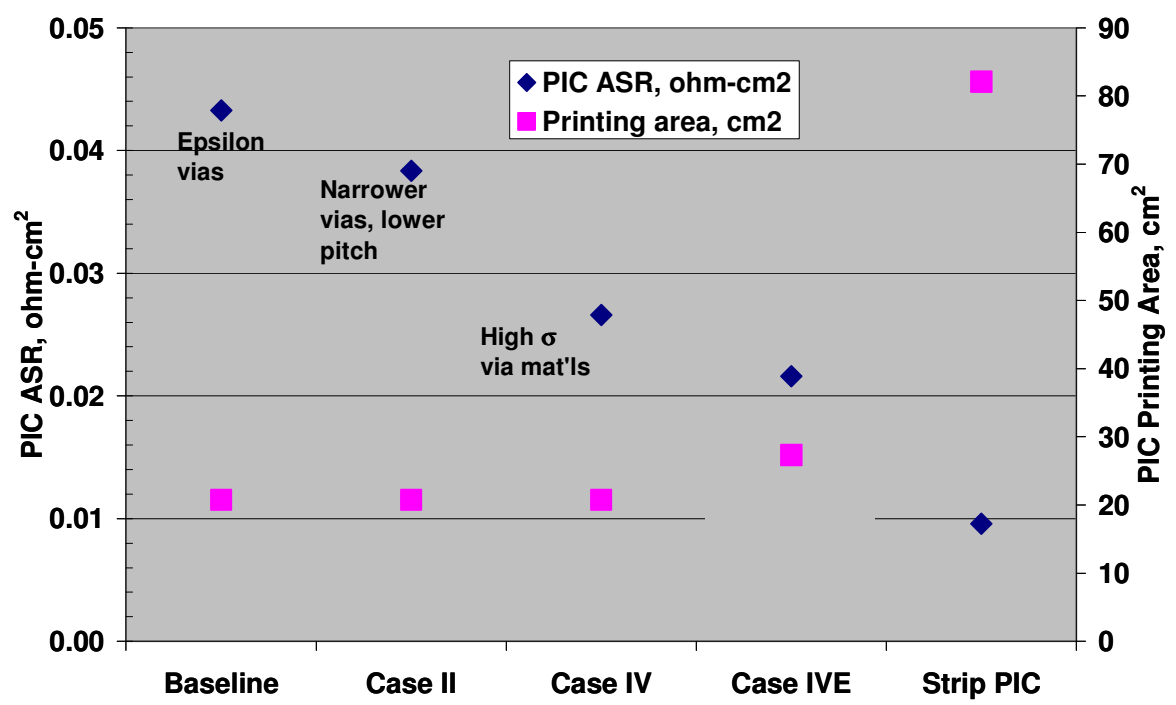

Figure 20. Calculated PIC ASR of different design based on the model 
To understand the lowest PIC ASR achievable for this technology, 5-cell subscale test articles were prepared and tested. Fig. 21 summarizes durability results of two subscale cells using the non-via, strip design with one cell using lower conductivity material and another using higher conductivity material. Up to $1800 \mathrm{hrs}$ of testing under simulated system gas conditions, both cells have low and stable PIC ASR, 0.03 to $0.035 \mathrm{ohm}-\mathrm{cm}^{2}$. PIC material conductivity did not make significant difference in PIC, and the PIC ASR value is above our expected value of $0.02 \mathrm{ohm}-\mathrm{cm}^{2}$, caused by the interface resistance between layers of the PIC; this is an area for further ASR reduction. More repeat tests of 5-cell subscale articles with long strip PIC design were performed, which showed even lower PIC ASR, 0.025 to $0.03 \mathrm{ohm}-\mathrm{cm}^{2}$. Meanwhile, the design captured in the Figure 12 test is being implemented to full-scale tubes for testing.

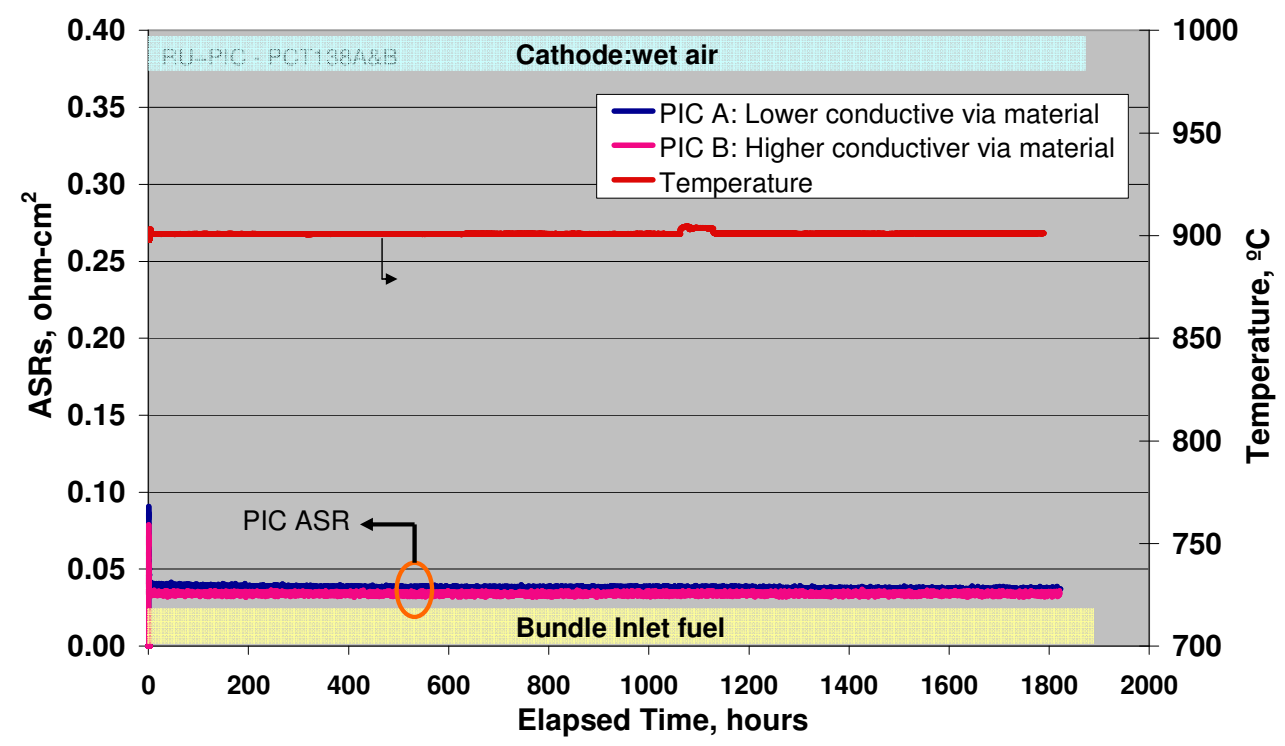

Figure 21. Lower primary interconnect ASR obtained with new interconnect design

Modification to the composition of that material is being pursued to lower the PIC ASR further.

The PIC utilized in the Figure 21 test represents the most extreme shift in design from what has been our standard precious metal cermet via design. The modeling activity indicated other design options in between those cases that provide an optimum balance in ASR improvement and cost. One optimized design was selected near the end of Phase II. Testing of 5-cell subscale test articles has been started but falls outside this reporting period.

Conclusion - The precious metal cermet primary interconnect of the epsilon technology has shown stable ASR sufficient for SECA Phase 1 and Phase 2 metric testing. This epsilon interconnect should be able to meet a minimum of 2-3 year service life with the optimization of design to insure meeting print layer requirements. Design changes to the precious metal cermet via design are being studied to lower the ASR associated with the primary interconnect; the objective is to slightly shift downward the operating temperature to improve durability, while maintaining the LSM-based cathode technology. Modified precious metal based primary interconnects compatible with future zeta anode technology is desired to benefit from potentially lower anode degradation rates as required to reach service lives approaching 5 years. Solutions to develop compatible PIC material with zeta anode technology were demonstrated up to 3,500 hrs. Multiple repeat tests were performed in short period of time. Ceramic interconnects remain an option for long-term PIC stability, but is a longer development path. 


\section{Task 4.2 Anode Development}

Approach - Anode development efforts are focused on the CTE control, cost reduction, performance, and microstructure stability for durability. Primarily two anode designs have been developed during the SECA program. First, CTE matched, high in-plane conductance and cost reduction were the focus of development for the standard anode-ACC epsilon design (primarily Phase I activity). The second design has been the focus of the Phase II effort and is guided by further cost reduction and improvement in anode microstructure stability for long term durability. Development activities utilize subscale single and pentacell with detailed instrumentation to separate ASR contributions by AC impedance and post-test analysis us performed to guide further developments.

Results and Discussion - During the Phase II development, we have kept focus on the next generation (zeta) anode with two approaches. (1) maintaining a bilayer structure with the anode current collecting layer engineered for thermal expansion and conductance (optimum metal contents) and (2) a single layer anode serving the dual roles as catalyst for the oxidation reaction and the current collecting layer. A key objective of this development activity is validation of an anode showing improved microstructure stability compared to epsilon anode technology, especially at the higher operation temperature ( 900C) and bundle outlet (high fuel utilization) condition.

The standard epsilon anode completed 16,000 hour durability testing using a 5-cell article at middlebundle fuel conditions and mid-block temperature (860C) with good durability trends ( $<1 \% / 1000$ hours). A pressurized bundle test with epsilon anode shows very similar durability performance for 4,000 hours with less than $1 \% / 1000$ hour of power density change. Post-test analysis shows that the epsilon anode has reasonably good microstructure stability at low and middle block temperatures. Although the standard epsilon anode achieved adequate microstructure stability to meet the overall durability targets, microstructure stability at high system temperature ( 900C) where steam partial pressure is also high and metal depletion between anode and ACC still remains to be improved.

To eliminate the poor interface due to metal migration at anode and ACC interface, a single layer (zeta) anode is being developed. Thermal expansion match to the substrate to avoid electrolyte cracking was a critical area for the optimization for successful transition of the zeta single layer anode design to a full scale and insure high yield as well as maintaining anode conductance value above 1S. Conductance measurements were conducted at different screen meshes for a selected single layer anode composition. A mesh size of 200 is desired to achieve 1S conductance as shown in Figure 22.

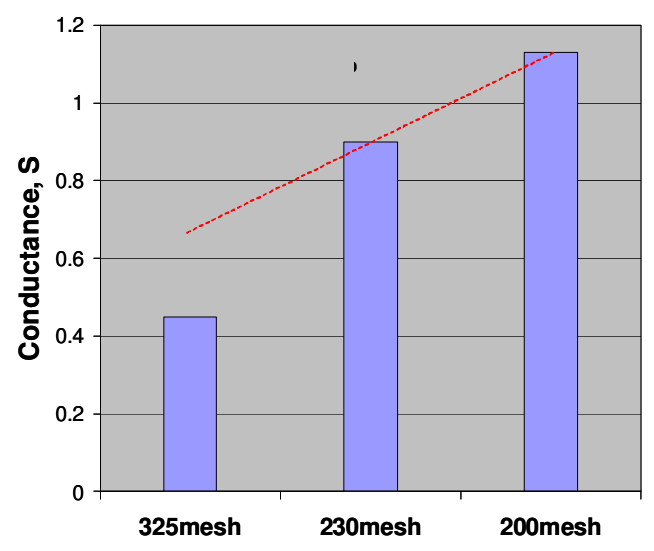

Figure 22. Conductance trends for single layer anode with screen mesh 
We have accumulated a database correlating thickness of selected single layer compositions and conductance. However, at such a thickness for $200 \mathrm{mesh}$, we periodically observed electrolyte cracking due to CTE mismatch. To optimize the CTE relationship between single layer anodes and the substrates, we are currently investigating modification of single layer anode compositions and also altering the CTE of substrate. The higher CTE substrates can allow application of higher conductance anode layers to provide some reduction in ASR. The further reduction of cell ASR is very important to improve durability performance by lowering the operation system temperature. More works on this area will be investigated.

During the Phase II, we achieved a 5000hr durability test of a single layer anode as shown in Figure 23. Single cell test with selected single layer anode composition was conducted for $3000 \mathrm{hrs}$ at 4 bar and an aggressive bundle outlet fuel condition at 925C (outside of planned system block operation) following testing for $2000 \mathrm{hrs}$ at $1 \mathrm{bar}$. The test experienced a problem related to the rig that caused some high ASR (cathodic increase from moisture) for about 1000 hrs of testing, but upon repair showed ASR recovery. Repeat tests are being conducted with repeated performance/ASR and durability being observed.

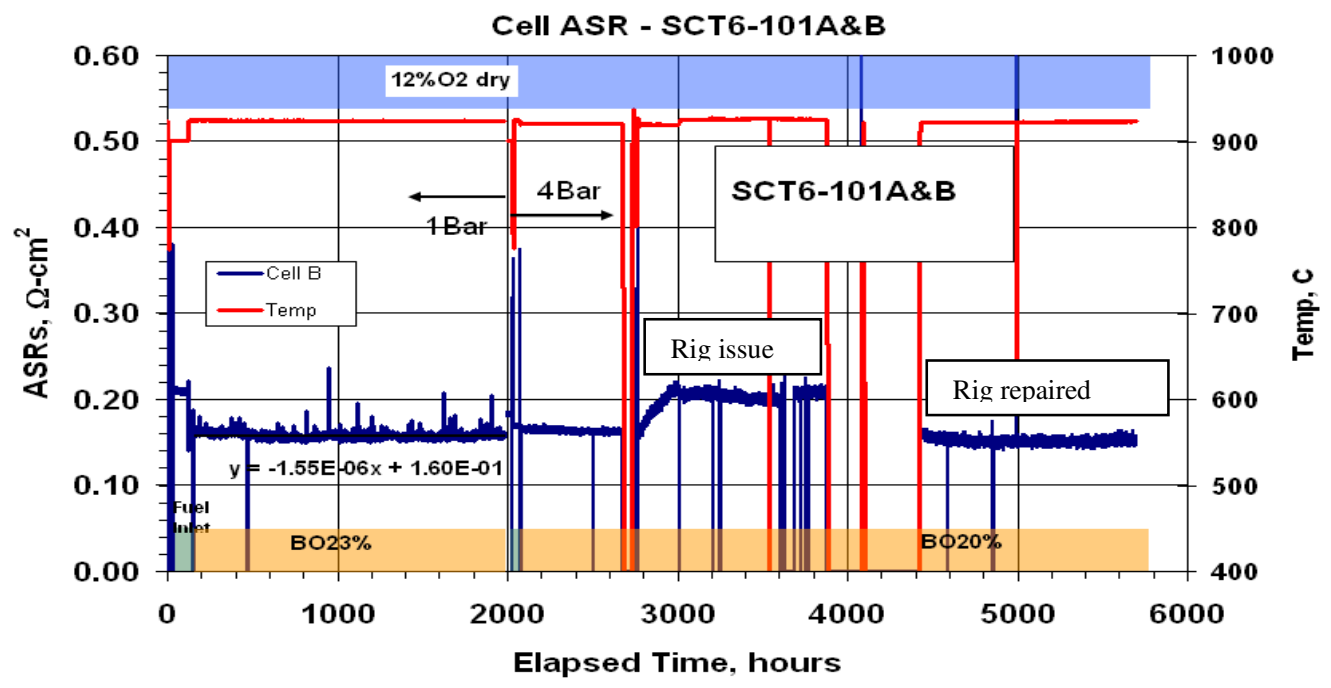

Figure 23. Durability result of single layer anode for $5000 \mathrm{hrs}(2000 \mathrm{hrs}$ at $925 / 1 \mathrm{bar}$ and $3000 \mathrm{hrs}$ at $925 \mathrm{C} / 4 \mathrm{bar})$ at aggressive bundle outlet fuel condition.

After the durability test, post-test analysis revealed that the single layer anode showed improved microstructure stability compared to epsilon bilayer anode as shown in Figure 24 . There is no severe metal depletion in single layer anode, which can be found between anode and ACC layer of epsilon design experienced similar testing conditions and durability test time. Good adhesion with electrolyte and layer below the anode was observed for single layer anodes as well. 

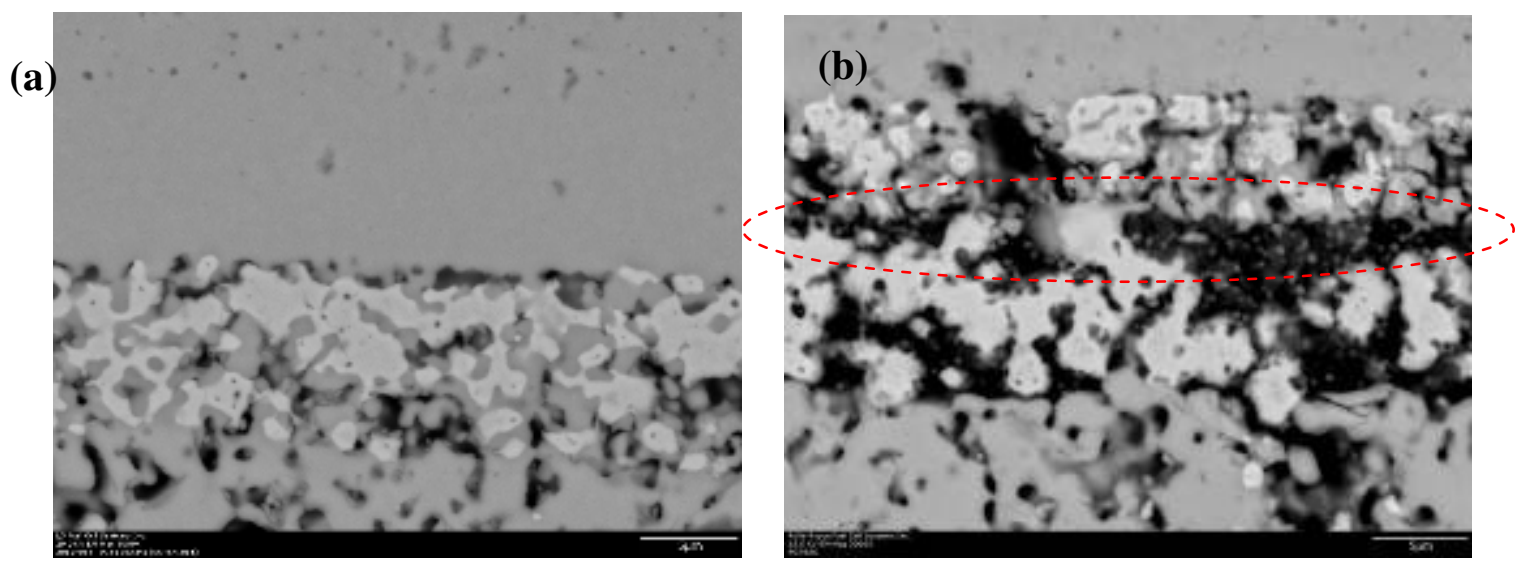

Figure 24. Microstructure comparison of single layer anode and epsilon for bundle outlet fuel at 925C. (a) single layer anode, tested for $5000 \mathrm{hr}$ (b) epsilon anode, tested for $4000 \mathrm{hr}$

We reported in Phase I some difficulty in matching epsilon PIC technology to single layer anodes to achieve low and stable PIC ASR values. During Phase II, more effort was performed to modify epsilon PIC for compatibility with zeta anode technology. Significant progress has been achieved, which was reported in task 4.1 interconnect development. Since PIC technology matching zeta anode is available, we are able to evaluate single layer anode in 5-cell subscale test articles. Figure 25 shows side-by-side durability test of modified epsilon anode (bilayer structure for anode) and single layer anode under simulated aggressive system conditions, bundle outlet fuel, 925C, and 4 bars. Within $\sim 3000 \mathrm{hrs}$ of net testing time, modified epsilon anode and single layer anode showed similar power density and degradation rate, $\sim 1 \% / 1000 \mathrm{hrs}$.

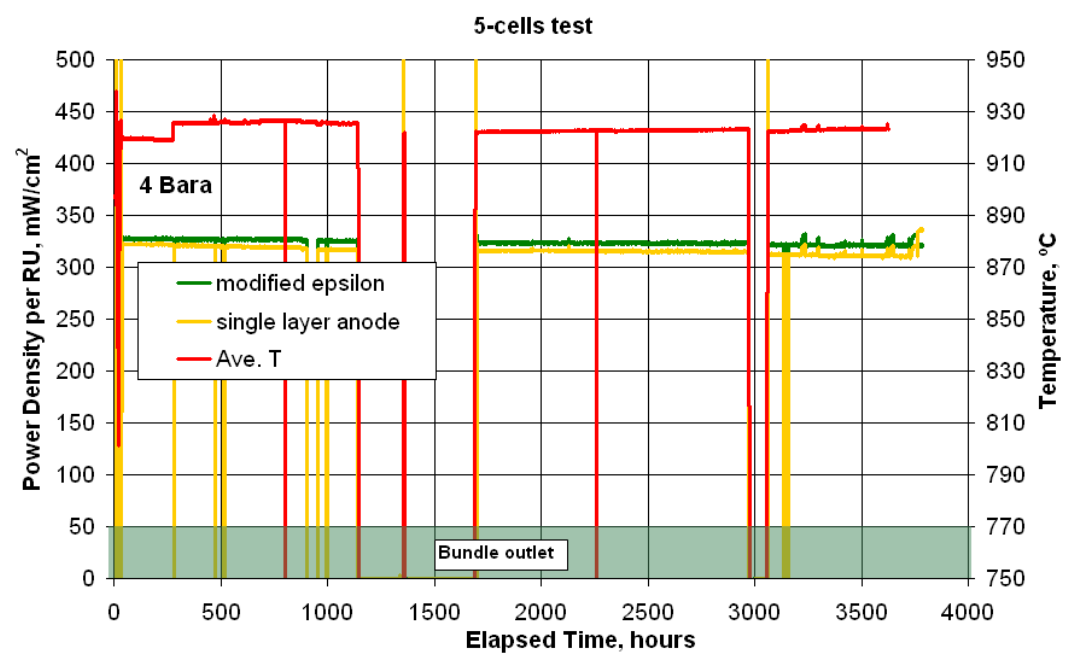

Figure 25. Durability comparison for 5 cell tests: modified epsilon and single layer anode for bundle outlet fuel at 925/4 bar.

Zeta anode technology (key activity in Phase II) was compared to epsilon and modified epsilon anode (Phase 1 development) in terms of cell ASR and degradation, see box plot data in Figure 26. Based on limited statistical data, the three different anode technologies may have similar initial cell ASR and degradation rate over the time periods thus far tested. Although the standard epsilon anode has shown respectable durability results based on subscale (5-cell) tests over 16000 hours, the post test 
microstructure examinations reveal significant microstructure changes that raise doubts over the suitability of the epsilon bi-layer anode+ACC for commercial use. Cell ASR and durability thus far performed on the zeta single layer anode is quite encouraging for initial $3000 \mathrm{hrs}$ of testing under aggressive system conditions (high temperature and high steam), showing much uniform microstructure than epsilon anode. Longer term durability testing for single layer anode under aggressive system conditions will be performed in phase $2 \mathrm{~B}$.
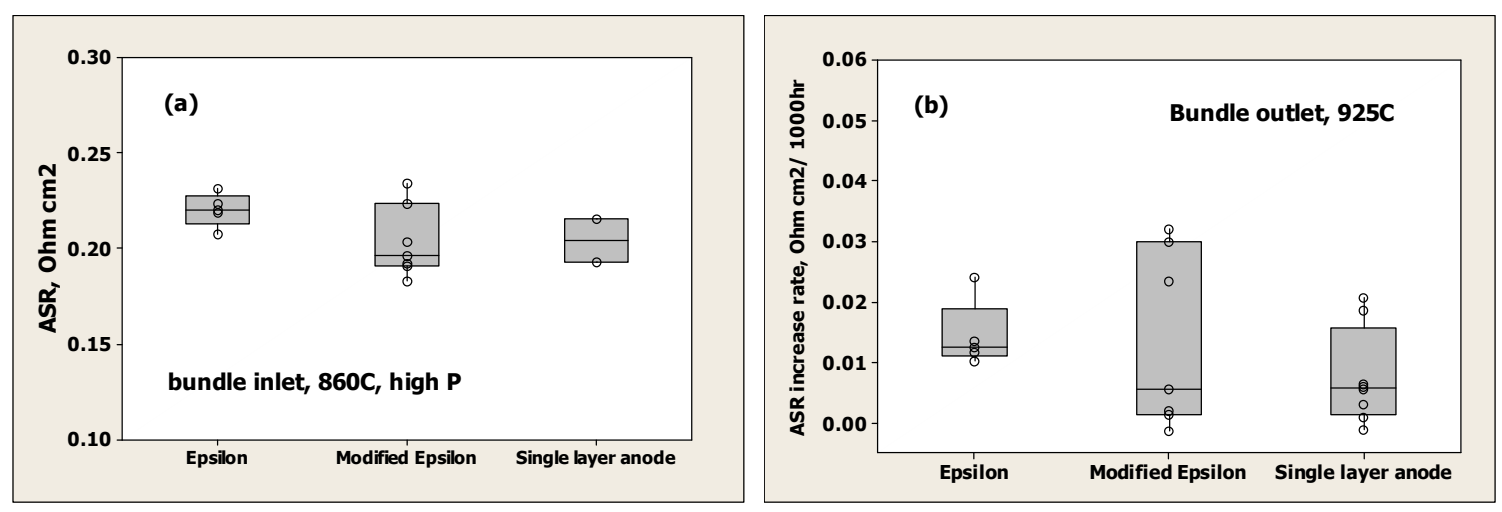

\section{Figure 26. (a) Initial cell ASR at $860 \mathrm{C} / \mathrm{high}$ pressure and Cell ASR increase rate for durability for different anode technology.}

Conclusion - The current standard epsilon anode materials are adequate for $5000 \mathrm{hr}$ operation time required for the SECA metric tests. We have demonstrated the standard epsilon anode performance with different test articles such as subscale cell $(16,000 \mathrm{hrs})$, pressurized bundle test $(4,000 \mathrm{hrs})$, and metric test with 2 strips-Block $(2,200 \mathrm{hrs})$. However, post test analysis of 5 cell test article following 8000 hours of testing at the most aggressive system conditions of $925 \mathrm{C}$ (higher than design point) and bundle outlet fuel (high steam partial pressure and high pO2) shows considerable microstructure deterioration and evidence of depletion and re-distribution of metal component. Even though the epsilon anode materials demonstrated acceptable durability for $16000 \mathrm{hrs}$ at middle and low temperature, microstructure stability of anode side material sets remain ranked as a high risk for achieving the ultimate level of electrochemical durability for commercialization.

Single layer anode technology shows promising potential for improved microstructure stability over epsilon anode throughout the durability test and post test analysis at high temperature. A selected single layer anode demonstrated stable durability performance for 5,000hrs at aggressive bundle fuel at $925 \mathrm{C}$ $(2,000 \mathrm{hrs}$ at ambient and 3,000 hrs at $4 \mathrm{bar})$ and post test analysis showed stable microstructure. One of challenge area for single layer anode is CTE versus conductance (thickness) relationship to scale up the single layer anode to full tube test. More works on optimization of anode composition and controlling CTE of substrate are being explored.

\section{Task 4.3 - Cathode Development}

Approach - Cathode development efforts have focused on establishing an understanding of a lowertemperature range (775C-825C) moisture effect that adversely affects the cell ASR, and that does not appear to be long-term degradation issue but rather a short-term ASR increase/materials equilibration phenomenon. Activities have also involved screening of alternate LSM-based cathodes tolerant to ambient levels of moisture with an overall goal of the reduction in cathode polarization resistance to allow lower temperature stack operation as an approach for extending stack life. Linked with the moisture effect studies are investigations into the role of free $\mathrm{MnOx}$ on cathode polarization resistance.

Development of an improved LSM-based cathode has been the main thrust but LGFCS has also continued 
its investigation of the newer class of nickelate MEIC cathodes. Electrochemical screening tests are first conducted using cathode symmetrical button cells and single-cell substrate test articles with AC impedance analysis. .

The effect of chromium contaminants from the balance of plant components on LSM-based cathode longterm durability is also being explored. Ultimate validation of cathodes for commercial systems will require testing under representative contaminants/environments. Since many degradation mechanisms only become realized over long testing periods, it is important to develop accelerated electrochemical screening tests to more rapidly identify improved technologies.

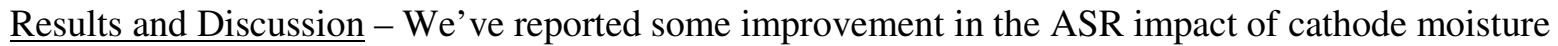
$(3 \%)$ at lower stack temperatures $(\leq 800 \mathrm{C})$ for alternate LSM-based cathodes during Phase I. All cathodes, including standard epsilon and alternate LSM-based cathodes, show similar initial performance and durability at high temperature as shown in Figure 27(a), consisting of four 5-cell subscale test articles (one epsilon cathode and three alternate cathodes) tested in the same test rig under simulated system conditions and 4 bara. The temperature sweep in Fig. 27 (b) before durability shows all the alternate cathodes have a slightly lower ASR than the epsilon cathode at lower temperature. This result is consistent with cathode symmetric button cell $R_{p}$ data (not shown here). Based on AC impedance results, alternate cathodes have lower polarization at lower temperatures because of lower activation energy, and therefore less dependent on temperature change. Up to 2000 hours cell ASRs are stable and there is no obvious degradation difference among tested cells. These alternate LSM cathodes are undergoing more exhaustive long-term durability screening within the Phase II extension program. The candidate LSM cathode compositions were optimized for improved phase stability, less occurrence and formation of free $\mathrm{MnOx}$.
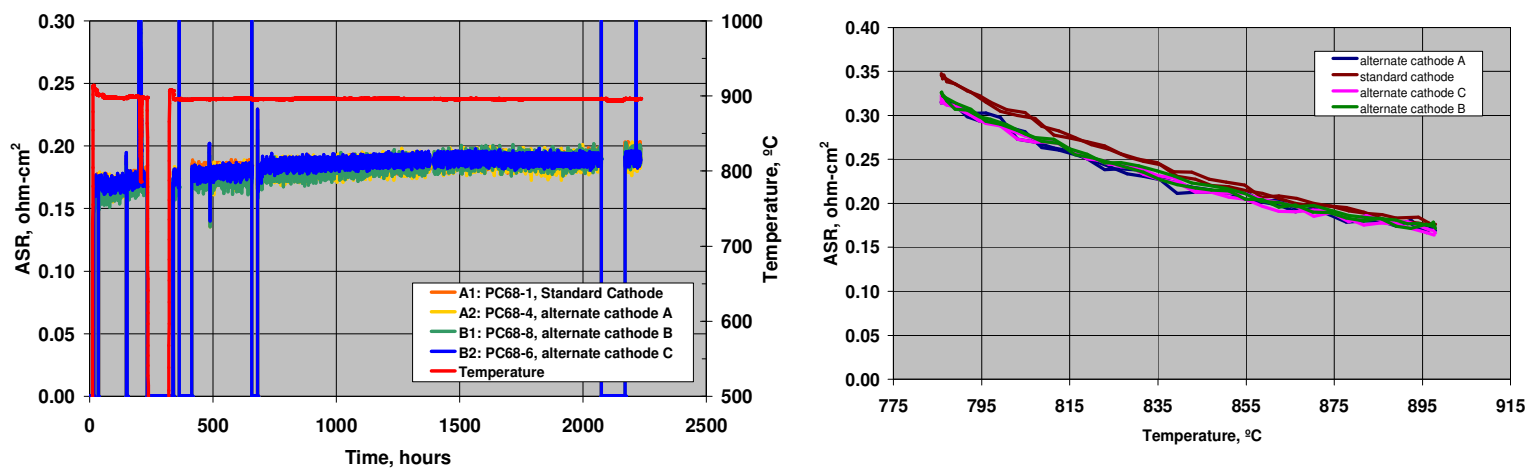

Figure 27. Standard cathode and alternate cathodes high temperature durability (a) and initial temperature sweep (b) test under simulated system conditions (4 bara)

Investigation of the degradation trends and mechanisms for LSM cathodes continues. LGFCS has worked closely with Case Western Reserve University (CWRU) and performed detailed analytical microscopy by means of state of the art equipment. Shown in Figure 28 is post-test analysis by CWRU of the epsilon baseline cathode following 8500 hours at $925 \mathrm{C}$ showing segregation of the stabilizing cations of the zirconia resulting in region of high versus low stabilization. This mechanism could be a cause of the increased polarization resistance. Although not highlighted in the Figure, the analysis also showed the presence of $\mathrm{Mn}$ in the zirconia grains containing the high concentration of stabilizing ions. Alteration of the ionic phase is being explored to avoid this mechanism. 


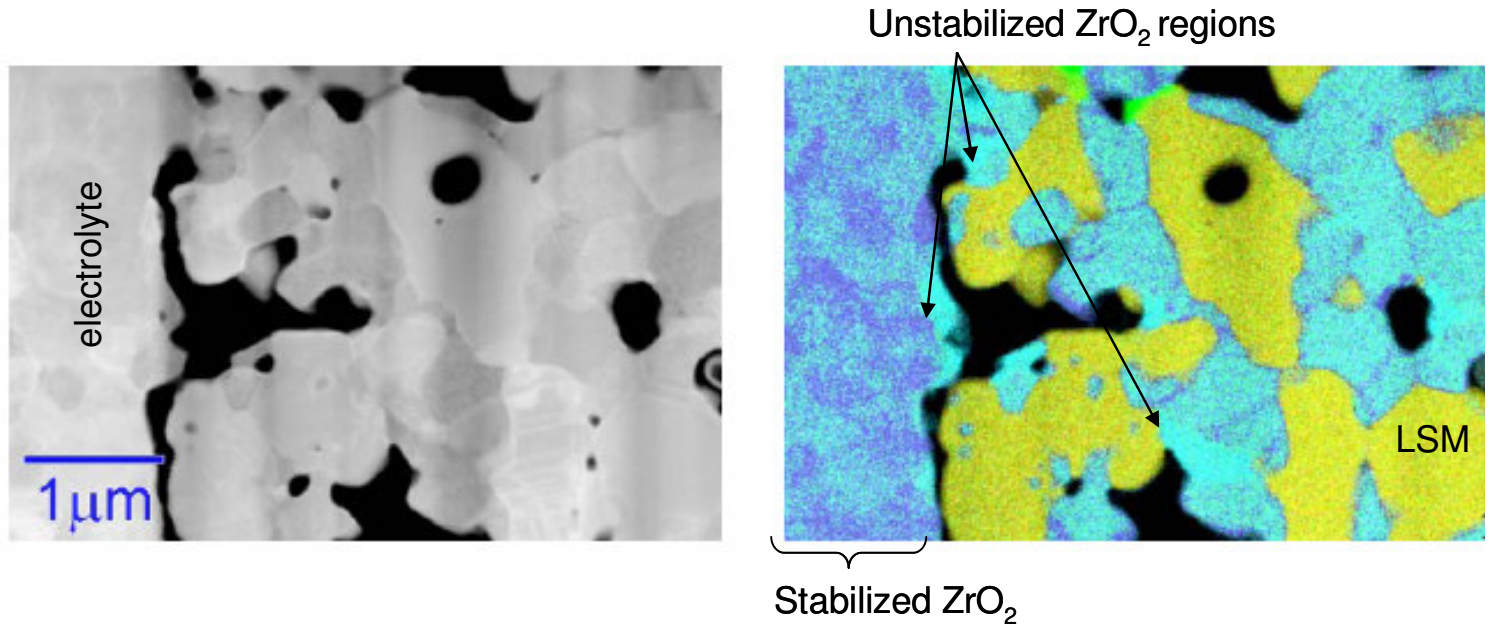

Figure 28. Segregation of zirconia phases observed following 8500 hours at $925 \mathrm{C}$

Cells from a prior alpha-technology (same cathode chemistry) $14 \mathrm{~kW}$ block test (non-SECA) were used for analysis by CWRU to investigate the interaction of the free- $\mathrm{MnO}_{\mathrm{x}}$ phase of the standard cathode with $\mathrm{Cr}$-vapor species origination from balance of plant components. As expected the $\mathrm{Cr}$ contamination was manifested as a Cr-Mn spinel phases (Figure 29). Based on the mixed valence observed for the Mn, the likely spinel compound is $\mathrm{Mn}(\mathrm{Mn}, \mathrm{Cr})_{2} \mathrm{O}_{4}$. The conclusion of this analysis was that the epsilon LGFCS cathode shows the typical sort of chromium contamination, reactivity with $\mathrm{MnOx}$, as reported in the literature. As we know that the epsilon cathode has free $\mathrm{MnOx}$ based solely on equilibrium chemistry, we feel improvements in chromium tolerance could be achieved by optimizing the LSM-based cathode.
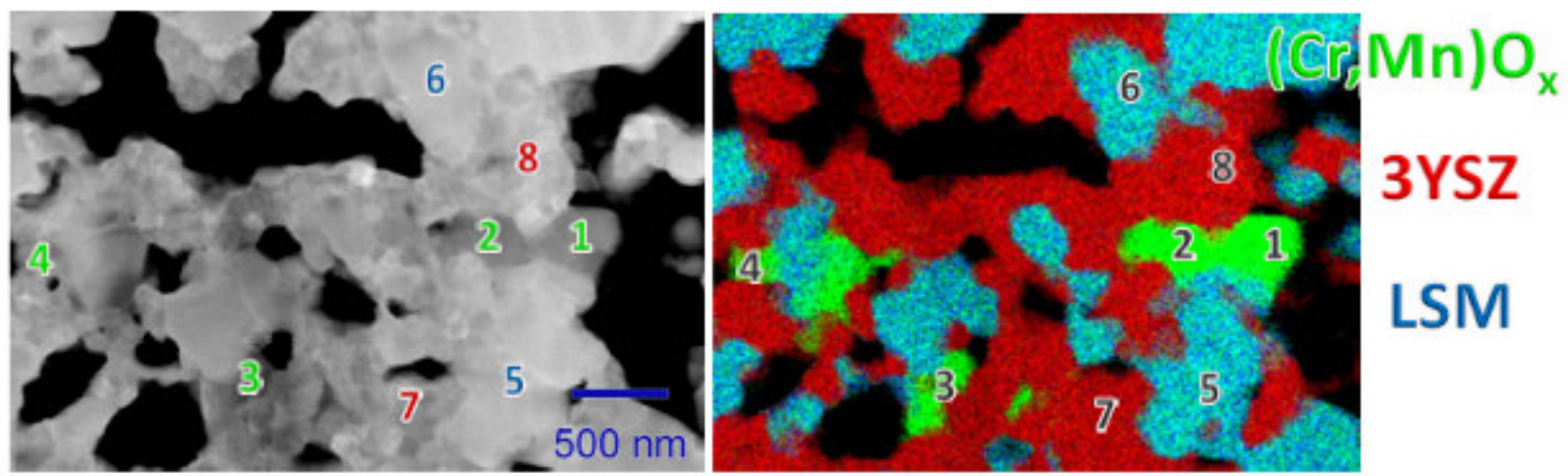

Figure 29. Cr-Mn spinel phases resulting from block scale testing, old system cycle with high cathode moisture content and associated high equilibrium partial pressure of volatile $\mathrm{Cr}$-species

The chromium effect on LGFCS LSM-based cathode durability remains inconclusive - we have not statistically quantified higher degradation rates for test including a chromium contaminant source versus tests absent a chromium source. Figure 30 shows the results of a test run at $900 \mathrm{C}, 6.4$ bar in a rig with a chromium source, and many of the cells showed low degradation rates. Post-test WDS analysis of the 4 cells showed varying levels of chromium at the cathode-electrolyte interface and within the CCC layer (Figure 31). The cells with the lowest degradation rate did show slightly lower chromium contents, but much more testing relating degradation rate to chromium contamination level is required. 


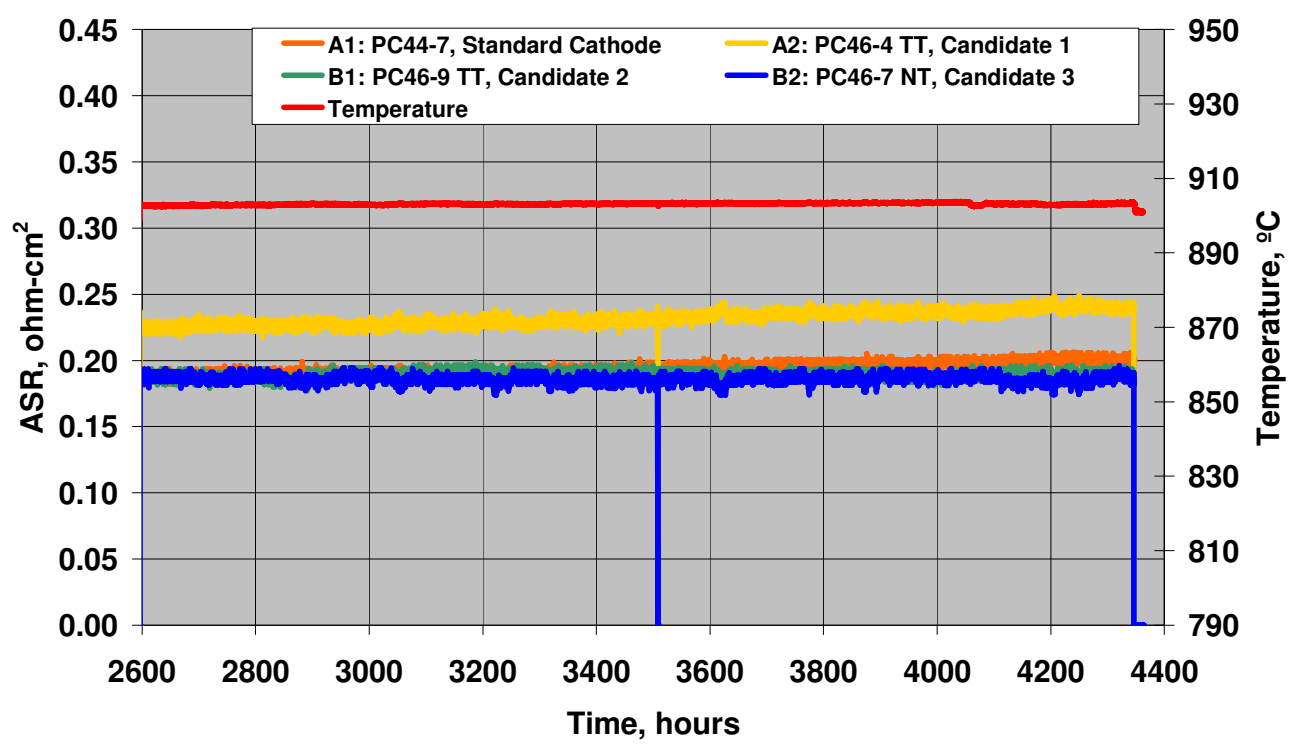

Figure 30. Comparison of standard and alternate LSM-based cathodes at 900C, 6.4 bar and fuel inlet composition (rig with $\mathrm{Cr}$ contaminations source)

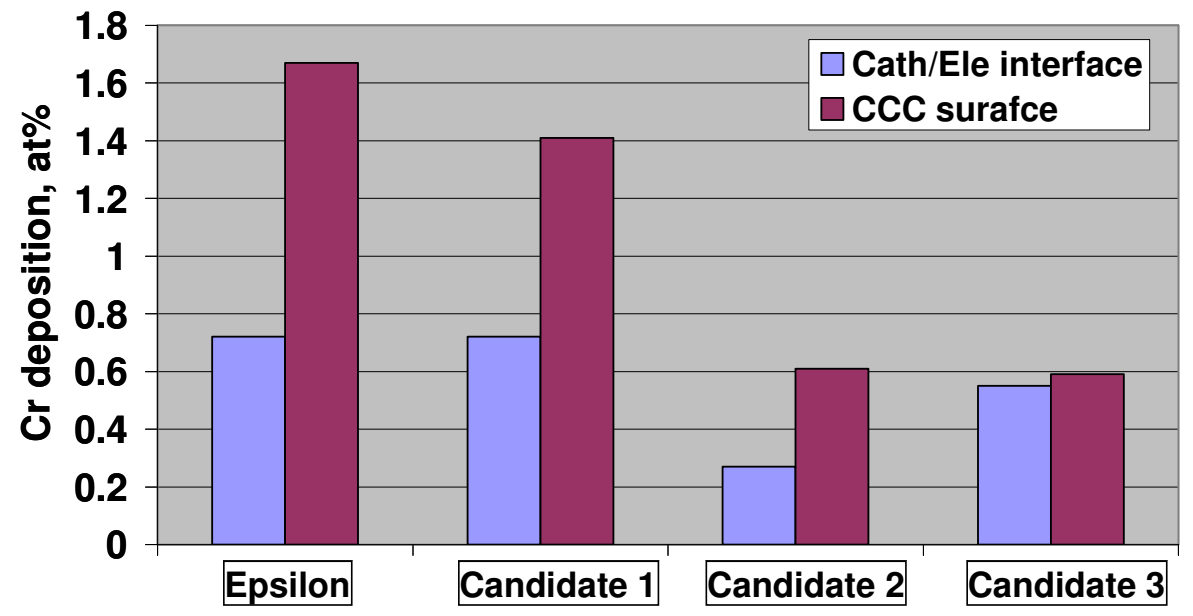

Figure 31. Cr deposition in different LSM-based cathode after testing of $4000 \mathrm{hrs}$ at $900 \mathrm{C}$ with $\mathrm{Cr}$ source in cathode side

A significant degradation mechanism observed for cells tested for 16,000 hours is epsilon cathode densification near the electrolyte (see Figure 32). Case Western Reserve University performed detailed FIB 3-D reconstruction analysis of articles tested for 8000 and 16000 hours (3-D analysis supported outside of SECA program) that quantified and mapped the lower porosity regions after longer term testing. 

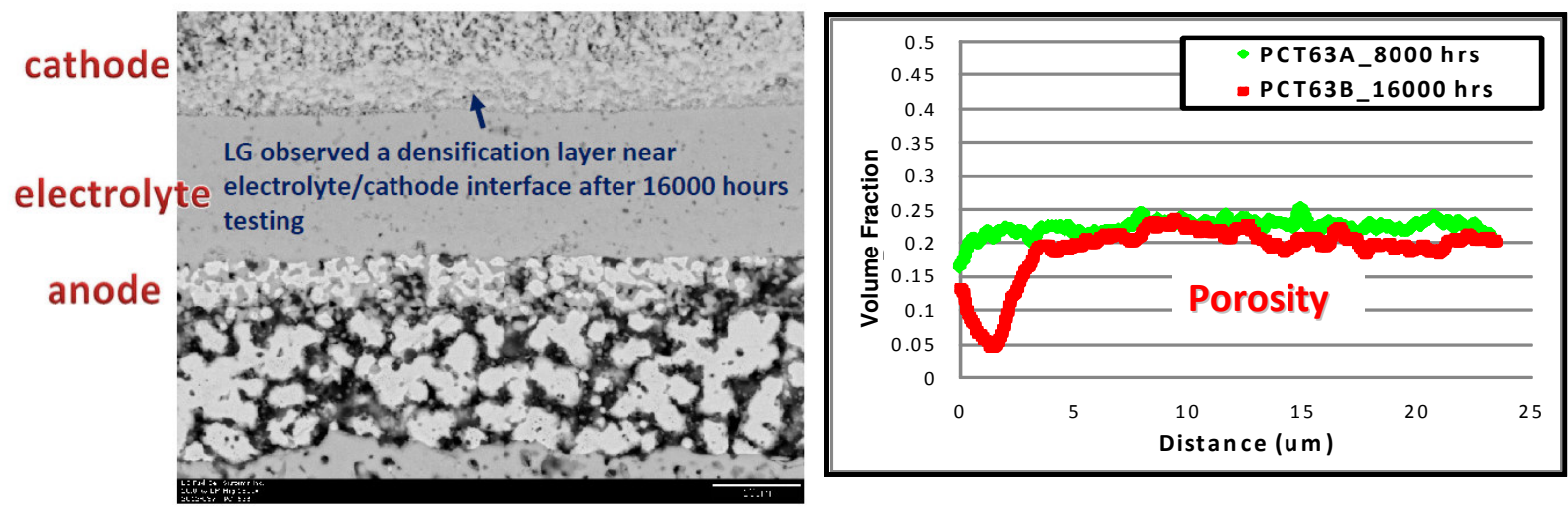

Figure 32. Cathode densification near electrolyte following 16,000 hours testing at $860 \mathrm{C}$ and comparison of porosity from 8000 to 16000 by CWRU FIB 3-D reconstruction

Minimizing such cathode microstructure changes of the LSM-based cathode is a prime development activity. The fact that such a mechanism did not reveal itself until testing beyond 8000 hours creates a challenge in solving this mechanism in a short time period. LGFCS is pursuing accelerated degradation testing as a means for better understanding the factors influencing the densification and to screen and identify improved LSM-based cathodes. Cathode symmetric cells are currently being tested at 1000C (90C in excess of peak block operating temperature) and $1 \mathrm{X}$ and $2 \mathrm{X}$ standard current densities and at both 1 bar and 4 bar conditions. A range of LSM-based compositions are included. For some tests, to increase quantities of cell tested, we have included several cells in series for individual test conditions and so degradation rates of the individual symmetric cells are not able to be compared. The tests will run for 2000 hours initially to determine whether the densification mechanism has been induced in a shorter test period, as determined by SEM analysis. The results of one accelerated test (Figure 33) in which the individual cells performance is measured shows very little difference in degradation at $950 \mathrm{C} / 1 \mathrm{X}$ current density, but we may begin to be seeing a difference at 1000C. LGFCS is identifying several approaches for mitigating the densification mechanism and such concepts will be put into test during Phase IIB.

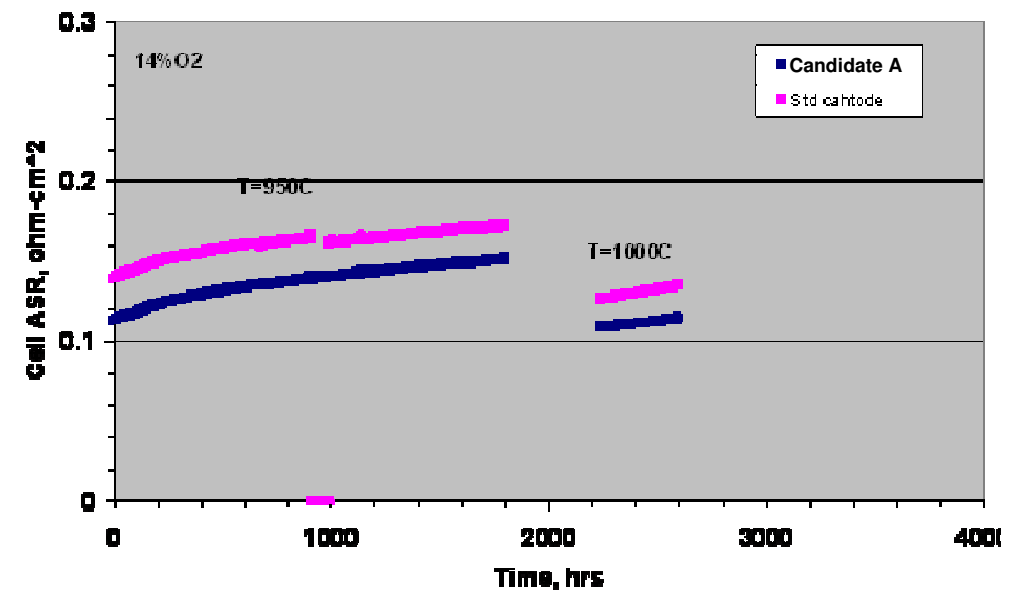

Figure 33. Accelerated cathode symmetric test of standard cathode versus a candidate for reduced densification 
Development continues on nickelate cathodes to achieve lower ASR. Barrier layers which boosts nickelate cathode performance by preventing nickelate interaction with electrolyte is being screened through cathode symmetrical button cell and microstructure analysis. The current collector (CCC) is also being optimized to achieve defect-free CCC by managing CTE difference between CCC and cathode and the microstructure of CCC layer. The greatest challenge remains long-term phase stability of the nickelate. The University of South Carolina began their nickelate studies late in the budget period - that work is focused on powder synthesis and phase analysis, stability studies including interactions with ceria and YSZ phases.

Conclusions - LGFCS has reported that the degradation of the epsilon technology is dominated by cathode effects based on parametric AC impedance analysis, although anode degradation mechanisms also become significant at the high block temperatures and fuel outlet conditions. Key post-test analysis results of the standard cathode are the presence of the $\mathrm{MnO}_{\mathrm{x}}$ phases, observation of segregation of the zirconia stabilizing ions to the extent of forming monoclinic phases within the cathode, Mn-enrichment of zirconia surface and densification along the electrolyte. The key to selecting an optimized cathode for eventual entry-into-service products is relating reduced electrochemical degradation rates to lesser changes in the microstructure, phases and characteristics of surfaces in and around triple phase boundaries. This is a major objective of the Phase 2 extension. The impact of $\mathrm{Cr}$ vapor species contamination from the balance of plant components is critical variable for including in the final screening of the cathode technology to meet the commercial degradation targets.

Nickelate cathodes remain a potential means for reducing the ASR and peak operating temperature of stacks and achieving the durability improvements necessary for eventual 5-year service life.

\section{Task 5.1 - Subscale System Relevant Testing}

Approach - At the start of the program it was important to establish the targets for cell performance (average ASR) and durability (degradation rate) to ensure efforts were properly directed at achieving outcomes which would result in a viable product technology. An effort was undertaken outside of the SECA program that looked at the design space of cost and efficiency, and has targeted performance as defined by an average beginning-of-life ASR of $0.29 \mathrm{ohm}-\mathrm{cm}^{2}$ and end-of-life ASR of $0.42 \mathrm{ohm}-\mathrm{cm}^{2}$. This range of ASRs establishes the efficiency and stack requirement target for the fuel cell system product.

The degradation rate is a very important factor in the overall economics of a fuel cell system. With the above defined range of ASR for the life of the stack, the rate of ASR degradation can be determined to give a particular stack life. The use of an ASR degradation rate is preferable to a power degradation rate as it is more applicable to understanding how a system will operate in the field. Figure 34 below shows the effect of different degradation rate on plant operation. During the useful stack life, the plant will likely operate at a constant power level while efficiency is degraded. After the maximum average ASR is reached, further operation will require reducing the output power to maintain a constant heat release rate to balance the system operation. In Figure 34, the SECA Phase II target of 1.5\% power degradation per 1000 hours (assumed under constant current operation) has been converted to an equivalent ohmic degradation rate of $0.038 \mathrm{ohm}-\mathrm{cm}^{2} / 1000$ hours. At this rate, a plant could maintain constant power for less than half a year. To achieve a 5 year stack life a rate of $0.003 \mathrm{ohm}-\mathrm{cm}^{2} / 1000$ hours is required. The current epsilon technology exhibits a service of approximately 1.5 years. 


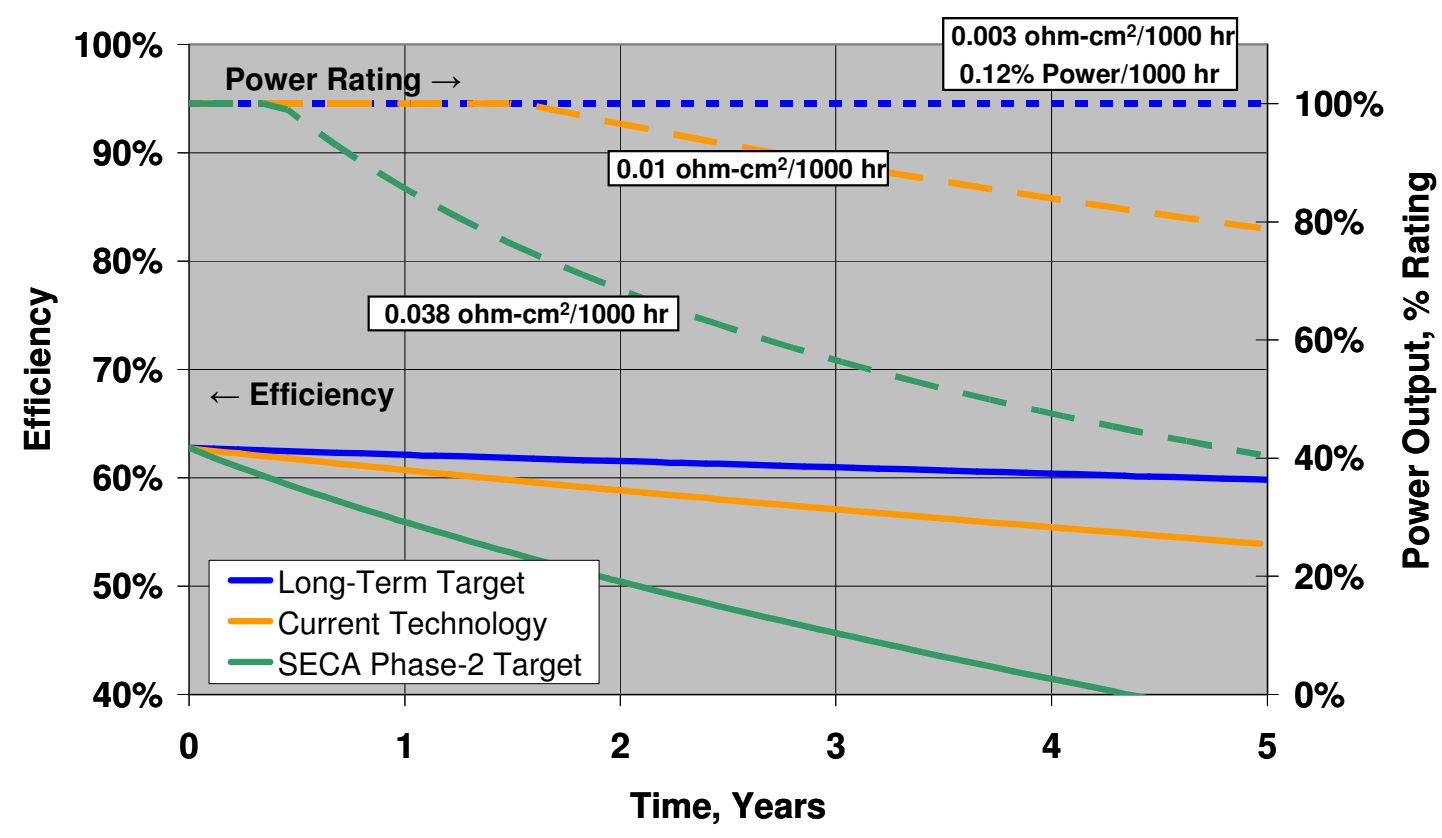

Figure 34. Plant Operation for Different Degradation Rates

The LGFCS technology plan is intended to progress from the current material set to a suitable entry-intoservice (EIS) technology toward what is deemed a mature product (MP) technology based on performance and durability, including meeting the requirements for coal-based IGFC systems.

The majority of the durability database has been based upon subscale five-cell samples, an example of which is shown in Figure 35. The sample is designed with anode and cathode voltage taps which can separate the voltages losses from the secondary interconnect (SIC, through which current flows to and from the tube), the primary interconnect (PIC, between cells), and the cells themselves. Some tests have extended beyond 16000 hours while others were shorter duration tests to allow interim post-test analysis.

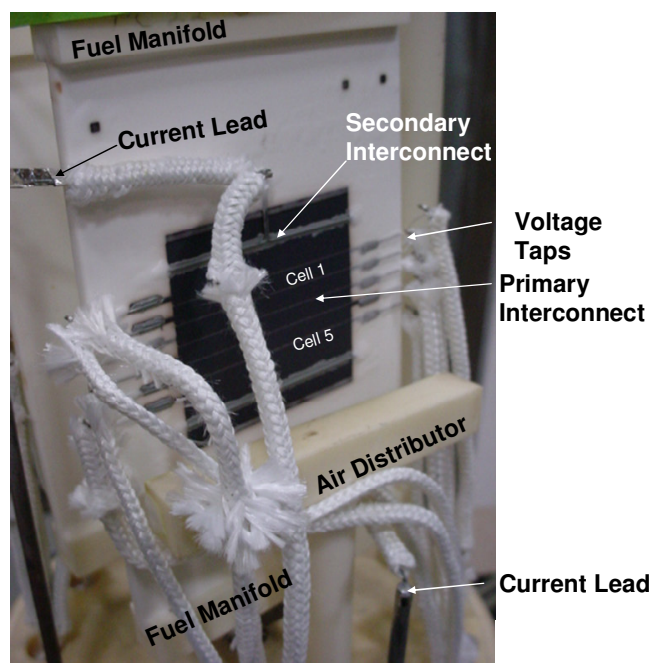

Figure 35. Five-Cell Sample with Detailed Voltage Taps 
Beyond 5-cell scale tests, the next size of scale for durability testing is 6-tube bundles. Two test platforms exist for testing bundles; an atmospheric pressure test setup with dry air on the cathode, and a pressurized test stand with full capability to match system conditions (shown in Figure 36).

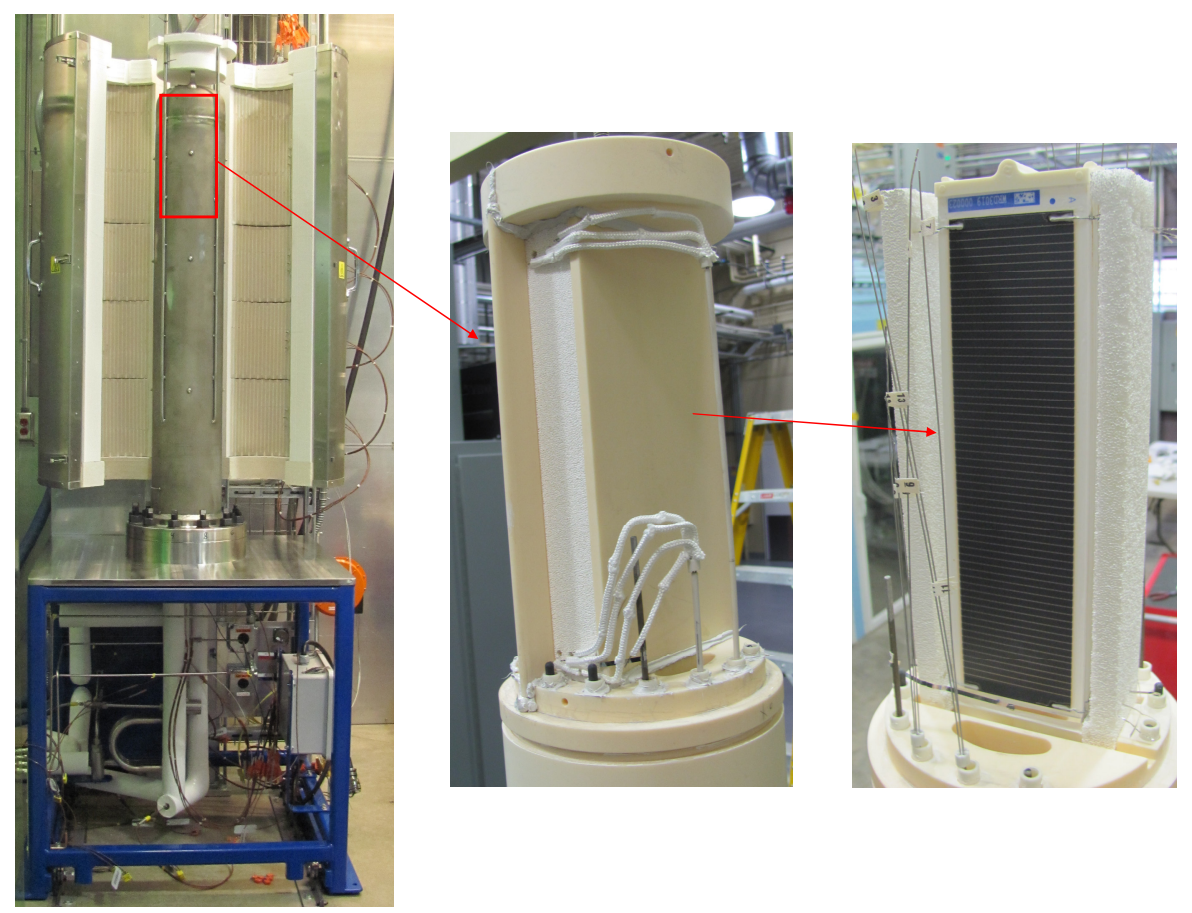

Figure 36. Pressurized Bundle Test Stand

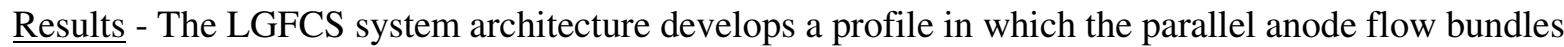
experience a range cathode conditions from the inlet to the outlet of the block. As such, the anode experiences the full range of conditions across the range of cathode conditions, for which we define the four corners of operation:

- Anode Inlet/Cathode Inlet

- Anode Outlet/Cathode Inlet

- Anode Inlet/Cathode Outlet

- Anode Outlet/Cathode Outlet

Durability performance was mapped across the four corners of the operating envelope using 5-cell, highly instrumented fuel cell tube samples under fully representative test conditions for durations of at least 2000 hours. Due to the high steam condition at the anode outlet, it was determined that this was the most harsh condition on the anode side materials. Figure 37 shows the power density durability per repeat unit (RU), which is a cell plus primary interconnect, at three temperatures covering the operating range of a system block. All the PCT (5-cell) tests shown were tested at the bundle outlet condition except for PCT63 which was the bundle midpoint fuel composition. In addition, the power trace from a 6-tube bundle tested at $860^{\circ} \mathrm{C}$ for $\sim 4000$ hours is shown. Overall, the rate of degradation is lower than the $1.5 \%$ power/1000 hour Phase II target. 


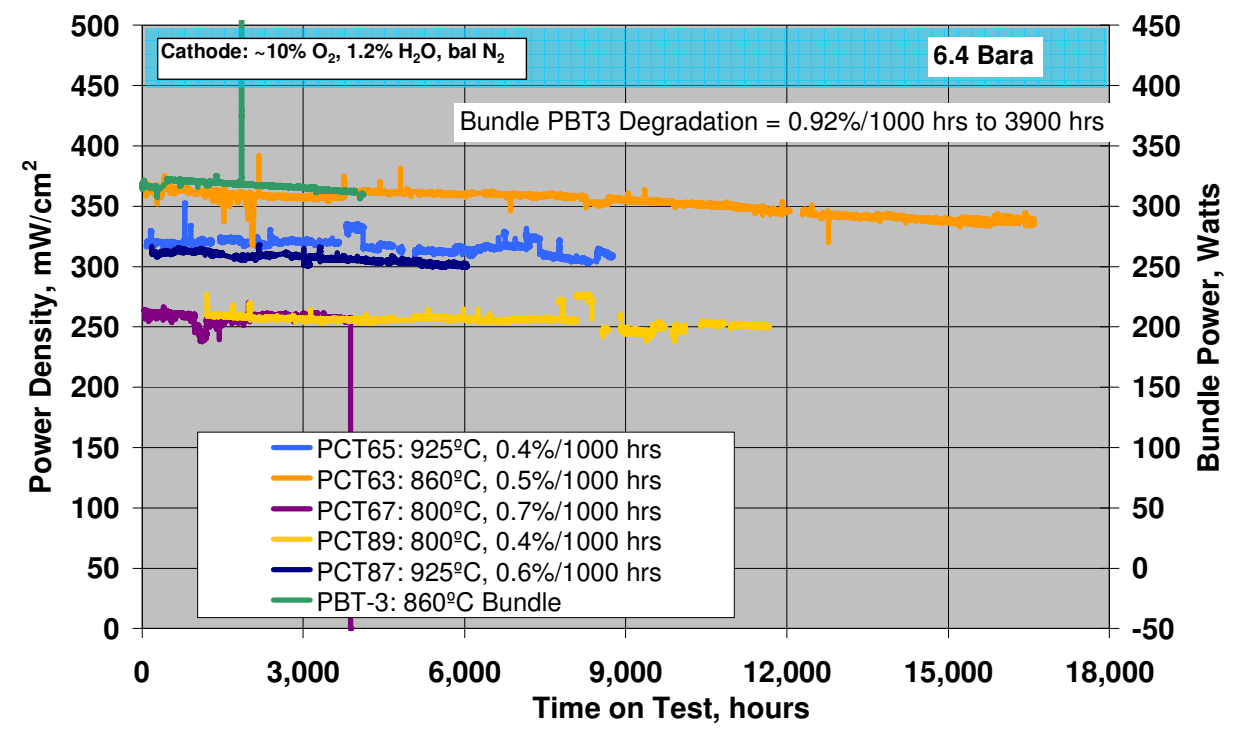

Figure 37. Power Density Durability over Temperature Envelope

A map summarizing the durability testing over the operating envelope is shown in Figure 38. The green and red lines are a model generated ASR versus temperature curve which represent a starting ASR of 0.29 $\mathrm{ohm}-\mathrm{cm}^{2}$, and an end-of-life ASR of $0.42 \mathrm{ohm}-\mathrm{cm}^{2}$, respectively. Data points are included from selected tests which show initial, final (or current), and projected ASR. The projections are based upon the final (or current) ASR and the degradation rate trend, cast forward to 2 years ( 16,000 hours of operation). As shown, the higher degradation rates at the higher temperature range result in ASRs slightly outside of the projected band of stack life, although the lower degradation at the low temperature end results in an overall average ASR which is slightly outside of the 2-year stack life desired for initial entry-into-service performance. A 1.5 year service life is estimate for the current epsilon technology.

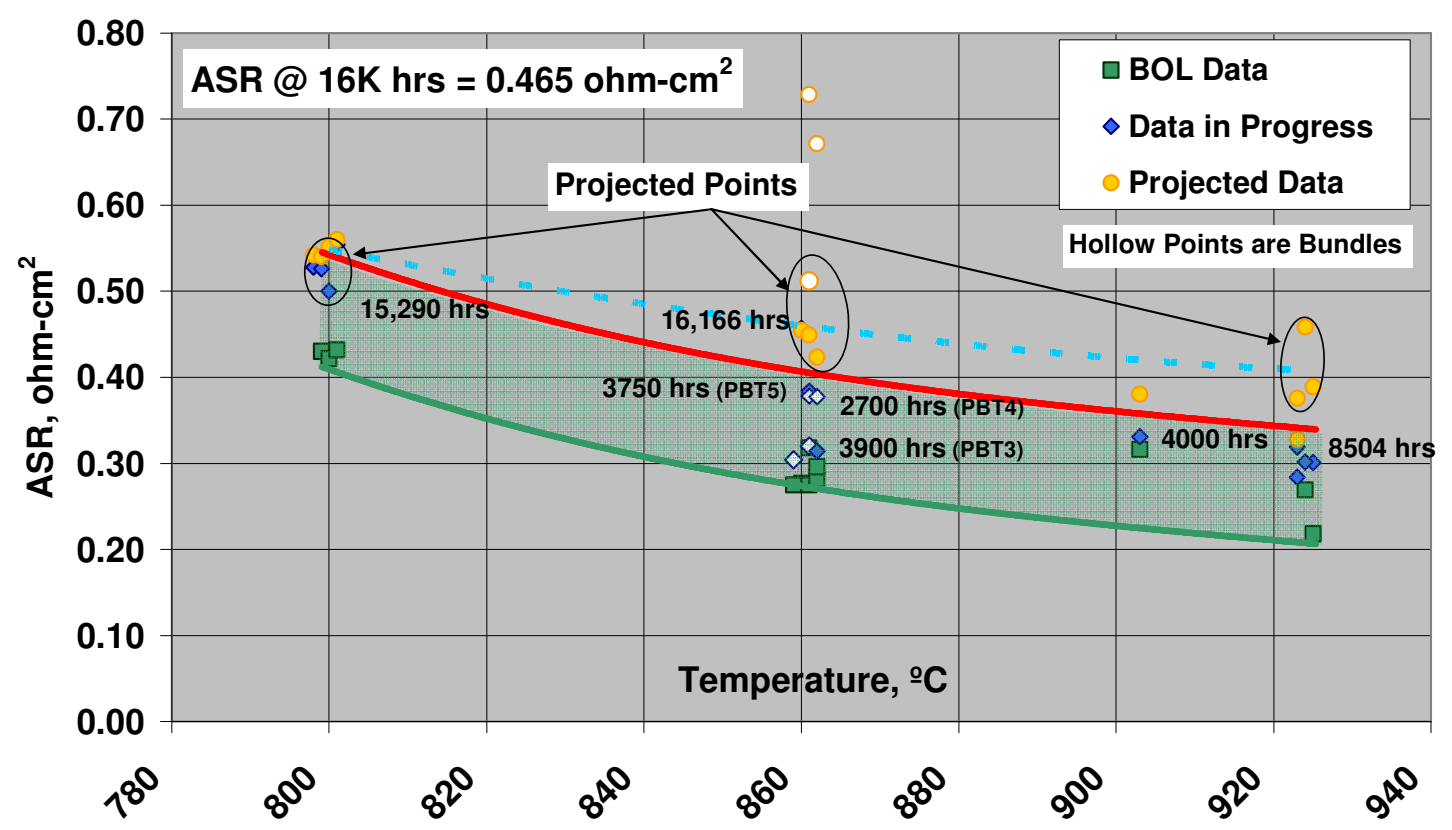

Figure 38. Map and Projection of Phase I Durability Testing Data 
The Phase II program had a milestone for a 3000 hour pressurized bundle test. The purpose of this test was to gain confidence in durability when using Gen2 tubes that have a slightly higher $\mathrm{CaO}$ and $\mathrm{SiO}_{2}$ impurity level, and to insure there is no impact on degradation rates since the Gen2 substrates are to be used in the Phase IIB block metric test. The result of the Gen2 pressurized bundle test is shown in Figure 39. The degradation rate of the bundle is tracking at $\sim 1 \% / 1000$ hours before a restart at 2500 hours, very similar to the trends of the subscale tests and pressurized bundle test PBT3 that used Gen1 tubes (durability trend in Figure 37). The conclusion is that the slightly higher impurity levels of Gen2 pose no risk on durability.

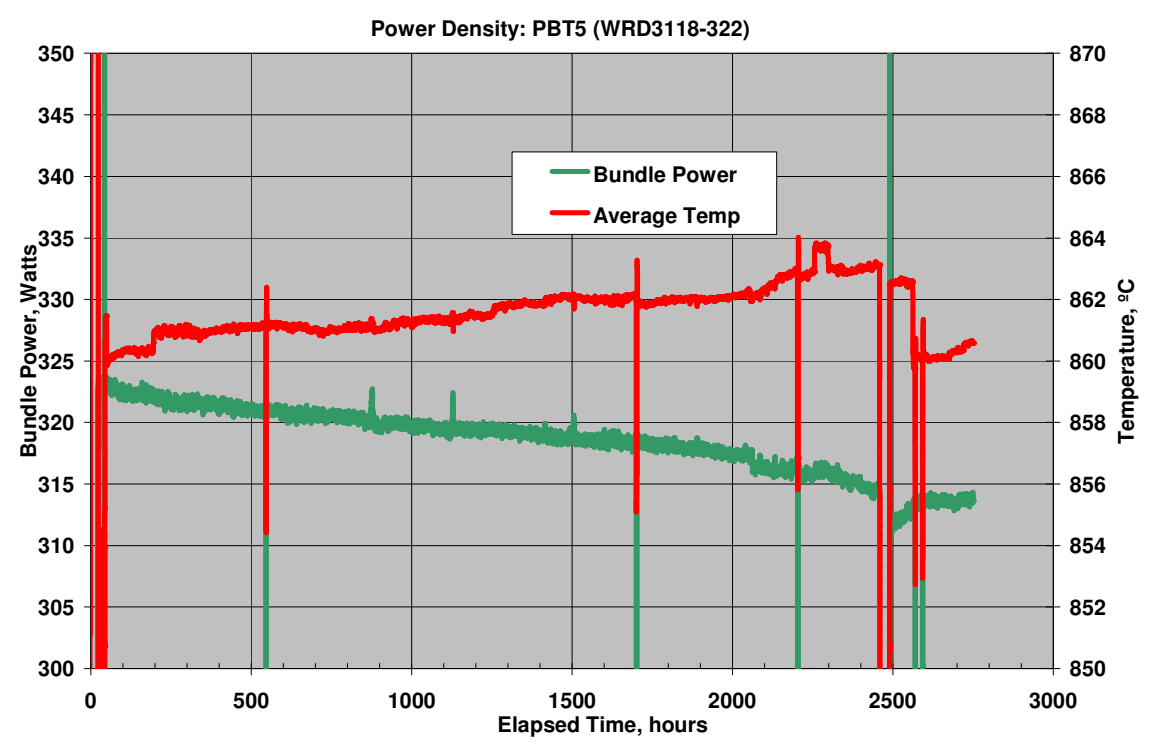

Figure 39. Pressurized bundle ( 4 bar) test using Gen2 substrates

The process of improving the degradation performance requires developing an understanding of the sources of degradation. This understanding is acquired by:

- Steady-state data from detailed voltage taps

- AC Impedance Testing of cell performance versus time. LGFCS has previously reported the results of parametric impedance testing of selectively varying fuel and air compositions that help to identify the frequencies for the cathodic and anodic processes.

- Post-test microstructural and material mapping

The breakdown of the contributions to degradation can be separated using the voltage taps into interconnect and active cell sources. As highlighted in section 4.1, the primary interconnect shows good stability over 16,000 hours of testing. The degradation of the epsilon technology is dominated by the active cells/electrodes.

The AC impedance analysis of the long-term 5-cell subscale tests have helped to identify the dominant degradation mechanisms across the temperature range of the blocks. As shown in Figure 40, the fundamental degradation is higher at $925^{\circ} \mathrm{C}$ than at $860^{\circ} \mathrm{C}$ or $800^{\circ} \mathrm{C}$, and the cathode appears to dominate the degradation, although degradation in the higher frequency range (to the left-hand side) is also evident at $925^{\circ} \mathrm{C}$ which is attributable to anode degradation. 


\section{Low-Temperature $\left(800^{\circ} \mathrm{C}\right)$ \\ Cathode degradation is dominant}

Cathode material migration Densification TBD

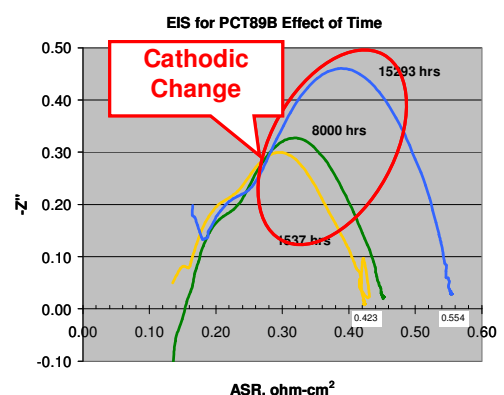

Overall Degradation Rate:
Mid-Temperature (860ㅇ)

Cathode degradation is dominant

Cathode material migration and densification

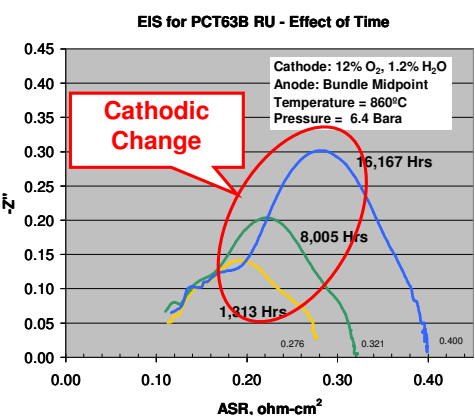

Overall Degradation Rate: 0.0082 ohm-cm $2 / 1000$ hrs
High-Temperature (925C)

Anode + Cathode

degradation observed

Anode material migration

Cathode ionic phase decomposition

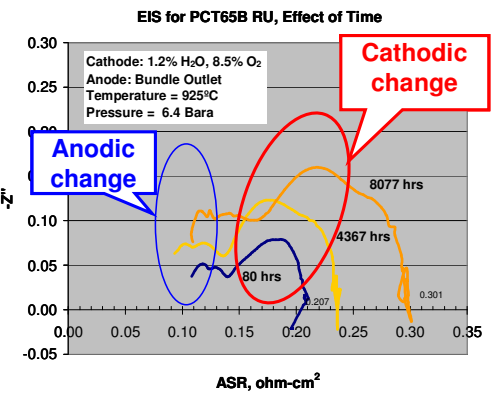

Overall Degradation Rate:

$0.0120 \mathrm{ohm}-\mathrm{cm}^{2} / 1000 \mathrm{hrs}$

Figure 40. AC impedance analysis of long-term testing across the block temperature range

The cathodic degradation is likely a result of free $\mathrm{MnOx}$ formation along the electrolyte interface (Figure 41) observed for low and high temperature conditions. As reported in section 4.3, substantial densification of the cathode was observed by 16,000 for testing at $860 \mathrm{C}$, whereas the extent of densification at 8,000 was limited. Based on this finding, the accelerated degradation rates beyond 8,000 hours is assumed related to the cathode densification.
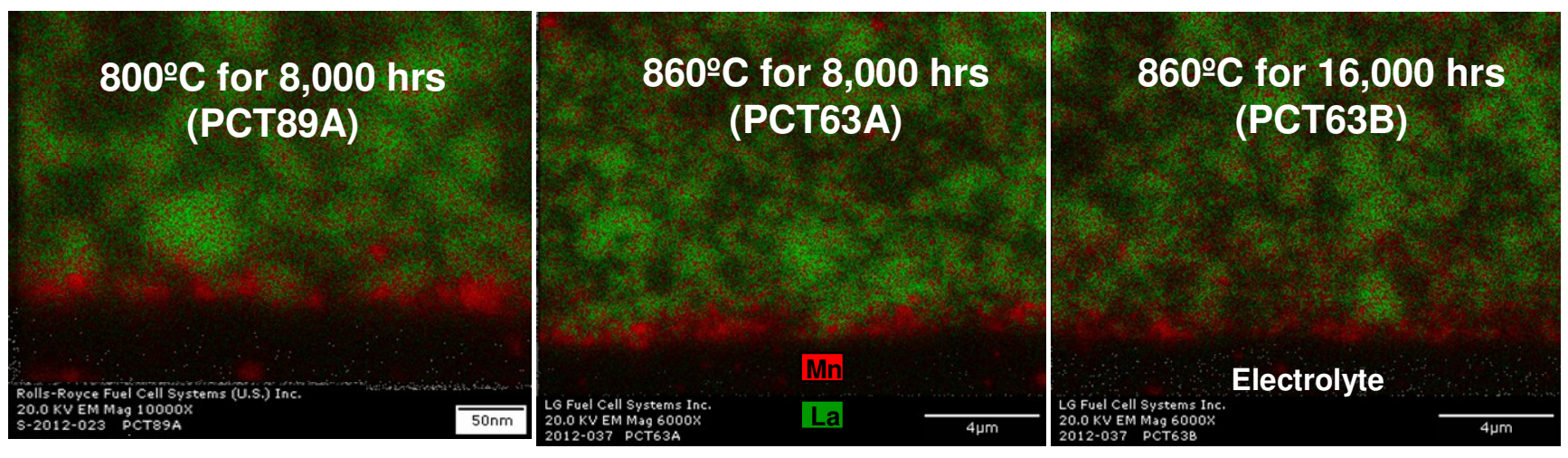

Figure 41. MnOx accumulation observed along electrolyte interface

A source of degradation at higher temperatures are in the frequencies associated with the anodic processes, and as reported appear related to anode microstructure coarsening and potential metal phase loss and redistribution, especially under conditions of high fuel utilization (bundle outlet). Figure 42 shows that under mid-block temperature and fuel conditions, there is little change in anode+ACC microstructure in 8000 and 16000 hours of testing. 

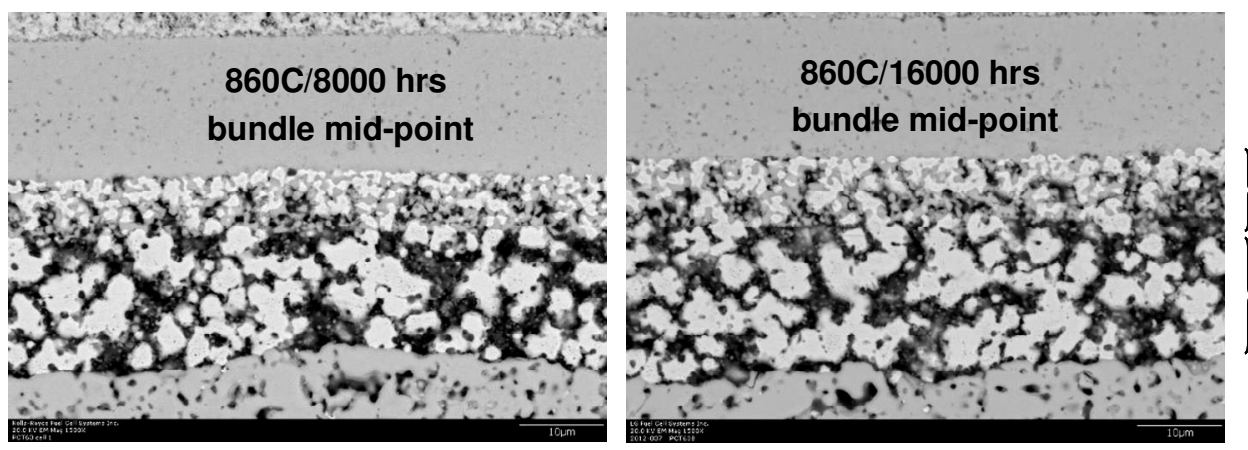

Active anode

Anode current collector

\section{Figure 42. Anode microstructure similarity between 8000 and 16000 hours testing $860 \mathrm{C} / \mathrm{bundle}$ mid-point fuel composition}

As LGFCS relies heavily on subscale 5-cell and bundle tests for assessing the durability of its cell technology, it is important to understand how the durability trends compare to that obtained in the fullscale block configuration. The ASR degradation trend (Figure 43) of the Phase 12 -strip $7.6 \mathrm{~kW}$ test showed a similar rate as 5-cell articles even though the area of the active strips is $2400 \mathrm{X}$ that of the 5-cell articles. LGFCS feels that the small cell area of the integrated planar design coupled with the ability to well match the fuel flow to current density provides for a very scaleable SOFC technology. The somewhat higher ASR of the strip is attributed to temperature variations within the strip caused by less than optimum air flow distribution within the block - the block is being redesigned to address this.

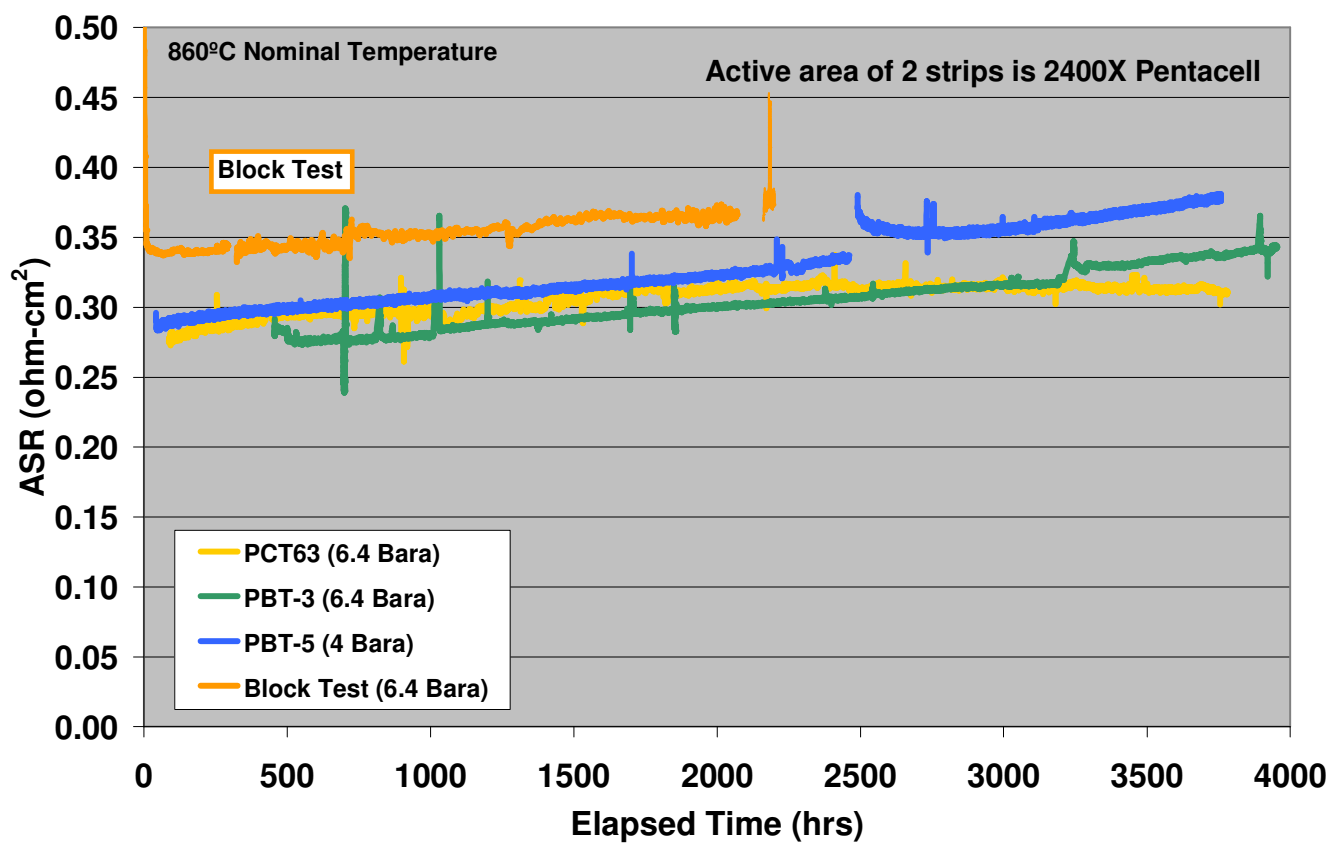

Figure 43. Similarity of durability trends with various scales of test articles

Conclusions - Subscale durability testing has shown that the epsilon stage of cell technology is satisfactory for meeting SECA degradation targets, but would limit a SOFC system to a $\sim 1.5$ year service for meeting power output at a minimum efficiency level. Degradation mechanisms have been identified and solutions are being developed through work under task 4, Cell Development. The target is to evolve the technology to achieve a 3-year service life for entry-into-service product. 


\section{Task 5.2 - Stack Test Stand Preparation}

Approach - Assembly of a pressurized block (stack) test stand in Canton was supported through an Ohio Department of Development program with cost share provided by LGFCS. The SECA program has supported design modifications of the stand from its original purpose of testing a distributed energy natural gas cycle to being able to simulate an IGFC system cycle and fuel composition and supported the acquisition of the necessary hardware for supplying the simulated coal syngas fuel as well as the commissioning of the test rig. The SECA block metric tests have been run using a simulated natural gas reformate rather than the coal-based syngas composition.

LGFCS does not run stacks with on-cell reforming and relies on external steam reforming within the SOFC module. The external steam reformer was removed from the Canton block test stand internals to simply it since one of the objectives for the design was to reduce risks associated with long-term operation. An additional objective was to make this test, as much as possible, strictly a stack test versus a combined stack plus systems test. The Phase I metric test was thus designed to be run with a single pass on the fuel side and the inlet fuel composition was representative of the post-reformer composition with an appropriate recycle ratio as designed for the MW-scale system. A key feature of the test stand was the Oxy-CPOX reactor. It used natural gas, carbon dioxide, steam, and oxygen to generate the natural gas or simulated coal syngas. The reactor's operation was designed to avoid any short-term, high oxygen partial pressure conditions that could oxidize the anode while enabling long-term operation of the catalyst in the Oxy-CPOX reactor. The operation of the Oxy-CPOX reactor was verified during mechanical commissioning during Phase 1.

The UK block test rig (Figure 44) used for the Phase II metric test matches the MW-scale system cycle, and is in fact termed a mini-tier rig as it matches the basic design features of the $250 \mathrm{~kW}$ pressurized tier but contains a single block being the repeat unit within the $250 \mathrm{~kW}$ tier. The Phase II program has the added requirement that the metric test be performed in a thermal self-sustaining manner. When testing at the single-block level the mini-tier does not include a turbogenerator so the recovery of off-gas combustor energy at the turbine, and subsequent pre-heating of ambient air by the compressor is not present. For testing at the single block level the portion of the off-gas combustor heat not transferred to the cathode air through the heat exchanger (just downstream of cathode air circulator) is discharged through the test rig exhaust pipe. The incoming cathode air is pre-heated using an electrical air heater. This is illustrated in Figure 44 .
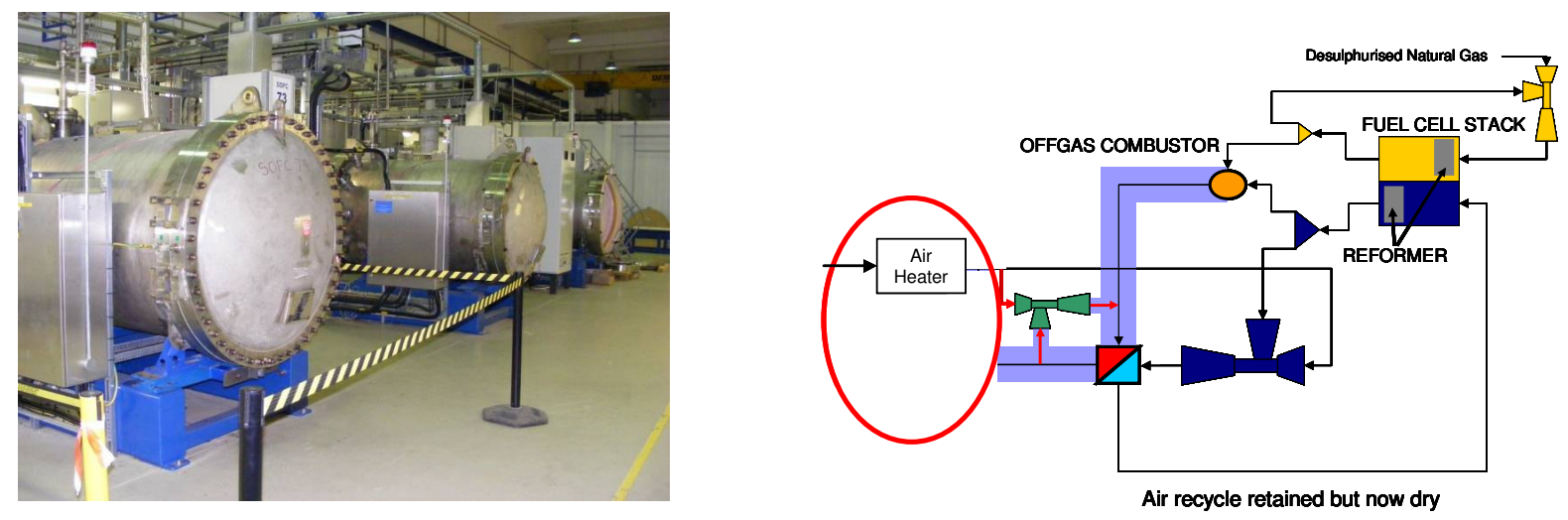

Figure 44. UK block test stand configuration with single block

In addition to making up for the absence of the heat of compression provided by the turbogenerator the electric air pre-heat requirement must also account for excessive heat losses from the test rig due to the relatively high pressure vessel surface area per block, and due to a high number of penetrations for 
instrumentation and experimental equipment compared to a full-scale product. Heat losses from the minitier have been estimated from data gathered during dry-cycle testing and is based on all mass flows into, and out of the mini-tier, and the thermal power of the off-gas burner and air heaters. Based on those data approximately $3.7 \mathrm{~kW}$ are lost through the walls of the pressure vessel and penetrations. Due to the high heat loss for the mini-tiers an additional $2.04 \mathrm{~kW}$ of air preheating is required to maintain stack temperatures whilst offsetting the $3.7 \mathrm{~kW}$ lost through the pressure vessel walls and penetrations.

The equivalent heat loss from a full-scale generator module having a smaller vessel surface area per block, and fewer penetrations, is estimated to be approximately $1.6 \mathrm{~kW}$ (roughly $2.1 \mathrm{~kW}$ per block less than the losses in the mini-tier rig). Therefore in a full-scale generator module no additional preheating is required and the cycle is thermally self-sustaining.

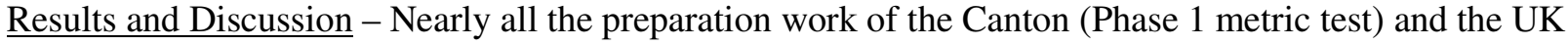
(Phase II metric test) were completed during the prior program budget period. However, some final electrical commissioning of the Canton block test stand was performed using older alpha (30-cell tubes) stack technology. Cooling requirements for the load controllers were verified along with and startup and shutdown procedures. Commissioning of the test stand was successful completed in October 2011. The test stand was passed to the test team in early-November 2011 for installation of the epsilon (60-cell tubes) stack technology for the Phase 1 metric test.

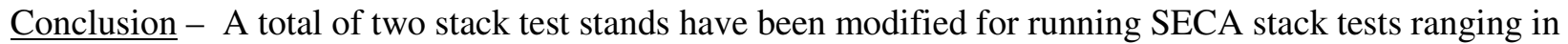
power output (NOC) between $\sim 7.6 \mathrm{~kW}$ (2-strip) and $\sim 19 \mathrm{~kW}$ (5-strip) using epsilon technology. These test rigs are representative of full system operation conditions and are thermally self-sustaining, meeting SECA Phase 2 requirements

\section{Task 5.3 - Stack Metric Testing}

Approach - This task involves the execution of the block-scale metric tests. During the FY2012 budget period the program supported the 2-strip $(7.6 \mathrm{~kW})$ Phase 1 test and the initial 5-strip $(19 \mathrm{~kW})$ Phase 2 test. The stack metric test plan initially included the execution of a 5000 hour Phase 1 metric test in Canton and a 3000 hour Phase 2 metric test in the UK.

\section{$\underline{\text { Results and Discussion - }}$}

Phase 1 Metric Test - A Test Plan was approved by DOE in November 2011. The test was arranged as 3 epsilon strips to produce roughly $11 \mathrm{~kW}$ and a $4^{\text {th }}$ older technology alpha strip added for the purpose of heat balancing to best match operating condition for the epsilon strips to that expected in a full 5-strip block design. The test only began with 3 epsilon strips because of substrate supply issues occurring at the time from the sole vendor.

The Phase 1 metric test started during the first full week of December 2011 (Test T1404). Upon reaching operating stack temperature $(\sim 800 \mathrm{C})$ a gas sampling line was detected as open between the inner and outer pressure vessels of the rig. The rig was cooled to $\sim 500 \mathrm{C}$ stack temperature and the problem corrected. The rig was reheated to $900 \mathrm{C}$ to perform the strip reduction. Immediately upon introduction of the fuel for the initial reduction step, regions of localized temperature rise were detected within the stack from thermocouples located between strips. Low OCV was also recorded for some strips which combined with the observed localized hot spots, indicated probable leaking strips within the stack. The stack was switched to a safe condition for a few hours before starting the CPOX reactor to feed the reformate fuel composition. The stack was run for $\sim 12$ hours on CPOX generated syngas before being shutdown to remove the stack and assess the location and severity of leaks. Leakage testing revealed high gross leakage for one epsilon strip, a $\sim 3 \mathrm{X}$ increase in leakage from the as-manufactured state for a second 
epsilon strip while a third epsilon strip was similar to its as-manufactured leakage rate. Visual inspection showed 2 substrate edge cracks in close proximity for the moderately (3X) leakage strip and 6 cracks at 2 locations for the leakier strip (see Figure 45). These damaged locations covered 4 bundles out of the 36 epsilon bundles comprising the 3 epsilon strips. The strips were repaired using previously proven repair techniques.

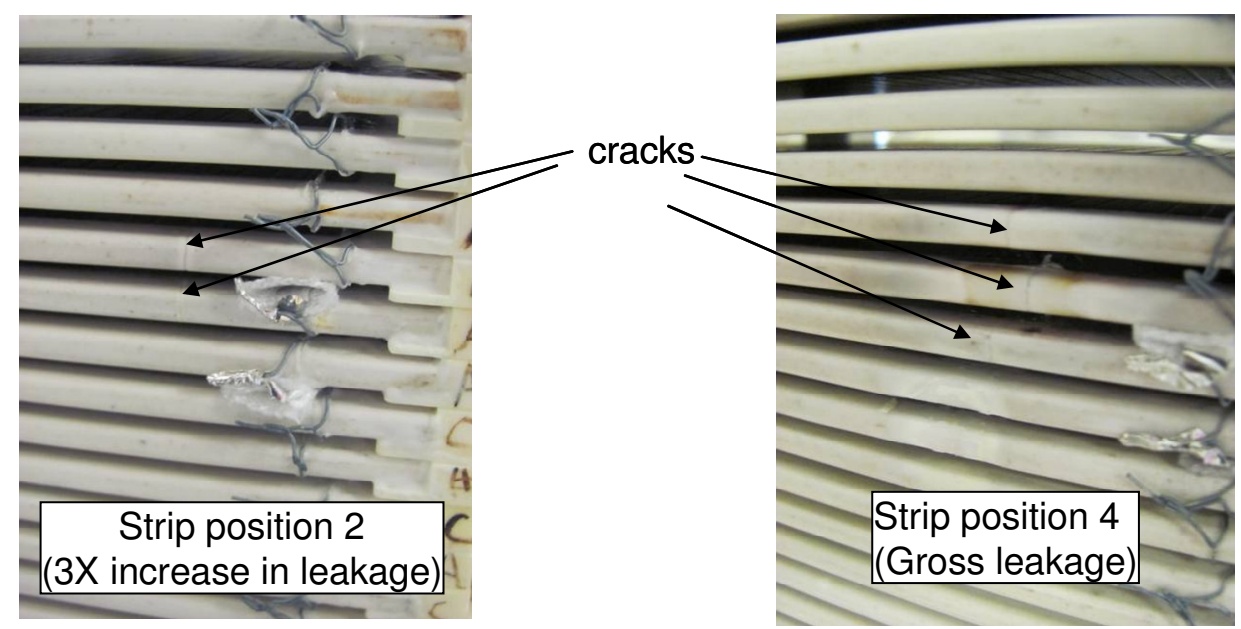

Figure 45. Substrate edge cracks observed in metric stack test

A detailed root cause analysis was performed for the failed test (non-SECA expense). The leading cause for the cracked tubes was a non-typical transient during a reheat from an intermediate hold temperature of $\sim 500 \mathrm{C}$ following a cool down to correct a leaky gas sampling line that was detected prior to strip reduction after the initial heating cycle. Transient thermal models were run that estimated mechanical loads on the strips. Results suggest that the stresses caused by the transients when combined with the residual stresses present within strips at the intermediate hold temperature could be sufficient to fracture substrates. Standard operating procedure for the test rigs were updated to require a cool down to room temperature rather than allowing a warm restart. The initial 3 epsilon strips prepared for the Phase 1 test were the first of a kind and experienced some quality issues arising partly from compromise required on substrate selection influenced by substrate quality and supply issues. Irregularities in the strip dimensions may have also created non-typical mechanical loadings of the strips within the stack.

Once the two cracked strips were repaired a second test (T1405) was started (March 9, 2012). Upon reduction, one of the three epsilon strips was observed to have a low OCV. The stack was cooled to room temperature and post-test diagnostics showed that the low OCV strip had a higher leakage rate compared to the pre-test measurement. To repair/replace the faulty strip would have required three to four weeks of downtime. A business decision was made (with agreement by DOE) to isolate the faulty strip and to move forward by restarting the test as a 2-strip epsilon stack test with a lower power rating. Root cause analysis focused on the heating ramp rate during lighting of the off-gas burner at approximately 550C. This burner provides the additional heat input beyond what is provided by the electric air heaters to raise the temperature of the stack to operating conditions. During burner light-off there is a short period of time, several minutes, during which the heat rate from the burner exceeds the average targeted heating rate. The operating procedures for burner light-off were modified to minimize the initial heating rate during burner light-off.

The third test (T1406) was started on March 19, 2012 using the modified stack heating cycle. The strips exhibited the expected OCV and the strips were then taken to normal operating conditions. The performance of the strips was as predicted for the epsilon technology and matched favorably with the ASR result of the pressurized (6.4 bar) bundle test PBT4 as shown in Table 3. 
Table 3. Performance comparison of Phase 1 metric test strips 2 and 3 to PBT4 bundle result

\begin{tabular}{|c|c|c|c|}
\hline Test & PBT4 & T1406- S2 & T1406- S3 \\
\hline Avg Temp & $860^{\circ} \mathrm{C}$ & $844^{\circ} \mathrm{C}$ & $870^{\circ} \mathrm{C}$ \\
\hline Power & $321 \mathrm{~W}$ & $318.2 \mathrm{~W}$ & $320 \mathrm{~W}$ \\
\hline ASR, $\Omega-$ cm $^{2}$ & 0.315 & $0.364-0.375$ & $0.308-0.331$ \\
\hline Flams Out & $24.5 \%$ & $28.8 \%$ & $25.8 \%$ \\
\hline
\end{tabular}

Results for T1406 indicated that the degradation rate ( $<1 \% / 1000$ hours), was well within the SECA $2 \% / 1000$ hour range. The initial 250 hours of test data for the four half-strips is shown in Figure 46. Performance was measured at the half strip scale because of the configuration of the power electronics. Each strip generated approximately $3.83 \mathrm{~kW}$ and the two strips combined generated $7.66 \mathrm{~kW}$. At 266 hours into the test a small leak was detected, but there was no associated temperature increase across the strips so it was assumed the leak was not associated with the strips. The rig was cooled down to investigate. The cause of the leak was traced to a failed metal weld in the anode loop tubing. The test was resumed after a section of anode loop tubing was replaced with material having a thicker wall.

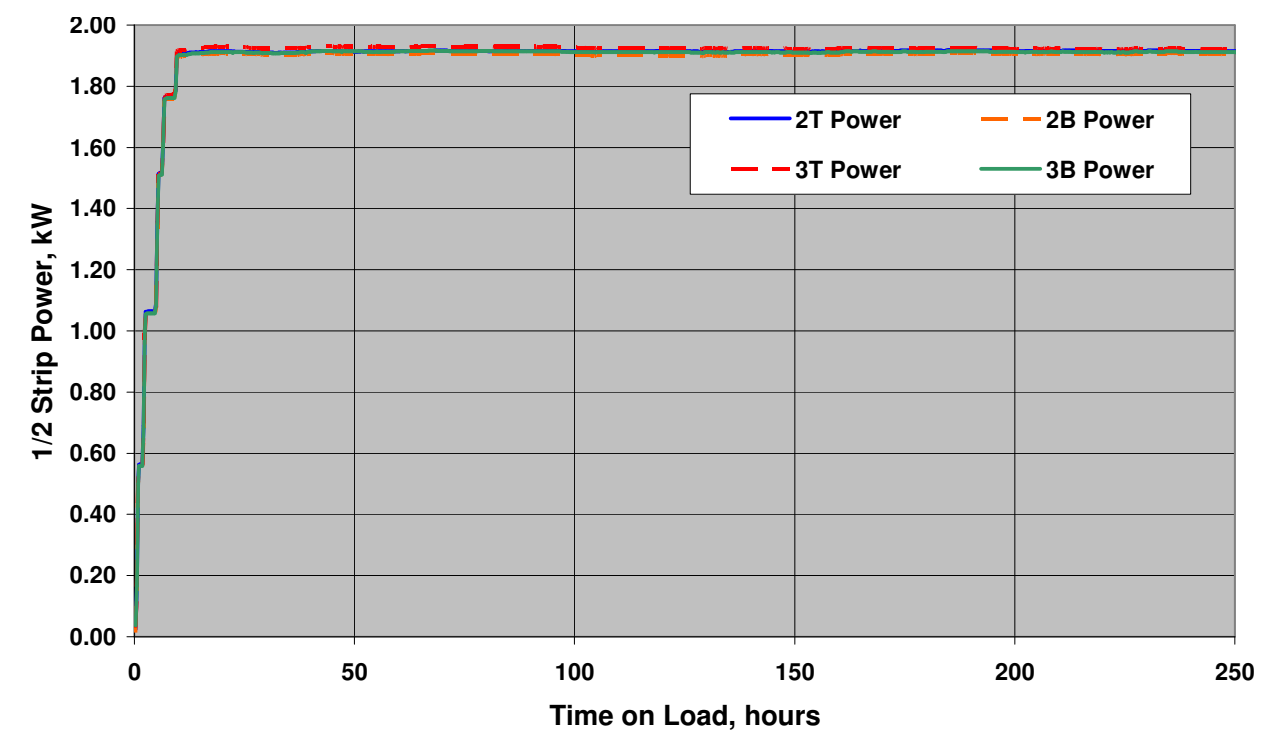

Figure 46. Initial durability results for the $7.6 \mathrm{~kW}$ Phase 1 Metric test.

The Phase 1 metric test continued until May 21, 2012. At that time the alpha strip that was included in the test for heat balancing on the test rig was showing an elevated leakage rate. The decision was made to shut the test down and isolate the alpha strip. The stack had accumulated a total of 719 hours on load at that time. The test was resumed after the alpha strip was isolated. The heat balancing of the test rig was maintained by feeding additional hydrogen to the off-gas burner resulting in the cathode air stream having a moisture content of $\sim 3 \%$, and thus representing a more aggressive test condition than the original planned ISO moisture level of $\sim 1.2 \%$. While the alpha strip was leaking between $300-700$ hours, the moisture level had climbed to $\sim 4 \%$.

The 2 epsilon strips test continued until the beginning of September displaying a power degradation rate of $0.4 \% / 1000$ hours (Figure 47). The similar degradation rate of the 2 strips compared to subscale test articles was very encouraging; in fact the metric test even included a sulfur contaminant level of $\sim 35 \mathrm{ppb}$ 
from the use of desulfurized pipeline natural gas to create the syngas via the Oxy-CPOX reactor. The measured degradation rate was well within the Phase 1 target of $<2 \% / 1000$ hours.

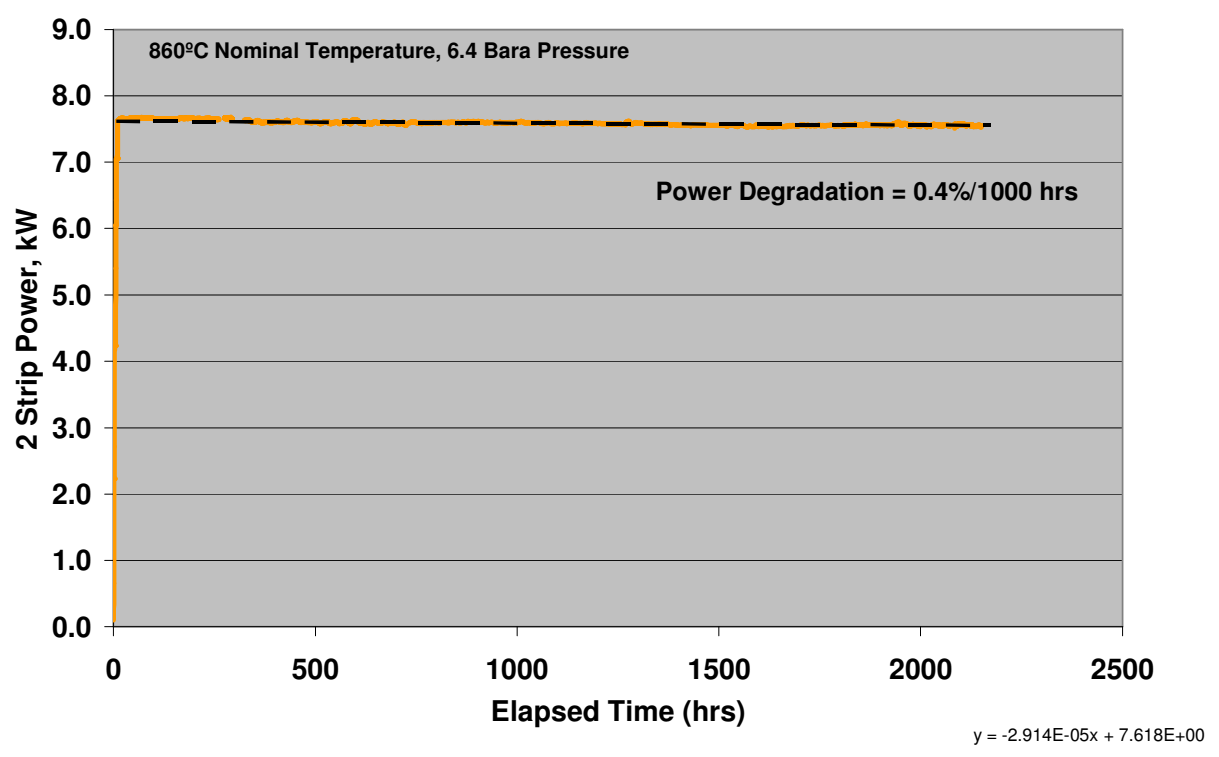

Figure 47. 2-Strip Phase 1 metric test degradation trends

The Phase 1 metric continued to run smoothly until September 1, 2012 when at 2135 hours on load a slight drop in power was observed; $120 \mathrm{~W}$ out of $7420 \mathrm{~W}$ combined for the 2 epsilon strips. Coincident with the drop in power was measurement of localized heating between the strips. The test was shutdown to diagnosis the problem. Post-test leakage measurement of the strips while still in the block box revealed damage to the strips. Upon removal from the block box some substrates were observed to have cracks. The damage appeared to have originated from a single location of strip 2, and resulted in some downstream damage to strip 3.

Root cause analysis was performed to determine the cause of the tube cracks. The prevailing theory is that a short circuit at a secondary interconnect (SIC) position occurred between adjacent tubes leading to local fuel consumption and heating causing a thermal stress state resulting in mechanical failure of a substrate based on the root cause conclusions from the initial Phase 2 test (see below). The SIC-to-SIC positioning for adjacent tubes has been redesigned to avoid this sort of failure in the future.

Phase 2 Metric Test: The Phase 2 test was started on 21 May and consisted of 5 epsilon strips. The test was performed in Derby, England (UK) where the stack block test rigs represent the full system cycle including anode recycle which is absent in the Canton SBTS. Upon anode reduction, it was discovered that 17 of the 20 quarter strips were performing as expected, while one quarter strip was performing below expectation, and two other quarter strips did not produce any current. The strips were unloaded and while held at hot idle stack temperatures suddenly rose. The stack was shutdown and inspection revealed localized damage to 4 strips. Root cause analysis has traced the primary cause to shorting between quarter strips once the anodes were reduced and full voltage realized. The hypothesis is that the shorting created local heating that created unacceptable thermal stresses. Testing of bundles with intentional shorts confirmed the localized heating. The shorts originated from defective tertiary interconnect feed-outs from the quarter strips to the busbars.

All 5 epsilon strips were returned to Canton for repair. The repaired strips became the first strips to undergo a pre-reduction cycle in a specialized test rig designed to measure voltage on all 12 bundles 
within a strip prior to committing the strips for build-up into a stack block. The rig also allows gas sampling at temperature with fuel flow to assess leakage/parasitic currents at the strip level. Historically, strips have been reduced within the stack block test rigs following the initial heating cycle. The strip prereduction rig now allows a quality check on the strips. This quality check would have caught the tertiary interconnect issue that caused the delay in the start of Phase 2 metric test. Results for the minimum and maximum open circuit voltages measured for each strip along with parasitic currents and leakage rates are show in Table 4. All strips showed a low skew in OCV and low leakage rates.

Table 4. Results from pre-reduction of 5 repaired/replacement strips supplied for restart of the Phase 2 metric test

\begin{tabular}{|l|c|c|c|c|c|}
\hline Mfg \# & ESR 4R & ESR9 & ESR10 & ESR 6R & ESR 8R \\
\hline T1313 \# & S1 & & & S4 & S5 \\
\hline \hline Average OcV (Volts) & $\mathbf{3 5 3 . 7}$ & $\mathbf{3 4 9 . 6}$ & $\mathbf{3 4 8 . 9}$ & $\mathbf{3 4 9 . 4}$ & $\mathbf{3 5 1 . 4}$ \\
\hline Max & 357.5 & 353.7 & 352.2 & 352.9 & 354.8 \\
\hline Min & 350.7 & 346.8 & 347.1 & 346.4 & 349.2 \\
\hline Max-Min & 6.8 & 6.8 & 5.1 & 6.5 & 5.5 \\
\hline Parasitic Current (mA/cm2) & 23.1 & 25.95 & 26.1 & 26.3 & 24.8 \\
\hline Post Test Leakage (sccm) & 27 & 35 & 25 & 58 & 63 \\
\hline
\end{tabular}

The five repaired and pre-reduced epsilon strips were shipped back to Derby UK (September 2012 receipt) and the initial start-up of the Phase 2 test occurred in early October.

Conclusion - There have been some challenges in the execution of the block metric tests, but root cause analysis is pointing to electrical short circuits as the cause of substrate damage either at the start of tests as experienced with the Phase II test (from manufacturing issues) or in the case of the Phase 1 test after some period of test time. Additional analysis of the stack design and solutions to avoid shorts are being pursued. SECA degradation targets have been met. Although the Phase 1 test only ran 2135 hours of the planned 5000 hours, the degradation rate was $<0.5 \% / 1000$ hours during the test period. The Phase II $\sim 19$ $\mathrm{kW}$ test was delayed because of the substrate structural failures associated with short circuits present at the start of test. That experienced led LGFCS to establish a strip pre-reduction test rig that qualified the 5 repaired strips for the repeat Phase II metric test that ran successfully during government fiscal year 2013 and met SECA Phase II power degradation rate of $<1.5 \% / 1000$ hours during a 3000 hour test.

\section{Task 6.0 - Manufacturing}

Approach - A new task was added in Phase II to cover the manufacturing activities. This includes strip print, build and repairs for metric block tests. Also covered are manufacturing optimization studies to reduce the number of print/fire operation.

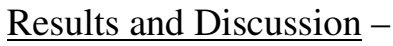

Strip manufacturing:

- This task supported the completion of the initial 3 epsilon strips that were assembled into the Phase I metric test.

- The two epsilon strips damaged during the initial start-up of the Phase I test were repaired under this task.

- Five epsilon strips were fabricated for the Phase II metric block test.

- The five epsilon strips damaged during the initial start-up of the Phase I test were repaired under this task. 
Print/Fire Process Reductions:

- Eliminated one print and one firing cycle for the cathode side layers

- Eliminated one firing cycle for the fuel-side active layers

- Firing cycle time was reduced to 14 hour cycle to allow morning printing of tubes following a late afternoon start of a firing cycle.

The reduced firing cycle time was an important advance to insure no lost printing days. The process reductions steps demonstrated have been subsequently adopted in the current LGFCS manufacture prototype line based on achieving similar ASR values for the processed substrates (Figure 48). LGFCS has identified another 3 print and 3 firing cycles that could ultimately be eliminated with further process development, and such an effort has become part of the LGFCS internal program.

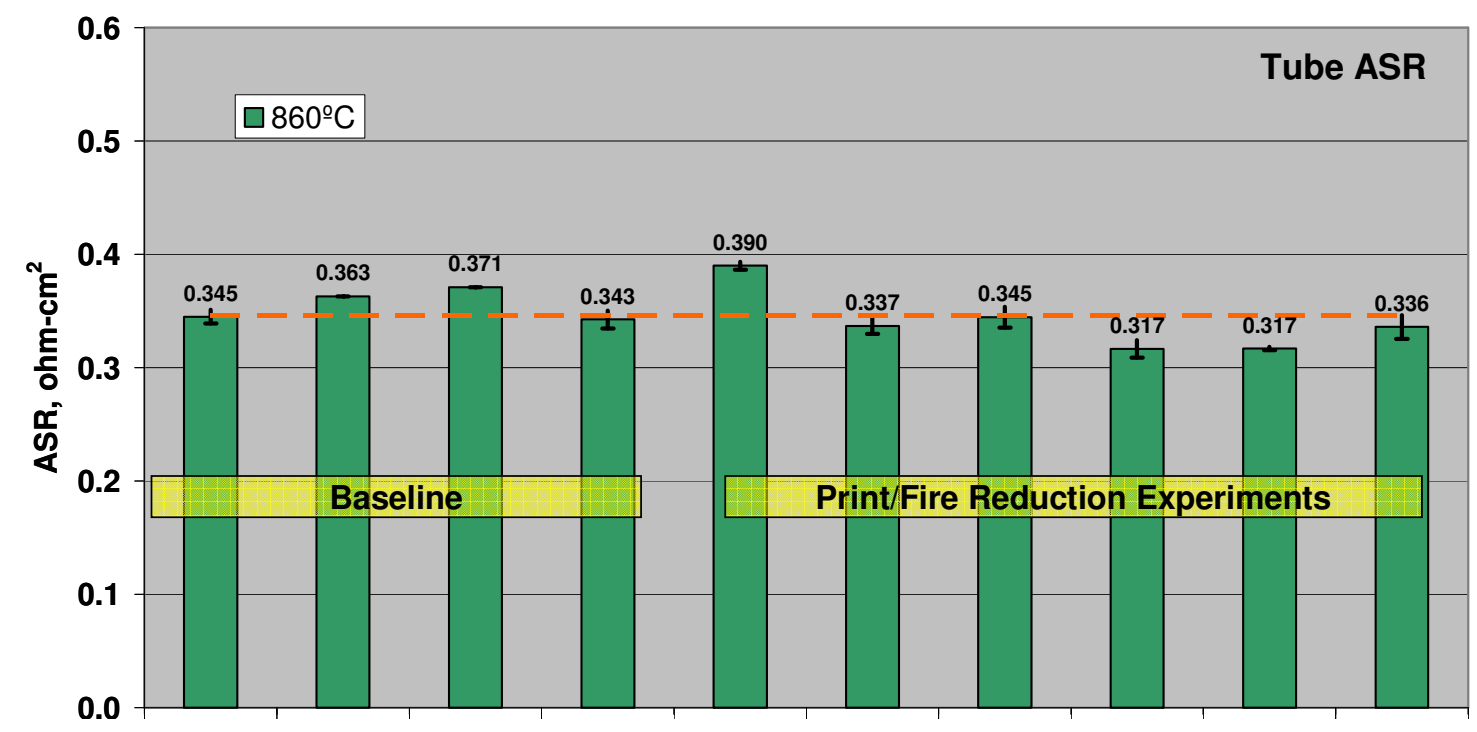

Figure 48. Similar substrate ASR with print/fire reduction processes 